\title{
Building Survey Forms for Heterogeneous Urban Areas in Seismically Hazardous Zones. Application to the historical center of Valparaíso, Chile
}

\author{
Belén Jiménez ${ }^{1}$ Luca Pelà ${ }^{1}$ Marcela Hurtado $^{2}$

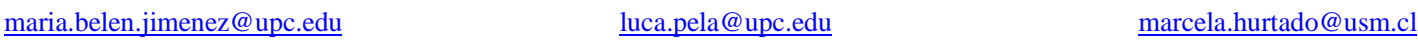 \\ ${ }^{1}$ Universitat Politècnica de Catalunya (UPC-BarcelonaTech), Department of Civil and Environmental Engineering, Campus Nord, Jordi Girona 1-3, 08034, \\ Barcelona, Spain \\ ${ }^{2}$ Universidad Técnica Federico Santa María, Architecture Department. Avenida España 1680, 2340000, Valparaíso, Chile.
}

\begin{abstract}
Building survey is an essential data-collection procedure to feed large-scale seismic vulnerability assessment. The available strategies usually consider survey forms to gather information about the urban buildings. The application of the available survey forms poses important challenges for the case of the heterogeneous urban centers including different structural typologies. This work proposes four specific survey forms for traditional structural typologies constructed with masonry, reinforced concrete, mixed steel-reinforced concrete and timber. The proposed forms request essential information on the parameters necessary for seismic vulnerability assessment, by evaluating the lateral-load resistant system, regularity, condition of conservation, and existing damages. The survey forms were applied to the study of 111 buildings of the historical center of Valparaíso, Chile. The proposed methodology was complemented with the use of Geographic Information Systems to obtain a complete database with the structural characterization of the most representative typologies for future works of large-scale seismic vulnerability assessment.
\end{abstract}

Keywords: Seismic Risk, Building Taxonomy, Survey Form, GIS, Second Level Assessment, Urban Scale, Seismic Vulnerability Assessment, Historical Centers, Building Typologies, Timber Frame Structures.

Running head: Building survey for seismically hazardous urban areas

\section{Introduction}

Seismic hazards generate large concern due to their potential consequences on urban areas. Many cities around the world have recently undergone the devastating effects of major earthquakes in their urban territories, such as L'Aquila (Italy) in 2009, Bio-Bio (Chile) in 2010, Manabí (Ecuador) in 2016, and Amatrice (Italy) in 2016. All of these events produced very high numbers of fatalities and economic losses due to the collapse of numerous structures. After years, these urban centers have not yet recovered their original functionality due to their extremely low resilience. Devastating events, such as the mentioned ones, show the importance of considering the mitigation of the seismic risk and the disaster management as primary concerns in global policies. 
Seismic risk assessment at urban scale is a necessary activity to evaluate the potential consequences of major earthquakes. It is composed of a systematic series of working stages, starting from the seismic hazard identification, following with the vulnerability assessment of buildings, and ending with the development of risk maps and proper mitigation plans. Mapping the potential risk on the urban layout can help to develop the necessary strategies for seismic risk management and reduction. Such strategies are aimed to reduce the potential effects of earthquakes and to safeguard the vital network of the urban areas. Cities are complex systems, in terms of morphology and functionality, since they are composed of different elements or sub-systems working together to guarantee the correct functioning of the whole network (Oliveira 2016). The different exposed elements have to be carefully analyzed to estimate how their local vulnerability can affect the global vulnerability. Staniscia, Spacone, and Fabietti (2017) proposed a performance-based methodology for application to seismic risk assessments. Their studies introduced the concept of Minimum Urban Structure (Fabietti 1999) considering the minimum amount of elements that must remain functional after major earthquakes with a view to keep the city open. This concept recognizes the needs to establish hierarchy in the urban system components and the definition of acceptable risk (or performance) levels of the study zone. Strategic buildings, roads, and open spaces are the main components of the urban network, which should be considered in large-scale seismic assessments.

According to the Terminology on Disaster Risk Reduction (UNISDR 2009) the term disaster risk is considered as a function of hazard, exposure and vulnerability. This concept is commonly defined as the probability of losing life, injuring or damaging capital stock in a certain period. Several methodologies for large-scale evaluation of the seismic risk were developed in the last decades to reveal the possible occurrence of earthquakes in inhabited territories. Seismic risk evaluation procedures determine the nature and degree of the risk by evaluating potential hazards and existing vulnerabilities. Such conditions could potentially injure exposed people, constructions, services, livelihoods and, more in general, the environment on which they depend (UNISDR 2009). Large-scale seismic assessment is mostly based on determining if the urban buildings are adequately designed and built to resist seismic forces (ASCE/SEI 41-13 2014) or, in other words, on estimating the seismic vulnerability of the built environment. These evaluations are necessary especially in historical centers, where the buildings were often designed before the implementation of the modern seismic design codes, and thus to resist only the vertical forces. According to Herrera et al. (2013) the objective of the vulnerability studies is to know the expected damage in order to plan mitigation solutions and decrease the losses that the earthquakes could cause in the future.

Numerous methodologies were developed in the recent years to determine the seismic vulnerability of the urban buildings. Such methods are classified by taking into account the following factors: nature and objectives of the assessment; availability and quality of the building data; features of the inspected buildings; scale of evaluation; methodology criteria; reliability degree of the results and their use in practice (Herrera et al. 2013). The available methods for seismic vulnerability assessment can be classified into empirical, analytical and hybrid, see Calvi et al. (2006), Herrera et al. (2013), Pitilakis et al. (2014) and Panagiotis and Vagelis (2015). The empirical methods evaluate post-earthquake information from previous events to define damage probability matrices and vulnerability functions. The analytical methods consider sophisticated algorithms to assess the building vulnerability, involving a direct physical assessment. The hybrid methods combine probability matrix or vulnerability functions with analytical procedures to simulate the building performance. Empirical and hybrid methods are more affordable than analytical ones in large-scale assessments due to their simpler application. 
Seismic vulnerability methods can be also classified according to their level of complexity and to the required input information. First level methods require qualitative inputs such as the building typology and the age of construction. Second level approaches request more specific information about the morphology and structural configuration of the buildings. Third level approaches involve sophisticated analysis, such as numerical simulations, and consider detailed models of the buildings. Third level approaches imply analytical procedures that are feasible for single buildings but result hardly applicable to largescale assessment due to their high computational demand.

The studies on seismic vulnerability of urban areas are closely linked to the collection of the available information about the existing structures. The data about urban buildings constitute the input parameters of seismic risk assessment procedures. The quality and completeness of the available information determine the level of the analysis and the accuracy of the results. However, one of the main challenges of large-scale seismic vulnerability assessments is the need for collection of data about a large number of buildings. Access to such large amount of data is usually difficult and cities including historical architectural heritage usually have incomplete construction databases. For this reason, the use of building taxonomy (Pitilakis et al. 2014, Brzev et al. 2013) is propaedeutic to the definition of classes of buildings characterized by homogeneous behaviour, and often constitutes an essential step of vulnerability assessments at large scale. Building taxonomy describes and classifies different construction types, taking into account their structural attributes relevant to seismic performance, e.g. material properties, geometry, age, type of resistant system or foundation, etc. The goal of taxonomy is to create building catalogues classifying meaningful parameters and specific characteristics. The knowledge of existing buildings is fundamental to define reliable taxonomy and this activity shall be based on detailed survey activity.

Different building survey strategies were developed to obtain the information necessary for the seismic vulnerability assessment of historical centers. RADIUS (UNISDR 1999) and RISK-UE (Mouroux et al. 2004) projects considered holistic approaches taking into account the seismic threats and their effects on buildings and population. Both methods consider first level approaches to analyze the vulnerability of the buildings, requiring only the age of construction and general information about the building typology. On the contrary, the Gruppo Nazionale per la Difesa dai Terremoti (GNDT 2007) adopted the Vulnerability Index Method developed by Benedetti and Petrini (1984) that constitutes a second level approach. The method considers a score system with eleven parameters related to different structural characteristics of the building: type and organization of the resisting system, quality of the resisting system, conventional strength, building position and foundations, horizontal diaphragms, plan configuration, height configuration, maximum distance between walls, roof, non-structural elements, and general maintenance conditions. Each parameter can be classified from A to D as it contributes to an increasing vulnerability of the building. The score for uncertain or unknown information about a specific structural parameter is D. GNDT (2007) proposed two types of survey forms, for masonry and reinforced concrete buildings respectively (Figure 1a), together with two practical manuals to assist the evaluation of each parameter according to the observed condition of the building. It is important to note that the Vulnerability Index Method requires a good quality of the building knowledge in order to obtain reliable results.

The Rapid Visual Screening of Buildings for Potential Seismic Hazards (FEMA 2015) is another study on seismic vulnerability analyses that is based on proper survey methodologies. This approach proposes a simple data-collection form (Figure 1b) to gather information about the building documentation, its occupancy, the type of soil, the falling hazards and the building type. The evaluation of the building type is based on the previous studies of HAZUS and FEMA 155 report (ATC, 
2002) which established vulnerability scores for fifteen structural typologies constructed with steel, reinforced concrete and masonry, based on the analysis of fragility curves.

Another approach for post-earthquake survey and vulnerability assessment is AeDES (Baggio et al. 2007), which was released by the National Seismic Survey (SSN) and GNDT after 1997. This methodology was created as an improvement of the GNDT (2007) method by considering damage assessment as well as short-term countermeasures for damage limitation and evaluation of the post-earthquake usability of ordinary buildings. AeDES survey form (Figure 1c) is composed of nine sections listed as: building identification, building description, building typology, damage to structural and non-structural components, external danger, soil and foundation, usability assessment, and notes. A noteworthy advantage of AeDES form is its userfriendly template for simple and fast on-field survey applications. AeDES forms were used by Masi et al. (2014) for a vulnerability survey of 18 villages located in the Basilicata region (Sothern Italy). The adopted survey methodology was called "peace time building-by-building survey" and was proposed as a typological survey for large-scale assessment in cities without post-earthquake databases. Vulnerability Survey form in Peace-time (VSP) was calibrated only for masonry and reinforced concrete buildings. The study was based on the collection of building documentation, geometrical dimensions, use, structural characteristics and soil condition. A typological survey and technical description of the representative buildings were considered in a first stage. The vulnerability class of each building was evaluated referring to the most important structural characteristics, the age of construction or retrofitting, and the horizontal and vertical structural types of the most vulnerable story of the construction. Classes A, B, C and D established in EMS-98 (Grünthal 1998) were correlated to the evaluation of the surveyed buildings. The obtained results were statistically sorted and compared with the data of the 2001 census by the Italian Institute of Statistics (ISTAT), with significant differences associated to the different criteria of the considered methodologies.

A similar typological survey was carried out by Taffarel et al. $(2014,2016)$ to evaluate the seismic vulnerability of the city centers of Safed (Israel), Acre (Israel) and Timisoara (Romania). The proposed methodology was based on a preliminary knowledge stage, consisting in the collection of data related to the historical evolution of the buildings, structural interventions, damage mechanisms and identification of the vulnerability elements. The knowledge stage considered on-site activities to recognize the building stock through a visual survey and a careful on-site inspection to identify the vertical and horizontal structural configuration. Next steps were the statistical and typological analysis, followed by the seismic vulnerability analysis based on the Vulnus methodology (Bernardini et al. 1988).

Another approach to building survey was proposed by Monteiro et al. (2016) in the framework of the SASPARM 2.0 project. The main objective was the definition of fragility curves for the building structural typologies of the city of Nablus (Palestine). The first step was the definition of a catalog of the building typologies of the city. Two building survey forms were proposed, i.e. a more technical one for expert practitioners (Figure 1d) and a simpler one for the inexpert population. The expert forms have 6 sections, i.e. identification of the building, description of the building, structural data, regularity, geomorphological data, and notes. Surveyed data were used to perform the vulnerability assessment for each typology. Nonlinear static analyses were carried out to estimate the seismic performance of the Palestinian buildings and to plot eventually their fragility curves.

The management of the collected data and the development of graphical outputs are very important activities during and after survey activities. Geographic Information System (GIS) applications are among the most suitable tools to generate 
databases, as well as to store, analyze and manage a large amount of building information. GIS platforms can build survey maps using spatiotemporal locations of unequivocal elements (vectors or raster) that represent the territorial items, such as buildings or streets, linked to alphanumeric information. The principal advantage of the use of GIS platforms is the application of georeferenced databases to analyze and plot the gathered information of a large number of elements in terms of maps, graphs or 3D models.

Building survey should constitute an essential activity in urban centers of seismically hazardous areas that lack construction databases, historical records or technical documentation. However, in-depth inspections of all the buildings are hardly feasible in large urban settlements with inhabited constructions. This problem is normally due to the lack of resources for comprehensive survey, inaccessibility to large number of buildings, and hidden condition of the investigated structural systems. These obstacles are typical in historical centers with old and heterogeneous constructions characterized by a huge variety of conditions. To counteract such uncertainties, proper typological survey and building taxonomy of the most representative structural schemes could help to determine the seismic vulnerability of each building.

This paper focuses on data-collection survey strategies for building stocks of urban historical centers with heterogeneous structural typologies and possibly lacking of consistent construction databases. The principal aim of the study is to define a methodology for typological building survey able to collect essential information for the subsequent seismic vulnerability assessment. The proposal considers relevant factors such as building morphology, structural configuration, damage conditions, and current condition of the buildings. The gathered data provide the basic information to make a characterization of the existing typologies in the building stock relevant to seismic vulnerability. The methodology is based on the application of four typological survey forms for traditional buildings of the historical centers, i.e. masonry, concrete, mixed steel/iron and timber frame structures. The proposals of ad-hoc survey forms for historical mixed steel/iron and timber frame structures constitute an important novelty of the present research. The forms were elaborated considering the influence of specific structural and non-structural characteristics that can influence the seismic response of the building. A guidance for the correct implementation of the form is also presented considering pre-field survey activities (Section 2.1), on-field survey applications (Section 2.2), and management of the collected data (Section 2.3).

The proposed methodology was applied to the study of 111 buildings of the historical center of Valparaíso, Chile. This urban area was considered an excellent pilot case due to the remarkable heterogeneity of the existing structural typologies. The surveyed information allowed the statistical analysis of the building data, the characterization of the representative building typologies, as well as a preliminary detection of their most important vulnerabilities. The obtained results were implemented into a GIS platform to provide a suitable database for future seismic vulnerability analyses at the urban level.

\section{Proposed methodology of building survey}

This work presents a methodology intended to be applied to the survey of buildings in heterogeneous urban historical centers, focusing on the traditional structural typologies composed of masonry, reinforced concrete (RC), mixed steel/iron, and timber frame systems. The proposal includes survey strategies and calibrated tools to inspect each building in a reliable way. Four singular survey forms are set, each of them corresponding to a specific building typology, taking into account the structural parameters denoting the seismic vulnerability of the investigated building. The proposed survey forms constitute a tool for second level assessments of the seismic risk in existing buildings. The procedure is divided into three stages: (1) pre-field 
activities, (2) on-field survey, (3) data management and outputs. Pre-field activities include essential works that must be developed prior to the on-field survey and the preparation of the survey forms. Lastly, proper management strategies are used to build suitable databases and outputs with GIS tools.

\subsection{Pre-field activities}

Pre-field activities are necessary to optimize the available resources and the operational efforts in terms of time and costs. The first stage of the pre-field activities is to determine the boundaries of the study area and the number of buildings to be investigated. After the recognition of the area, all the elements must be labelled with an identifier number (ID) for the database. Local city administrations usually consider IDs to classify buildings in their databases, such as the land registry, and the IDs for the building survey should be the same of the local existing ones. Local IDs are helpful to localize effectively the major technical information of the building in the archives or historical records.

The main pre-field activity is the collection of the existing information already gathered in local archives. This step is termed desk survey and it defines the remote data-collection procedures from local records, inventories or literature. The main aim is to collect the original documentation of the buildings from legitimate sources, such as drawings, plans, photos, technical specifications, etc. All this sources can provide remarkable historical and technical information about the building, see Figure 2. Backup and possible digitalization of the collected data, with a proper link to the buildings' IDs, is a very important step of the desk survey.

A relevant step of pre-field activities is also the use of taxonomy in defining the expected classes of buildings that characterize the area under investigation. The identification of the most representative structural typologies within the urban context will also allow to extrapolate meaningful data useful for buildings with missing information but similar characteristics. Good indicators of common features among the buildings could be the age, the construction materials, the stylistic resources, the façade configuration, the average height of the floors, etc. Typological surveys are frequently based on extrapolation strategies, like in the seismic vulnerability studies carried out by Taffarel et al. (2016) and Masi et al. (2014).

Pre-field activities should also include a preliminary check of the completeness of the survey forms to be used during the following on-site survey. This control should be done with respect to the specific stock of buildings under investigation time by time. In fact, some specific integrations could be sometimes useful as a function of the specific structural typologies that characterize the region under investigation.

The last pre-field stage is the preparation of a survey strategy, prior to on-field inspection, called survey path. This work implies the mapping of survey routes by taking into account the accessibility, the topographic conditions, the available resources, the time and number of examiners. Survey path strategies ensure a systematized survey and management of the resources.

\subsection{On-field activities: use of survey forms}

The on-field survey activities consist mainly in the inspection of the urban buildings that are object of study. The buildings should be inspected both from inside and outside in order to fill optimally the proposed survey forms and obtain homogeneous and consistent databases. However, the experience often shows that such an optimum scenario is not easily 
achievable. For this reason, extrapolation strategies, typological surveys and use of taxonomy may be necessary for the buildings without accessibility or lacking information, as previously reported in the Section 2.1 "Pre-field activities".

The focus of the on-field survey is to achieve an overall understanding of the potential behavior of the buildings by checking their structural configuration. The survey of heterogeneous historical centers must involve a wide range of structural types, materials, and details in order to get the best match for each particular situation. This paper proposes four survey forms to support the on-field inspection and to allow the examiner to collect in a systematic way all the information necessary for the second level assessment of the seismic vulnerability. The forms are specifically formulated according to the structural material of the construction, i.e. masonry, reinforced concrete, steel/iron, and timber structures. The most representative features and typologies are considered in each case. Forms are composed of seven sections: (1) general information, (2) building typology, (3) structural regularity, (4) soil and foundations conditions, (5) non-structural elements, (6) damage condition, and (7) current condition of conservation. The data are introduced in the forms through either alphanumerical records or multiple-choice answers that can have a scale of assessment from A to C, where C represents the worst condition. The grading scales are used to perform a preliminary visual analysis of the global condition of the buildings and to derive eventually statistical trends.

As already mentioned above, the main outcome of the proposed survey forms is the systematic acquirement of data useful to apply seismic vulnerability models. The type of information requested refers mainly to second level seismic assessment. The following paragraphs present a detailed description of all the sections of the proposed survey forms, and report the relevant references of different types of data to the corresponding seismic vulnerability methods. The approaches available in the scientific literature have been carefully analysed in order to make the survey forms compatible with them. It is worth mentioning that the proposed forms could be also complemented with further detailed studies at the level of single buildings, such as experimental inspection techniques, to assist third level assessments and carry out analytical structural analyses of specific constructions.

The Section 1 "General Information" presents an overview of the building with the identifier number (ID) and the address. The use and number of occupants constitutes also a source of useful information to understand the role of the building within the urban asset, as suggested by Baggio et al. (2007) and FEMA (2015). Additionally, the user can insert some notes with a brief description of the physical appearance, and a possible graphical sketch, see Figure 3a.

The Section 2 "Building Typology" (Figure 3b) reports the main characteristics of the structural configuration. The number of stories and age of the buildings (Question 2.1 and 2.2) are preliminary data to determine the exposure in the study area, in accordance with FEMA (2015) and AeDES (Baggio et al. 2007) survey initiatives. The possible compliance with any local seismic design codes is also necessary to understand if the construction followed seismic criteria from past or present standards. The existence of later structural retrofits (e.g. insertion of tie rods, floor stiffening, etc.) or modifications that may have altered substantially the original structural system, (e.g. elevations, new floors or roofs, etc.), must be also reported in this section.

The identification of specific structural features, such as the nature of the load-bearing system and materials, are requested from Questions 2.3 (Figure 3b) to 2.5 (Figures 4-5). The structural system should be preliminary defined as hybrid or unique (Question 2.3). The forms allows the choice of a number of common hybrid typologies, as presented in the following. Main lateral load resistant systems are identified according to the load-bearing systems and story structures. Each typological form identifies the most representative structural systems among those established by Eurocode 8 and Eurocode 5 (EN 1998-1 
2004, CEN EC5 1.2 2004), the Italian standards of Construction (NTC 2008), the guidelines by the Italian National Group for Earthquakes Protection GNDT (2007), the SYNER-G project (Pitilakis et al. 2014), and the New Zealand technical guidelines for the Seismic Assessment of Existing Buildings (NZSEE 2016).

Vertical load-bearing systems are identified according to the type of material, the arrangement of resistant elements, and the quality of the whole system. According to the Seismic Design Handbook (Farzad 1989), the seismic behavior and inplane deformation of story systems are mostly influenced by the relative rigidity of the diaphragms compared to that of vertical resistant structures. The different typologies of stories are thus classified into rigid, semi-rigid, and flexible. The rigid stories are relatively stiffer than lateral force-resisting members and distribute the story shears to the supporting lateral members based on their relative rigidities. The flexible ones can experience flexural deformations in their own plane and thus they transmit the story shears to the lateral resisting members based on their tributary areas. Semi-rigid diaphragms basically represent a condition between rigid and flexible. The quality of the connections of the story with the vertical structures is also an important evaluation parameter.

The survey forms are then particularized according to the construction material of the structural system, i.e. masonry, reinforced concrete, steel/iron and timber. All the different cases are carefully described in the following.

The first variant of the survey form applies to buildings with masonry load bearing system, see Figure 4a. Masonry buildings represent one of the oldest and most widespread structural system around the world. The global dimension of the masonry heritage is reflected in the wide range of structural solutions, typologies, materials, in line with local available resources. The major concerns in the seismic assessment of historical masonry buildings are the unreinforced masonry structures lacking of engineering skills during their construction and adopting rudimentary materials and technologies. All these factors can constitute potential sources of high seismic vulnerability. In these cases, the masonry quality, as well as the actual effectiveness of past reinforcing interventions, must be carefully evaluated in order to identify correctly the seismic vulnerability. The proposed forms for masonry structures classify them into reinforced, confined, and unreinforced. Their seismic behavior depends mainly on factors such as the type of materials, the regularity of the texture, and the quality of the connections. The minimum requirements for wall thickness refers to the magnitudes reported in Eurocode 8, i.e. $0.35 \mathrm{~m}$ for unreinforced and $0.24 \mathrm{~m}$ for reinforced and confined masonry. Although such values actually refers to new construction and real thickness can largely vary from a masonry type to another, this tentative check can contribute to a quick preliminary assessment of the adequacy of the wall's geometry. The regularity in the geometrical organization of the blocks depends on their size homogeneity and the type of bond. Regular blocks arranged along regular layers are normally indicators of wellexecuted walls. Regarding the monolithic condition of the walls, it is important to evaluate the quality of both the existing mortar and the connections. Cementitious or hydraulic mortars commonly provide high resistances and are considered as the best quality ones. Inconsistent or floury mortars are defined as bad quality ones. Attributes contributing to the good seismic performance of the masonry structures by means of the so-called "box behavior" are well executed wall to wall interlocking, as well as uniformly distributed connection devices (e.g. tie rods, tie beams, anchors, and bracing systems).

The identification of the load resistant system of masonry buildings is the purpose of Question 2.5. Specific categories are reported depending on the load-bearing and story systems (Fig. 4a). Existing masonry structural systems are complex and different combinations could be possible in real cases. Since trying to represent all the possible typologies would produce extremely complex forms, the proposed approach considers an approximation to nine classes, i.e. three possible classes for 
each masonry typology (reinforced, unreinforced stone and brick masonry). The first class includes buildings with no sources of vulnerability in the load-bearing resisting system (e.g. good thickness, regular texture and well executed connections), the second class presents some sources of vulnerability (e.g. insufficient thickness or irregular texture or bad connections), and the third class has numerous sources of vulnerability (e.g. insufficient thickness, irregular texture and bad connections). As for the description of the story typologies, it is based on relative stiffness and quality of the connection with the vertical elements. The unknown choice is also possible, since the inspection of floors is often challenging due to their difficult accessibility during the inspection activities. In the case of masonry buildings, the observation of the possible thrusting effect of the roof system is requested in the Question 2.6. The categories of non-thrusting, slightly thrusting, and thrusting roofs are defined according to relevant criteria formulated by GNDT (2007), Vicente (2008) and Pitilakis et al. (2014). According to these studies, nonthrusting roofs are horizontal or inclined with specific solutions to eliminate the thrust at the top of the supporting walls, e.g. metallic tie rods or timber truss systems. Slightly thrusting roofs are inclined with the roof ridge supported either by a load bearing wall or by a beam with a span to height ratio lower than 20. Thrusting roofs are all the other solutions not respecting the previous conditions.

The second variant of the survey form applies to buildings with reinforced concrete (RC) load bearing system, see Figure 4b. RC structural systems represent a widespread technique since XIX century. Although these typologies usually imply engineered design and construction, they might not respect the fundamental seismic criteria due to possible deficiencies referable to inaccurate project or execution stages. As well as for the survey masonry buildings, the compliance of RC buildings with the local seismic codes can help considerably to understand if they may present structural vulnerability to possible earthquakes.

The proposed form for RC buildings classifies load bearing systems into moment resistant frames, shear walls, dual systems (resistant frames and structural walls), and mixed RC-masonry, see Question 2.5 of Figure 4b. Moment resistant frame systems resist vertical and lateral loads by spatial frames that can be filled or not with masonry structures. Shear wall systems resist vertical and lateral loads by vertical structural walls. Dual systems support vertical loads mainly by spatial frames, while walls and, to a lesser degree, frames provide resistance to lateral loads. Mixed RC-masonry systems include different varieties of typologies and arrangements inspired more by functional aspects than structural ones (Cattari and Lagomarsino, 2013), e.g. buildings characterized by perimeter masonry walls and internal RC frames, masonry buildings with enlargements or raising made of RC frames, and masonry buildings with RC walls enclosing staircases.

Additionally, soft story building irregularities are reported in this section due to their remarkable source of seismic vulnerability (Guevara-Perez 2012). This structural weakness, also known as open story, is associated with a significant difference between the stiffness and resistance of one of the stories and the rest of them. The soft ground story is the most typical case of soft-story irregularity, i.e. in buildings with a large number of non-structural rigid components (such as masonry walls) connected to the columns in the upper stories, while the ground story presents high flexibility due to the null or reduced number of rigid elements.

For the specific case of moment resistant frame systems, the description of the stiffening effect given by the possible presence of masonry infill is taken into account according to the simplified criteria reported in the GNDT manual for RC structures (GNDT 2007). The RC frames infill is considered of good quality and well-connected to the resisting frame if it is 
made of solid or half-hollowed bricks, the openings do not exceed the $30 \%$, the height-thickness ratio is lower than $20 \%$ and the gap with the frame is lower than $1 \mathrm{~cm}$.

Appropriate story systems in RC structures should have slab behavior and high rigidity against in-plane deformations. These requirements can be reached thanks to a good quality of the connections and materials, as well as the presence of stiffening elements. Representative story system typologies commonly used in RC buildings are classified in the survey form as shown in Figure 4b. The categories for RC lateral load resistant system can vary from A1 to F7.

The third variant of the survey form applies to buildings with steel/iron mixed load bearing system, see Figure 5a. The possible presence of mixed typologies is frequent in historical centers with heterogeneous buildings. Mixed RC or masonry buildings can exhibit the presence of steel or iron resistant elements in their lateral load resistant system. The use of wrought iron/steel elements, in addition to RC or masonry members, was a common technique in old and large-scale buildings. Old steel/iron structures may be characterized by some uncertainties. In all these cases, it is very important to identify the contribution of resistant metal elements within the lateral load resistant system, in order to clarify the mixed character of the structure and to evaluate the established parameters for the survey form. Wrought iron frames systems, filled with concrete or masonry walls, are also rather typical in historical buildings, and the quality of the infill and connections are the most important parameters of evaluation.

The form for mixed steel/iron structures classifies the vertical load-bearing systems into moment resistant frames, structural wall systems and dual systems. Each group defines the most representative systems, as shown in Figure 5a. As the above typologies, story systems are defined by their relative rigidity and connection conditions. The categories for steel/iron lateral load resistant systems can vary from A1 to F7.

The fourth variant of the survey form applies to buildings with timber frame load bearing system, see Figure 5b. Timber dwellings represent an important part of the built heritage across the world. Historical timber structures are often associated with the concept of vernacular architecture, which refers to traditional structures made of local materials and following well-tried practice and configurations (Stevens Curls and Wilson 2015, Oliver 1997). For this reason, different structural solutions have been developed, among which original models can be clearly identified. The essential language governing the timber-framed heritage is the Box Framing. Box frame typologies are composed of a primary heavy frame bearing the loads, and a secondary structure of smaller dimension elements, setting the internal partitions of the structure and supporting the inner and outer coverings (M. Lewis 2009). Braced, Stud, Balloon, and Platform frames gradually replaced the earliest box frame archetype. Such generic typologies present slight changes in their configuration, such as smaller dimensions' pieces, use of bracing elements, different construction solutions (e.g. types of connections, frame arranged, joints, etc.) which simplify the frame configuration and the building process. It is important to note that timber structures can vary significantly depending on the local context, seismic demand, and available resources. Therefore, each specific solution must be carefully identified in studies related to the assessment of the seismic vulnerability of this type of structures.

In general, low-rise timber buildings exhibit good structural performance and can ensure life safety for major earthquakes (NZSEE 2016). The good seismic behavior is partly due to their lightness and ability to deform considerably without losing their load bearing capacity. The major sources of seismic vulnerability are given by elements increasing mass magnitude and introducing mass/stiffness irregular distribution, such as heavy wall partitions, weighty story systems, cantilevers, or asymmetrically distributed braced frames. 
The load-bearing system of timber structures is typically composed of braces and diaphragm elements (shear walls and stories systems) that provide lateral stability to the building. The behavior of these elements is strictly related to their physical properties, such as the type of wood, the cross-section, the thickness, the depth and slenderness ratio, and the connection details. In addition, the seismic performance of the timber shear walls is influenced by the stiffening elements, such as bracing systems and external sheathing. Typical dispositions of the braces are shown in Figure 6a-c, i.e. let-in, diagonal, and dog leg. Adequate bracing and sheathing systems significantly improve the strength characteristics of a wall, e.g. double layer or diagonal boards, corrugated metal sheets, etc.

Another important factor to consider in timber structures is the existence of infill within the main frame. Recent studies by Poletti and Vasconcelos (2015) and Duţu, Sakata, and Yamazaki (2015) have demonstrated that the presence of infill can significantly modify the whole seismic response due to the confining effect on the timber frame. The presence of the infill could increase considerably the stiffness, such as in the case of timber frames with masonry or stone infill, and thus a possible irregular distribution in plan of infilled frames may localize the damage on few shear walls of the structure in case of seismic actions. Weaker typologies are given by branches infill, adobe, quincha etc. (Ceccotti and Sandhaas 2015). The proposed survey form requires information about the type of infill in timber shear walls in Question 2.6.1 (Figure 5b).

The connections are critical for the deformation capacity of the timber structure. Nailed and well-reinforced carpentry connections are considered the most reliable types (EN 1998-1 2004). Unfavourable conditions are provided by carpentry joints with minor reinforcement (intended only to avoid disassembling), or by nail corrosion, mechanical damages, biotic attacks, etc. Question 2.5 of the proposed survey form for timber structures requests information about the vertical load-bearing condition, the existence of bracing systems and the condition of the connections. Additionally, Questions 2.6.1 and 2.6.2 request the presence of additional stiffening elements, such as infill and/or external sheathing.

The behavior of the diaphragm depends on the relative stiffness compared with the lateral stiffness of the connected vertical elements (NZSEE 2016). Sheathing elements or specific stiffening devices, such as cross ties, struts, etc., influence the rigid behavior of the stories. According to Valluzzi et al. (2010), stories with double (or more) layer of timber board sheathing, or reinforced with wooden networks, are the most desirable typologies for the seismic case, followed by stories braced with wood or steel diagonals. Question 2.5 of the survey form defines the story typologies according to their rigid, semi-rigid, and flexible behavior, as shown in Figure 5b. Weighty retrofitted stories non-connected to the walls are considered as unfavorable cases, such as stories with subsequent RC toppings, metal decks with RC topping, or any structure adding a significant mass without improving the connections with vertical elements. The categories for timber frame lateral load resistant systems can vary from A1 to F5, see Figure 5b.

The Section 3 of the proposed survey form is called "Structural Regularity" (Figure 7a) and assesses the morphology of the building in plan and in elevation. Main examination parameters are the overall dimensions of the building, the plan position (aggregate condition), the presence of irregularities (in plan and elevation), and the characteristics of the openings (alignment condition). The evaluation of all these parameters follows the procedures proposed by the GNDT II level manual (GNDT 2007) and the AeDES form (Baggio et al. 2007). The structural interaction with the adjacent buildings is evaluated by indicating the position of the building in the urban aggregate (Question 3.2. Figure 7a) since it can influence significantly the seismic performance (Formisano et al. 2015). Irregularities in plan are critical in seismic vulnerability evaluations, since asymmetrical shapes can induce dynamic torsional effects and thus severe damages to the structures. Buildings with elongated 
shapes or large protrusions are evaluated according to the criteria adopted from GNDT through ratios $\beta 1$ and $\beta 2$ (Equations 1 and 2) where $l$ is the longest side in plan, $a$ is the shorter, and $b$ the appendix dimension (Question 3.3, Figure 7a).

$$
\begin{aligned}
& \beta 1=a / l \times 100 \\
& \beta 2=b / l \times 100
\end{aligned}
$$

Irregularities in elevation are also critical and have to be identified (Question 3.5, Figure 7a), especially in the cases of mass variation along the height, given by strong differences of plan, existence of setbacks, porches or tower shaped elements. The mass variation and setback conditions are both evaluated in percentage terms, being the former quantified by the ratio $\Delta A / A$ between the variation of area of the upper stories $\Delta A$ and the area of the ground floor $A$. The so-called "tower condition" is evaluated by the ratio $T / H$ were $T$ and $H$ are the tower and building heights, see Figure $7 \mathrm{a}$.

The Section 3 of the survey form also takes into account the possible existence of misaligned openings, since they can considerably affect the seismic behavior of the façades (Vicente et al. 2008).

Section 4 "Soil and foundations conditions" (Figure 7b) examines the type of soil, the slope and the thrusting conditions of the terrain, as well as the existence and quality of the retaining walls and foundations according to GNDT (2007). Loose and thrusting soils in steeped terrains, or poor types of retaining walls and foundations, are unfavorable conditions that can seriously affect the seismic behavior of the structures. RC cantilever or anchored retaining walls, as well as masonry or stone gravity walls, are considered as good typologies to reduce the thrusting effect of the soil. The presence of well-executed foundations clearly improves the seismic response of the buildings, especially for those settled in loose soils. The foundations shall be capable to transmit the loads received from the upper structures to the ground as uniformly as possible (EN 1998-1 2004). In this regard, well executed RC or masonry strips or isolated footings along all the structural elements are commonly considered as good solutions (Question 4.5). Significant differences in level foundation can also affect the seismic behavior of the structure, and thus this possibility is considered explicitly in Question 4.6.

Section 5 "Non-structural elements" assesses the stability condition of accessory members that may fall down during the earthquake, such as balconies, chimneys, cornices, etc. (see Fig.8a). The potential hazard of these elements is evaluated in accordance with their dimensions and heaviness, and considering large/heavy elements badly connected to the main structure as the most unfavorable cases.

Section 6 "Damage condition" identifies the current grade of visible damage in the main structural elements, i.e. loadbearing systems, stories, roofs, and non-structural elements (Figures 8b). The observed damage level definition is based on the AeDES form (Baggio et al. 2007) that consider the European Macroseismic Scale EMS 98 and the GNDT guidelines. Damage grade D1 is slight and does not affect significantly the capacity of the building and the safety of its occupants, even against the falling of non-structural elements. Damage grade D2 is medium-severe and can partially affect the capacity of the structure but not bringing it to the collapse. Damage grade D3 is very heavy and could change the capacity of the structure significantly, bringing it to the collapse.

Finally, Section 7 "Current condition of conservation" evaluates the current state of the building as for the overall condition of the structural elements, see Figure 8c). The evaluation criteria consider factors such as the damage grade of the material (i.e. cracks, spalling, corrosion, decay, etc.), past maintenance interventions, hazardous structural additions, and 
presence of strengthening elements. The user must evaluated carefully later retrofit interventions since they might significantly jeopardize the capacity and global seismic behavior of the building. Large structural additions, such as upper floors or badly connected enlargements, constitute unfavorable interventions. Three classes are established from A to C, where A is the most favorable condition.

The application of the proposed survey methodology is intended for urban areas with residential or public buildings, housing blocks and traditional dwellings. Churches and masonry palaces constitute more peculiar construction systems deserving specific tools for survey and seismic assessment (Presidenza del Consiglio dei Ministri - Dipartimento della Protezione Civile, 2011a-b). The proposal of specific surveys forms for such historical structural typologies may constitute a possible future development of this study.

\subsection{Post-field activities: data management and outputs}

All the data collected during the survey activities can be suitably compiled by using GIS databases to evaluate the current status of the study area. GIS is a methodical collection of computer software, geographic data, and designed tools to efficiently capture, store, update, analyze and display all forms of geographically referenced information. These activities are essential in order to create reliable databases to understand the structural characteristics of the different building typologies of the study area. Accurate databases with complete information contributes to improve the quality and reliability of the largescale seismic vulnerability assessment.

The integration of GIS platforms is very common in the urban assessment due to their multiple possibilities of spatial analysis and statistical outcomes of large amount of georeferenced data. GIS softwares allow to create unequivocal geometrical data with individual IDs, generated from digital maps or another graphical source, that are flagged with alphanumeric information. Digital data are organized in layers that are properly linked with the corresponding element's ID. This advantage allows to feed the database and analyze the information according to the user criteria, by information-crossing procedures and map plotting.

A major advantage of GIS platforms is their possible use as decision support systems (multicriteria decision analysis system) for environmental or large-scale resolutions (Malczewski 2006), such as in the case of seismic vulnerability applications. Identifying topologic relationships among the seismic hazardous buildings, strategic buildings (e.g. hospitals, governmental palaces, schools, etc.), and main evacuation routes, can be helpful to determine seismic risk scenarios, emergency limit conditions, risk mitigation plans, and prioritize future investments on the cities. Numerous researches such as RISK-UE (Mouroux et al. 2004), MARVASTO (Indirli 2009), as well as the works by Vicente et al. (2008) and Barbat et al. (2010), applied GIS tools to analyze the seismic vulnerability grade and to estimate their risk through different methods.

Surveyed data by the form proposed in this research can be efficiently linked to GIS databases in order to get statistical results and plot useful maps for future seismic vulnerability analyses of the study areas.

\subsection{Correlation among pre-field, on-field and post-field survey activities}

Figure 9 summarizes through a flow chart all the necessary working stages for the proposed methodology of building survey of historical buildings in urban centers. As discussed in the previous sections, the whole process consists in three main 
groups of activities, i.e. pre-field, on-field and post-field. These activities are all necessary to collect, gather and analyze the information about the buildings for the large-scale assessment of the seismic vulnerability.

Pre-field activities lead to gather all the original information of the building stock available from local archives. Mapping of survey area, selection of the buildings and labelling by IDs, are necessary to form the boundary of the urban survey. Subsequently, desk survey allows to gather original documental information from local archives, such as original plans, drawings and technical reports of the buildings (Output 1). The collected data may be helpful to define a preliminary taxonomy of the representative typologies of the building stock. After having identified the representative building typologies of the study area, a typological on-field inspection of representative cases can be carried out. Survey path aids to plan logistically the onsite examinations and survey strategies.

On-field activities constitute the main core of the procedure and consist in on-site inspection of each building and identification of the representative and recurrent typologies. Photos, on-site measurements, drawings and morphological features of the building are expected to be collected by on-site inspections (Output 2). All the gathered information allows also the completion of the building taxonomy for the investigated area. In the cases of buildings with restricted access or complex inspection conditions, data extrapolation from documental information of representative cases and the use of taxonomy can help to fill the gaps of information necessary for the survey forms. This procedure implies the use of the surveyed information derived from deeply inspected cases to feed the survey forms of similar buildings with lack of information. After on-site inspection and/or extrapolation processes, survey forms are completed (Output 3). If some of the survey forms are still incomplete, deeper inspection to the buildings or representative typologies should be carried out, until obtaining all the necessary data for the seismic vulnerability assessment.

Once all the buildings of the stock have been surveyed, post-field activities can be carried out. GIS database is built to store and analyze the surveyed data. Processing all the information allows to obtain the last outputs of the survey, i.e. maps, statistical results and overall conclusions about the conditions of the urban building stock (Output 4). These final outputs are tools extremely necessary for the development of later policies of urban seismic risk assessment and mitigation.

\section{Application to the historical center of Valparaíso, Chile. The neighborhoods of Cerro Alegre and Cerro Concepción}

The city of Valparaíso (Chile) is located on the central Pacific coast, in an extremely high seismicity area. Historical earthquakes caused devastating consequences in the urban layout (8.2 Mw in 1906 and 8.0 Mw in 1985) and also the 2010 recent one produced visible damages on the built heritage. All these catastrophic events caused large economic and human losses to the city, due to the collapse of the buildings that had to be reconstructed in many occasions. In spite of the past consequences and constant exposure of the city, the available information about the post-earthquakes constructions conditions, such as technical reports or surveys, is very scarce.

Valparaíso presents an exceptional geographic condition, configured by a bay, an artificial flat zone, and surrounding hills (the so-called "Cerros”) where most of the city developed. The urban configuration on the hills is rather complex due to the steeped and irregular territory, in contrast with the regular urban layout of the flat area, see Figures 10a-b. The characteristic 
strategies of adaptation of the buildings to the slope, in addition to the valuable architectonic characters, is one of the most peculiar features of the built heritage of the city.

Valparaíso is an exceptional testimony of the early globalization in South America. The harbor of the city was considered one of the most important of the Pacific Ocean since the late nineteenth century. This boom fostered the arrival of several groups of immigrants and the consolidated growth of the downtown. Wealthy British and American families settled their dwellings especially in the Cerro Alegre and Cerro Concepción that constitute the historical quarter of the city with numerous well-conserved traditional constructions.

The historic quarter of Valparaiso was declared World Heritage Site by UNESCO in 2003 after recognizing the outstanding value of its urban layout and architecture as perfectly adapted to exceptional geographic and topographic environmental conditions.

\subsection{Pre-field survey}

The surveyed study area was selected due to its historical condition and strategic position in the downtown area. This zone includes three portions of the World Heritage Site: (1) Cerro Alegre and Cerro Concepción; (2) Anibal Pinto square and Almirante Montt street, and (3) Bank area and Arturo Prat street. Cerro Alegre and Cerro Concepción are well-conserved historical and touristic neighbourhoods, while the others are centric zones on the flat downtown with primary commercial and bank activity. According to The Regional Plan of Tsunami Evacuation of Valparaíso (ONEMI 2016), downtown zones are tsunami risk areas and their evacuation routes are delimitated in the Cerro Alegre and Cerro Concepción towards safe-zones, as shown in Figure 10c. Such evacuation routes are the same in case of the occurrence of an earthquake.

The building stock object of this study considers all the potential interfering buildings of the aforementioned evacuation routes according to the Emergency Limit Condition (ELC) guideline. Buildings are considered interfering when their partial or total collapse can obstruct their evacuation routes and thus the functionality of the emergency networks at the ELC. A total number of 111 buildings are identified along the main evacuation routes of the study area, as shown in Figure 10c-d, as well as two empty lots.

The building database was created with IDs assigned according to the local records by the Construction Management Department of Valparaíso (DOM). An important amount of original technical documentation such as plans, building specifications, drawings, and photos were collected from the DOM office archive. This source gathers original documents of the most important historical buildings of Valparaiso since 1900. Unfortunately, many of the oldest constructions do not have any available record, such as those built before the first proposal of the seismic design codes in 1960 . Only $40 \%$ of the surveyed stock possessed projects documentation in the DOM archives. In addition, technical reports and published literature (Jorquera 2015; Hurtado, Santander, and Muñoz 2016; Sánchez and Jiménez 2011) could contribute to the pre-field survey activity about the representative buildings and architecture of the study area.

The historical center of Valparaíso is characterized by the coexistence of different building typologies and materials. Suitable survey forms are necessary to gather knowledge on the seismic vulnerability of all the possible combinations of available structural systems. The large heterogeneity of the existing typologies of buildings is due to the multiple uses of the neighborhoods. Cerro Alegre and Cerro Concepción have mostly residential buildings, where timber frames and masonry typologies are the most diffused structural solutions. Downtown areas surrounding Anibal Pinto and Sotomayor squares are 
mainly commercial and bank zones, composed of high-rise RC and mixed iron-RC buildings. Most of the buildings of the surveyed stock were built between the last eighteenth and early nineteenth centuries and they present remarkable historical and architectonic values. Newer structures in RC were built under current seismic regulations but they are located outside the study area.

Before on-site inspections, the study area was subdivided into five zones to perform a survey path and systematize the on-field survey inspection. This activity was carefully planned according to the morphological complexity of the buildings and their mutual proximity (Figure 10d).

\subsection{On-field survey with the proposed forms}

The definition of the most representative features of each building typology is the result of the in-depth on-field inspection of archetypal buildings presenting favorable examination condition. The gathered information allowed to characterize each typology and to define a building taxonomy for the investigated area of the historical center of Valparaíso. The identification of common attributes in the buildings was essential to classify the different typologies and support data extrapolation procedures. All the buildings were inspected from the outside, but numerous buildings with full access were also inspected from the inside. The following sub-sections present a summary of the structural characterization of the 111 surveyed buildings according to the different material typologies of the study area.

\subsubsection{Masonry buildings}

Most of the masonry buildings of Cerro Alegre and Cerro Concepción present mixed use, combining residential, commercial and touristic activities. Ground levels are commonly for public use (restaurants, stores, etc.) while the upper floors consist of dwellings. The number of occupants varies between 10 to 100, which corresponds to a medium level of exposure.

Masonry buildings are mostly medium-rise buildings having between 2 to 4 stories with an average height of $3.5 \mathrm{~m}$ each. Historical masonry constructions (see examples in Figure 11a-c), built without anti-seismic design regulations in the early $20^{\text {th }}$ century, were carefully inspected. Roofs and stories, as well as internal configurations, presented the most challenging inspection conditions due to restricted access. For such cases, data extrapolation and some hypotheses based on the literature were considered.

Masonry walls are typically made of solid clay bricks with dimensions $0.41 \times 0.20 \times 0.06 \mathrm{~m}^{3}$ bonded with good quality lime mortar (Hurtado, Santander, and Muñoz 2016), as shown in Figure 12. The thickness of the walls varies with the height of the buildings, presenting staggered shapes with changing dimensions at each story. This configuration facilitates the support of the story structures, as shown in Figures 11d-e (Salazar 2014). The thickness can vary from $0.25 \mathrm{~m}$ to $0.8 \mathrm{~m}$ along the height of the façades and it can be smaller in the sidewalls, e.g. $0.5 \mathrm{~m}$ to $0.25 \mathrm{~m}$. The sidewalls also act as firewalls and are sometimes shared between two adjacent buildings. Several cases present iron tie rods connecting external walls to story structures.

Internal load bearing walls typically consist of timber frame structures made of Oregon pine or Oakwood. Direct internal inspection is always a difficult activity, mainly because the walls are commonly covered by the plaster. Representative walls which presented good inspection conditions were evaluated in order to determine their typical configuration. The principal components of the timber frames are vertical elements, named studs or posts, spaced at $0.4 \div 0.6 \mathrm{~m}$ from each other, and placed between horizontal elements called sills and plates. The posts are usually braced with diagonal elements, as shown 
in Figure 12a. This wall configuration is replicated along the height of the buildings and in-between the stories, according to the configuration called platform frame. The cross-section of the timber frame elements varies between $0.125 \times 0.125 \mathrm{~m}^{2}$ to $0.10 \times 0.10 \mathrm{~m}^{2}$ depending on the function of the frame, e.g. internal or external load-bearing wall. Generally, oak elements presented better state of conservation in terms of decay damage and biotic attack (termites), while pine ones showed more exposure to these damages, particularly in poorly insulated structures.

Stories were also difficult to inspect and representative cases allowed their characterization. These structures are commonly composed of timber joists spaced at $0.40 \div 0.45 \mathrm{~m}$ along the direction perpendicular to the façade. Joist noggings maintain the distance between the joists and stiffen the structure. Wooden or metallic girders are commonly employed to reinforce the joist stories in critical areas, e.g. in the case of large spans, critical connections, etc. The stories are covered with a single layer of wooden boards perpendicularly oriented to the joist, see Figure 12c. A second layer of wooden boards at the intrados of the story provides additional stiffness to the structure.

The general conditions to inspect roof structures revealed to be very unfavorable during the on-field survey in most of the investigated cases. Despite this limitation, previous studies could contribute to deepen the knowledge about these structures (Eujenio 2015). The typical roof configuration is made of rudimentary trusses presenting non-thrusting behavior. Exceptional cases are the "Anglican Church" and the "German School" at the end of Almirante Montt street, since they have very sophisticated roof structures.

With respect to the structural regularity, most of the masonry buildings presented regular shapes in plan and elevation and are enclosed in-row configurations. According to Formisano et al. (2011), the interaction of the buildings in aggregate affect meaningfully their seismic response. Buildings enclosed between lower constructions and placed at either the corner or the end of the aggregate were determined as the most vulnerable cases in this study. Most of the buildings of the study area have central positions in-row configuration and present similar heights in line, a condition which contributes to the good seismic behavior of the buildings. According to Siano et al. (2017), irregular openings in a wall, e.g. with different horizontal dimensions or variable number, negatively affect the load path within the structure and the global seismic response. Even though most of the studied masonry buildings present regularly distributed openings, some critical cases presented irregularities such as offsets or openings with different dimensions, as shown in Figure 11b.

A large number of masonry buildings are located on Almirante Montt street, where the terrain is very steep (20 $\div 40 \%$ slope). In these cases, the use of gravity retaining walls is recurrent to contain the surrounding thrusting soil. The thickness of a retaining wall is normally variable, and commonly vary between $2.0 \mathrm{~m}$ at the foundation to $0.5 \mathrm{~m}$ at the top. In some specific cases, these walls receive loads from the upper walls and story structures, as shown in Figure 12d. It should be noted that gravity walls are not present in hard rock soil zones, such as in the Almirante Montt and Urriola streets, as shown in Figure 12e. Gravity walls presented many difficulties of inspection due to their hidden condition. However, the representative gravity walls investigated in the hills prove to be made of materials of suitable quality and derived from a good seismic design, given their satisfactory seismic performance during past-earthquakes. The typical foundation system is the brick or stone masonry strip footing. Raised buildings, commonly placed in significantly steep lots, make use of a platform made of quarry stone. These buildings sometimes present habitable basements built with stone or brick masonry gravity walls. Staggered buildings in steep terrains present commonly difference of levels in the foundations $(1 \div 2 \mathrm{~m}$ average), a condition that negatively influences the seismic response of a structure according to GNDT (2007). 
Due to the historical and touristic character of the study area, a large number of buildings transformed their original residential use to new commercial or mixed uses. Largest buildings have apartments and hostels, with commercial activity at the ground floor. Most of the subsequent interventions were regulated by the current construction normative and proved to be well executed. Steel structures are typically used to create mezzanine stories or to reinforce the masonry walls and stories, as shown in Figures 12b-c. Internal timber frame partitions were commonly restored in the past by replacing the elements in bad state of conservation. Masonry buildings could resist several major earthquakes in the past, demonstrating their good seismic performance. However, the deterioration of the materials and the existence of some badly executed interventions constitutes major concern for future seismic vulnerability assessments.

\subsubsection{Reinforced Concrete buildings}

Most of the reinforced concrete (RC) buildings of the study area were built in compliance with the seismic design standards NCh 433.Of 96 (Instituto Nacional de Normalización 2009) after their first release in 1960. Chilean regulations for RC structures are very demanding due to the high seismicity of the territory. Minimum standards for material resistances and structural design are required in projects of RC structures and therefore they are generally reliable buildings if designed in compliance with construction standards. RC buildings are the largest ones of the surveyed stock in terms of area and height. These characteristics are associated to their predominant commercial and governmental use, such as the banks and administrative buildings in Sotomayor and Anibal Pinto squares, as well as in Arturo Prat street. Most of these buildings house more than 100 occupants, reflecting their high exposure within the stock. According to FEMA (2015) vulnerability assessment, high-rise RC buildings should be penalized in order to increase the assessment of the potential hazard of these buildings, and thus to encourage more in-depth analyses. RC surveyed buildings in the study area were identified as multi-story buildings (with more than 7 stories) and consequently must be carefully investigated.

Technical specifications of representative and contemporaneous RC buildings provided detailed information to characterize these building. The majority of these constructions present a unique structural system. The $63 \%$ of them were classified as A1 and A2, i.e. moment resistant frame structures filled with reinforced or unreinforced brick walls, and rigid and well connected stories, mostly cast in place RC beams with concrete topping slabs and dual systems respectively. Internal partitions are commonly made of brick masonry or light wrought iron profiles with thicknesses varying from 0.10 to $0.25 \mathrm{~m}$. Brick walls use clay-fired bricks bonded with mixed mortar of cement and sand. The good quality of the materials, as well as the rigorousness of the structural designs and execution of the project, lead to expect a good seismic behavior of these buildings. Roof structures, as well as the stories, are made of RC slabs supporting light steel trusses to achieve the minimum slope requirements. However, roof and stories presented very challenging examination conditions due to sheathing and restricted access. Hence, their characterization was based on the existing technical reports of representative buildings, and the obtained information was then extrapolated to similar and contemporary constructions.

RC structures have quite regular morphology. Few buildings present isolated plan position (Anibal Pinto and Sotomayor squares), while the remaining are enclosed in-row. Some of the RC buildings present moderately decreasing mass from the ground level to the top, and the openings are regularly distributed in most of the cases. These configurations contribute to the good seismic response of the structures to past events. 
Most of the RC buildings are located in the flat zones (Sotomayor and Anibal Pinto squares), but a few of them are in direct contact with the hillsides, such as in the cases of buildings at Arturo Prat and Almirante Mont street. In these cases, retaining walls are made of RC to counteract the thrusting effect of the soil. The available technical specifications of the surveyed buildings indicated that the most typical foundations are RC isolated or strip footings.

Most of the newer RC buildings present excellent conditions of conservation, given their anti-seismic solutions and newest character. Later addition of upper stories is a recurrent intervention in RC buildings. Even though some specific cases considered explicitly the possible later addition of stories and overloads in the original project, most of them did not. In these unfavorable cases, the quality of the later intervention must be carefully evaluated in order to determine its influence on the global seismic response of the building.

\subsubsection{Mixed iron-reinforced concrete buildings}

The oldest constructions of the study area are recognized as hybrid iron-RC structural typologies built between the late 19th and early 20th century. Even though they constitute a minority of the surveyed stock (only 5\%), their remarkable architectonic and structural value position them as important targets of this study. Despite their historical character, there is a scarcity of technical information in DOM and very few past studies on their structural configuration. All the mixed iron-RC buildings are located in Arturo Prat street in the commercial zone of the downtown area. Originally, the largest buildings of the stock were conceived to house banks or governmental organizations. Similar constructive solutions, stylistic patterns, materials and façade compositions (Figures 14-15) led to identifying them as analogous exemplars built with contemporary iron-RC techniques. Unfortunately, these buildings presented very unfavorable inspection conditions due to their large dimensions, complex configurations, and restricted access. To mitigate this difficulty, an in-depth inspection was carried out on a representative case of study in order to implement a reliable data extrapolation for the remaining analogous buildings. The similarities among the buildings were verified through available original information and overall field inspections in order to ensure the confidence of the extrapolation process.

The Bolsa de Valores de Vaparaíso was selected as case of study due to the excellent conditions of examination and the available technical reports which helped to make a consistent characterization of the hybrid structural typology. The structural and architectonic features of this buildings was widely described by Concreto Revista de Ingeniería y Arquitectura (1919) in Valparaíso. The construction of this Renaissance-style building, dating back to 1912 (Figure 14a), was undertaken by important engineer-architects of this period such as Carlos Claussen, Gustavo Jullian and the Italians Arnaldo Barison and Renato Schiavon. The building is located at the bottom of the Cerro Alegre at Urriola and Arturo Prat streets and it is positioned in the corner of the row in a semi-staggered land. The construction covers an area of $960 \mathrm{~m}^{2}$ and $37.50 \mathrm{~m}$ up to the dome. The main load-bearing system is made of laminated "C" profiles and complex truss systems of wrought iron, filled with plain concrete. The dimension of the profiles varies with the height of the buildings at each story. First and second floors have the largest section profiles, i.e. “C” profiles of $0.25 \mathrm{~m}$ depth. The walls of the third and fourth floors have smaller "C” profiles with heights of $0.20 \mathrm{~m}$ and $0.15 \mathrm{~m}$, respectively. The fifth story structure present double " $\mathrm{T}$ ” profiles with $0.15 \mathrm{~m}$ height. Sidewalls present wrought iron double "T" posts of $0.2 \mathrm{~m}$ height spaced at $2.5 \mathrm{~m}$ and linked by at least two horizontal profiles. The thickness of the plain concrete fill of the frame is $0.25 \mathrm{~m}$. The overall configuration of interior walls is similar to that of the main façade, with iron profiles filled with plain concrete and thicknesses varying from $0.20 \mathrm{~m}$ to $0.4 \mathrm{~m}$. Isolated continuous 
pillars support the upper stories and a dome structure in the central part of the building. The stories have double " $\mathrm{T}$ " beams, with varying section from $0.3 \mathrm{~m}$ to $0.2 \mathrm{~m}$ along the height of the building, according to the spans and load requirements. A set of secondary iron beams topped with concrete constitute the slabs of the buildings. Tiles or wooden boards cover the floor structure depending on the use of the rooms. Roofs are composed of iron trusses covered by galvanizes iron sheets. The last interventions date back to 1980 and 1981, and they did not bring significant changes to the primary structure. On-site inspections allowed to determine the current condition of the structures, where the main issue was the bad condition of conservation of non-structural elements. The roof of the central foyer made of wood and plaster, surrounding the dome, made of wrought iron and glass, present medium-severe damage, as the detachment of a large amount of plaster and rainwater seepage see Figure 14d. The dome experiences corrosion of metal elements and deterioration of the glass-metal joints, see Figure 14e. The visible remaining structures such as walls, columns, stairs, non-structural elements presented very good structural conditions (Figure 14).

The remaining mixed iron-RC buildings of the stock presented very similar structural configurations due to their contemporary nature, proximity, and use of comparable elements, such as columns, domes, materials, etc. (Figure 15). Therefore, the data extrapolation results constituted a very reliable approximation. Despite this, future detailed examinations will be aimed at providing more accurate information about each one of these buildings. On the basis of the assumed extrapolation analysis, the main lateral load resistant systems of the mixed iron-RC buildings were classified as A5 (83\%) and A1 (17\%), i.e. moment resistant frame structures filled with unreinforced masonry (brick or RC blocks) and light steel stories or RC slabs.

\subsubsection{Timber frame buildings}

Timber frame structures are the most diffused typologies in the historical center of Valparaíso, and in the surveyed study area constitutes $40 \%$ of the building stock. The foreign influences of this type of buildings are clearly visible in the Cerro Alegre and Cerro Concepción. Similar timber frame typologies were frequently constructed in British and American territories. The foreign influence in architectural and technological solutions is evidenced by news advertisements of the time, which promoted pre-cast buildings from Europe and imported material such as the Oregon Pine and Oakwood, as well as corrugated iron sheets. In addition, a noteworthy use of Victorian stylistic resources and architectonical shapes can be found, such as sashes, bow windows and ornaments (Jiménez 2015). Local techniques and materials co-exist with foreign structural solutions in the timber dwellings of the historical center of Valparaíso. The specific typologies of timber frame structures in Valparaíso became singular exemplars in Latin America due to their peculiar adaptation strategies to the complex topography of the territory. Most of the structures includes masonry elements such as foundations, sidewalls, retaining walls, and even present composite façades with lower stories built in masonry and upper ones in timber.

The main frames of timber structures are commonly hidden under the sheathing. This condition represented the principal obstacle to examine the configuration and conservation condition of the structure. Also, most of these buildings have residential use and consequently restricted access. These issues forced the use of data extrapolation techniques based on the study of different representative cases. The first step of this process was identifying the common features of these typologies i.e. materials, façade configuration, average height of the stories, stylistic resources, constructive solutions etc. to guarantee the 
confidence with the studied group (see Figure 16). Buildings undergoing transformation or with a significant part of the structure uncovered or lightened were carefully examined to achieve the structural characterization.

Load-bearing systems are made of unique timber frames (Figure 17a) or mixed masonry-timber structures. In the second case, internal partitions are constituted by secondary timber frames in most of the cases. The frames are made of heavy posts spaced at $0.4 \div 0.6 \mathrm{~m}$, braced with diagonal elements crossing the posts according to different configurations, see Figure 17a. Each diagonal crosses three posts, dividing the central one into two segments, and nailed at its ends to the internal faces of the external posts. The cross-sections of the elements revealed to be quite standard in all the surveyed buildings and could vary along the height of the building, as well as in the internal partitions, from $0.125 \times 0.125 \mathrm{~m}^{2}$ to $0.10 \times 0.10 \mathrm{~m}^{2}$. External walls are normally thicker than the internal ones due to the use of bigger timber elements. Reinforced carpentry joints connect most of the elements of the wall frames. The most common systems were the mortise and tenon, notching, and dovetail joints, as shown Figures 17b-d. Wrought iron and industrial nails of different dimensions are common as reinforcing elements for the connections. External walls are filled with adobe bricks, while internal ones with lath and plaster (see Figure 17e-f). Sidewalls are made of clay brick and lime mortar masonry, as described in Section 3.2.1. The thickness of the walls decreases along the height of the buildings. Their staggering allows supporting the stories that are usually made of timber joists with $0.05 \times 0.15 \mathrm{~m}^{2}$ cross section. These elements lean on the sidewalls and are connected by means of nails to the plates and sills of the lower and upper timber walls. Joists are spaced at $0.40 \mathrm{~m}$ each other and, as is the case of masonry buildings of Valparaíso, are covered by simple layers of wooden boards (Figure 17g). The roofs are typically pitched and composed of rudimentary trusses. All the examined cases were classified in A1 (Figure 5b) in the survey form.

The most frequent typologies of wood adopted in the construction are Oak and the Oregon Pine. Oak pieces are used in the main structural elements, such as main beams and façade frames. Unfortunately, there is an important lack of information about the properties of the materials employed in these constructions. Future research is required to investigate the mechanical parameters of these recurrent qualities of wood, since they could be implemented in vulnerability studies of several timber structures of Valparaíso.

Most of the timber frame buildings present a regular shape in plan and elevation. As well as the aforementioned typologies, they are enclosed in-row configuration. A common pattern of timber frame structures is the configuration of the façade. The dimensions of openings are commonly regularly aligned and restricted by the internal disposition of the studs presenting very similar dimensions and appearances, see Figure 16. In addition, the use of the same windows typologies (sash and bow windows) and external sheathing (corrugated iron sheets) confirm the correspondence between these buildings.

Timber frame is the most used structural system in the steep areas of Valparaíso. Their modularity and compatibility with other techniques, e.g. masonry, allowed the arrangement of well-adapted constructions. Also, the proved stability of the system against earthquakes, wind and thrusting soil effects positioned them as a very popular technique. Most of the buildings of the stock are placed in staggered lands, and had to make use of sophisticated construction solutions, see Figures 18a-b. The high difference of levels among the foundations and the bad quality of the retaining walls are conditions that negatively affect the seismic performance of the buildings. The foundations are commonly brick or stone masonry strip footings (Figure 17h). Brick masonry gravity walls are also employed to counteract the thrusting effect of the soil in staggered hillsides. 
Buildings with large bow-windows, projecting stairs, gutters, ornaments or badly connected sheathing represent conditions of concern in case of earthquake. Non-structural elements do not present important damage conditions and were considered as null or slight in most of the cases.

The damage recognition on the internal elements is always a challenging activity, thus external factors such as moisture detection and termites' residues on the surfaces are good indicators to identify damage conditions on structural elements. The degradation of the material by biotic attacks, decay, and mechanical damage, generates large concern in timber structures. Termite attacks are the main source of deterioration in Valparaíso, especially in elements made of pine. Medium to severe damage in structural elements can highly decrease their mechanical resistances and consequently jeopardize the global behavior of the structure. A poor insulation of the structures interacting with the foundations and hillsides leads to accelerated decay of the wood due to the high moisture conditions. Depending on the level of damage, timber structures can be repaired by replacing the deteriorated pieces and this fact eases the maintenance of this type of buildings. Mechanical damages caused by major earthquakes or fires, such as partial detachment of portions of walls or structural elements, are the worst damage scenarios for these typologies.

As well as masonry buildings, original timber dwellings were frequently transformed into touristic buildings, such as restaurants and hotels. Typical interventions are the addition of rooftop terraces and subdivision or rearrangement of the rooms by removal/addition of internal walls. The creation of "transparent walls" by removing the adobe infill is also a rather recurrent modification of the original system. Such later interventions were investigated carefully during the survey activities in order to detect possible sources of seismic vulnerability, such as addition of excessive massive elements or removal of stiffening components of the resisting system. However, later structural interventions or additions were executed in most cases by using wooden materials and light steel elements. These cases are categorized in the group A of the Section 7 of the form (Figure 8c).

\subsection{Survey results on GIS maps and statistical results}

The survey forms presented in Section 2 were used to collect all the information about 111 buildings of the study area. This section summarizes the results to determine a preliminary register of the current state of the buildings and to develop suitable databases for future seismic vulnerability analysis. The use of GIS tools was essential to build explanatory maps of all the surveyed data, as well as to carry out data-crossing and topological analyses according to the territorial position of the urban buildings.

The Section 1 of the survey forms "General Information" identified 45\% buildings with residential use and 27\% as commercial establishments. The remaining $28 \%$ corresponded to touristic, governmental, educational, or mixed activities facilities. The $11 \%$ of the surveyed buildings currently hosts less than 10 occupants, the $63 \%$ between 10 and 100 occupants, and the $26 \%$ more than 100 occupants. The overall analysis of the results emerged from the first section of the survey forms could show the strategic character and high exposure of the study area.

The Section 2 of the survey forms "Building Typology" allowed to recognize most of the buildings as historical heritage, even though in some cases the exact date of constructions was unknown. The 76\% of the buildings were not built in compliance with first releases of the Chilean Seismic Design code (since 1960), while the 34\% were subjected to later retrofit according to current seismic standards. These results highlighted the vernacular character of the building stock, mainly based on local techniques and construction materials. This fact motivates a systematic survey to detect possible seismic vulnerabilities 
not conveniently handled before the introduction of the modern design concepts. A total of $93 \%$ of the buildings presented multi-story condition: $34 \%$ had 2 stories, $28 \%$ had 3 stories, and 38\% had more than 4 stories. The highest buildings are on the flat area of the downtown, while the shorts constructions are on the hills. These data showed the remarkable heterogeneity of the aggregates and exhibited the potential interfering effect of the buildings in case of their collapse (Commissione tecnica per la microzonazione sismica 2014). These outcomes allowed the detection of the exposure of the buildings, thus the need to analyze in detail the most critical cases for future vulnerability analyses. Most buildings of the surveyed stock presented hybrid structural conditions (66\%). The typical mixed typologies are timber frame-masonry and iron-RC. However, the hierarchy of each material in the structure can vary significantly, and this fact complicates the determination of the primary lateral load resistant system. The $41 \%$ of the buildings were identified as timber structure resisting systems, followed by masonry (31\%), RC (24\%), and mixed iron-RC structures (4\%), as shown in Figure 19. These results were fundamental to understand the nature of the building stock, to determine the correct use of the forms and to examine the representative cases of each typology. These trends highlighted the intrinsic complexity of the surveyed area, due to the hybrid condition of the buildings and the overall heterogeneity of the stock.

Question 2.5 of Section 2 of the survey forms evaluates the structural configuration of the buildings. Materials and arrangements of the main lateral load resisting systems were identified in order to distinguish the possible weaknesses of the structures. Missing information about specific buildings led to the adoption of extrapolation data from representative casesstudies and, whenever necessary, to develop further field inspections.

The majority of masonry buildings are unreinforced with semi-rigid timber stories. The $64 \%$ of them were classified as G5, G6 and G7 since they present good quality structural configuration and conservation. The marginal compliance with seismic codes represented a major concern for these typologies. The remaining masonry buildings corresponded to reinforced and confined typologies with rigid and well connected stories, classified as A1, A2 and A6 and (18\%). Such buildings were designed in compliance with the current seismic codes and thus lower vulnerability is expected.

The $81 \%$ of RC buildings were classified as A1, A2, D1, which correspond to good-quality load-bearing resistant systems, as shown in Figure 20. The remaining 19\% corresponds to the oldest and low-quality RC buildings, generally designed without compliance to modern seismic criteria and thus representing the most vulnerable types within the RC building stock. The large scale of the mixed iron-RC buildings and their restricted access hindered detailed on-site inspections. The great amount of similarities among these buildings allowed to extrapolate the documental information of the representative case of the Bolsa de Valores de Valparaíso, whose structural features were described in Section 3.2.3. Although the mixed iron-RC buildings are minority into the stock, they presented high seismic exposure due to their large scale and amount of occupants. In addition, they are the oldest of the study area since they were built before 1900 without any compliance of seismic design codes. These conditions positioned them as potentially vulnerable building.

Timber frame structures presented a very regular structural pattern in all the surveyed cases and thus were classified as A1. The clear correspondence of all the inspected buildings of the stock in terms of structural arrangement, materials, façade composition, non-structural elements, etc. fully justified the data extrapolation of representative cases to those with lack of information. The typical main load-bearing system correspond to stud frames braced with diagonals elements across the posts and rigid story systems, made of joist and sheathed with simple layer of wooden boards. This configuration is traditionally known as platform frame. Vertical load bearing systems are filled with adobe or coated by lath and plaster. Vertically oriented 
corrugated steel sheets cover the external walls. The reinforced carpentry joints, as well as the stiffening elements like diagonal braces and external sheathing, contribute to improve the behavior of timber frame structures. Valparaíso's timber frame buildings are considered as reliable anti-seismic structures, as demonstrated by major past earthquakes. However, the current condition of the material and level of damage of the structural elements can might negatively affect the global behavior of the structure. The material degradation of structural elements due to decay by humidity and terms' attacks increase the potential vulnerability of these buildings.

The Section 3 of the proposed survey forms "Structural Regularity" reported that only $16 \%$ of the buildings present unfavorable irregular shapes in plan (class C). Most buildings presented regular plan without significantly protrusions or elongated shape which could affect the response of the structure. The enclosed conditions of the buildings in-row and aggregate configurations is a remarkable feature of the most of the buildings. The $60 \%$ of them has central position within the block, followed by the corner (30\%), and isolated buildings (10\%), as shown in Figure 21b. Adjacent buildings often share at least one perimeter wall. This interaction can highly influence the performance of the whole block/row configuration and should be considered in detail in further vulnerability analysis.

Elevation configurations have also mostly regular arrangements, without important mass variation and setbacks, and openings on the façades are regularly distributed (92\%) with absence of horizontal or vertical misalignments, as shown in Figure 21c. The prevalent regular morphology of the buildings is a good factor for the structural behavior of the buildings under lateral seismic loads.

The foundation soil of the study area is mainly of good characteristics. According to the geological cartography records of Valparaíso (Gana et al. 1996), the 86\% of the buildings are located in hills with hard rock soil. Only the 14\% of the buildings are located in the flat area, which presents loose and non-thrusting soil conditions, categorized as a poor category. Hillside's buildings present very extreme slope conditions, as shown in Figure 22. In these cases, retaining walls are usually employed to counteract the thrusting effect of the soil, especially when the buildings are directly interacting with the terrain. Masonry gravity walls are employed on the $63 \%$ of the cases, as shown in Figure 22-b. The foundations typologies were identified based on the original documentation of the buildings and on-site inspections of few buildings undergoing restoration works. Brick strip footings are typically employed in masonry and timber frame structures (39\% of the cases), while RC strip footings (36\%) are used in RC and mixed iron-RC structures. The construction of flat terraces or quarry stone platforms is a common strategy in staggered zones to level steeped terrains and reach stable foundation soils. All these evidences could show the general antiseismic character of the structures as for the use of good quality foundations and retaining walls. Section 3 of the proposed survey form also helped to detect negative factors such as the extreme slope conditions leading to thrusting effects of the soil and level differences between foundations. According to GNDT (2007), this last factor can negatively affect the behavior of the foundations, thus it needs to be specially considered in future vulnerability analyses.

The $77 \%$ of the buildings presented non-structural elements in good conditions, classified as A on the form (Section 6, Figure 8a). This group correspond to buildings without projected elements, or with small or light elements well connected to the main structure, i.e. with minor falling risks. The remaining 22\% are classified as B and C, such as small/light elements badly connected to the main structure or large/heavy elements, which means high risk in case of falling such as projecting balconies, windows, stairs, galleries or large chimneys, ornaments, signboards, etc. Historical buildings on the downtown area exposed to major risk of falling due to their large and numerous projecting elements such as ornaments, windows and balconies. 
It should be noticed the pragmatic character of timber and masonry buildings constructions without critical presence of hazardous projected elements.

The Section 7 of the proposed survey forms reported the damage condition of the buildings through the assessment of their principal structural and non-structural members. The damage grade assessment was one of the most difficult on-site activities due to the hidden condition of the structural elements. Several buildings allowed only limited inspection, especially for the interior structures, e.g. load-bearing systems, stories, and roofs. RC buildings presented the best condition of conservation, whereas iron-RC buildings exhibited damage in the external ornaments of the façade. Timber frame structures presented termites' attacks, especially in structural members made of pine. Moisture conditions showed to contribute to the decay of timber elements, especially in members in direct interaction with foundations or hillsides. Figure 23 shows some recurrent typologies of damage in the different surveyed typologies. In general, the current condition of conservation of the buildings is rather good. The $77 \%$ of the buildings is categorized as class A in the survey form (Section 7 of Figures 8 and Figure 24), i.e. with null to slight damage level and/or buildings without later additions, as well as those with small enlargements well connected to the main structure. The good state of conservation of the buildings is due to the heritage and protected character of the study area. The World Heritage Site title granted by UNESCO to the historical center of Valparaíso forced buildings to fulfil intervention guides to maintain the original appearance into the protected zones. In addition, the touristic and economic activity of Cerro Alegre and Concepción neighborhoods promoted the restoration of their historical buildings. However, in many cases, these improvements consisted only in external maintenance on the façade without significant structural interventions. These cases could not be considered as retrofitted buildings, and in-depth examinations are necessary to detect possible vulnerabilities at the main structural load bearing system. In addition, some structures presented inappropriate modifications, such as later executions of openings in the façade or alteration of load bearing elements (i.e. columns, shear

walls, etc.), that were categorized as B and C, respectively. Non-regulated and/or bad executed interventions such as weighty story additions, open stories or projecting enlargements were carefully detected since they can negatively affect the global behavior of the buildings.

The global analysis of the surveyed data in statistical terms provided an overview of the intrinsic vulnerability of the buildings to suffer damage in case of future seismic events. The evaluation of the relevant survey parameters brought to the identification of the structural arrangements, irregularities, environmental conditions, damage level and state of conservation of the main load bearing systems. The developed survey activity was very helpful to gain a preliminary understanding of the structural characteristics of the surveyed building stock. The use of GIS tools facilitated the analysis of the results and the detection of critical cases that need to be carefully inspected in further seismic vulnerability assessments. This research contributed to the creation of an extensive building database to support future seismic vulnerability analyses in Valparaíso.

\section{Conclusions}

This paper presented a building survey approach to collect suitable data to feed large-scale seismic vulnerability assessment. The proposal is aimed to survey heterogeneous historical centers in seismically hazardous areas with lack of building databases or post-earthquakes reports. The application of survey procedures poses important challenges for the case of heterogeneous urban centers including different structural typologies. This work proposed four specific survey forms for traditional structural typologies constructed with masonry, reinforced concrete, mixed steel/iron-reinforced concrete and 
timber. This approach is focused on the importance of the buildings' knowledge to afford the second level vulnerability assessment, according to GNDT (2007).

The proposed survey forms compile a set of structural parameters constituting the essential information for the seismic vulnerability analyses. They evaluate meaningful structural aspects regarding the main lateral-load resisting system, regularity, current condition of conservation and existing damages. An important novelty of the paper is the proposal of four specific survey forms, including mixed steel-reinforced concrete and timber frame structures, whilst the up to date scientific literature reports survey forms mainly restricted to masonry and reinforced concrete buildings. The paper presents also a useful guideline for typological survey with suggestions for pre-field, on-field, and post-field activities. All these working stages are aimed to organize the collected data, to establish suitable databases and to manage the results by using GIS platforms.

The proposed survey forms were applied to the study of 111 buildings of the historical center of Valparaíso, Chile. This city constitutes an exceptional case-study due to the remarkable heterogeneity of the urban buildings, the steeped territory, the high seismic hazard and exposition. The proposed survey forms could cover all the existing structural typologies found in the city, i.e. masonry, RC, timber frame and mixed iron-RC buildings.

The survey activities were carried out by analyzing the existent technical information of the buildings in the local archives, and after doing numerous on-site inspections. The main obstacles experienced in the on-field activities were the restricted access to the constructions, the hidden condition of the structural elements and the morphological complexity of the historical buildings. These unfavorable factors limited the on-site inspections to a representative sample of all the buildings of the investigated neighborhoods. However, the proposed methodology could overcome this important limitation by adopting proper data extrapolation strategies based on building taxonomy, in order to fill all the requested data in the forms for similar construction typologies. Data extrapolations were justified by careful desk and on-site activities aimed at proving the common similarities, patterns, materials and dates of construction of analogous structural systems. Representative buildings of each structural typology were extensively examined to extrapolate useful data to complete the forms of buildings with less available information or accessibility.

The overall results of the building survey showed that historical buildings in Valparaíso employed anti-seismic solutions, even rudimentary, in their design. This is true both for the newer constructions and the older vernacular ones, built before the introduction of seismic codes. The nature of these buildings can be explained by considering the constant exposure of the city to suffer major earthquakes since ancient times. The overall good design of the buildings can be associated to the configurations of the resisting systems, the regular morphology, the good condition of the foundations and the limited damage grade.

Good conditions of conservation were observed in general on the surveyed building stock. This is largely due to the heritage condition of the area, listed on the World Heritage and protected by UNESCO since 2003. This acknowledgement promoted the release of rigorous intervention standards for building modifications by considering their historical and architectonic value, the composition criteria of the façades, the maximum height of the buildings, and the wish of preserving the characteristic built environment of the neighborhoods and the whole city. However, renovation and conservation activities always require a good understanding of the structural configurations in order to execute reliable interventions. The lack of technical study of the representative typologies in Valparaíso supposes a huge disadvantage to lead these activities in a reliable way. Ignoring the intrinsic characteristics of the structures facing subsequent transformations could make them even more vulnerable to possible 
seismic hazard scenarios. This research contributed to fill this gap of knowledge by proposing a methodology to collect essential data for second level seismic vulnerability assessments of the most representative typologies of a pilot study area of the historical center of Valparaíso. Ongoing research is dealing with the assessment of the seismic vulnerability of the surveyed buildings to plan appropriate risk mitigation measures. Further developments are focusing on the determination of more accurate data about the mechanical characterization of the materials of the most representative typologies of Valparaíso. Another future stage of the research will be the integration of more structural systems into the survey forms, in order to cover additional vernacular and traditional building typologies. All these activities will contribute to the improvement of the overall understanding of the existing structures in historical centers and therefore to more precise seismic vulnerability assessments.

\section{Acknowledgements}

This research has received the financial support from the ELARCH project (Euro-Latin America partnership in natural Risk mitigation and protection of the Cultural Heritage), reference number 552129-EM-1-2014-1-IT- ERASMUS MUNDUS EMA21, funded with support of the European Commission. This document reflects the view of the authors, and the Commission cannot be held responsible for any use that may be made of the information contained therein.

The authors also gratefully acknowledge the financial support from the MINECO (Ministerio de Economia y Competitividad of the Spanish Government) and the ERDF (European Regional DevelopmentFund) through the MULTIMAS project (Multiscale techniques for the experimental and numerical analysis of the reliability of masonry structures, ref. num. BIA201563882-P).

\section{References}

ASCE/SEI 41-13. 2014. American Society of Civil Engineers Seismic Evaluation and Retrofit of Existing Buildings. doi:10.1016/j.aqpro.2013.07.003.

Baggio, C., A. Bernardini, R. Colozza, L. Corazza, M. Bella, G. Pasquale, M. Dolce, et al. 2007. "Field Manual for PostEarthquake Damage and Dafety Assessment and Short Term Countermeasures (AeDES ).” JRC Scientific and Thechnical Reports.

Barbat, A. H., M. L. Carreño, L. G. Pujades, N. Lantada, O. Cardona, and M.C. Marulanda. 2010. "Seismic Vulnerability and Risk Evaluation Methods for Urban Areas. A Review with Application to a Pilot Area.” Structure and Infrastructure Engineering 6 (4): 499-499. doi:10.1080/15732479.2010.481841.

Benedetti, D., and V. Petrini. 1984. "Sulla Vulnerabilitá Vismica Di Edifici in Muratura I Proposte Di Un Metodo Di Valutazione.” L'industria Delle Construzioni Vol. 18: pp.66-74.

Brzev, B, C. Scawthorn, A.W. Charleson, L. Allen, M Greene, K Jaiswal, and V. Silva. 2013. “GEM Building Taxonomy Version 2.0."

Calvi, G. M., R. Pinho, G. Magenes, J. J. Bommer, L. F. Restrepo-Vélez, and H. Crowley. 2006. "Development of Seismic Vulnerability Assessment Methodologies over the Past 30 Years.” ISET Journal of Earthquake Technology 43 (472): 75-104.

Cattari S., and S. Lagomarsino. 2013. "Seismic assessment of mixed masonry-reinforced concrete buildings by non-linear static analyses". Earthquakes and Structures, Vol. 4, No. 3, 241-264.

Ceccotti, A., and C. Sandhaas. 2015. "A Proposal for a Procedure to Evaluate the Seismic Vulnerability of Historic Timber Frame Buildings.” In Historical Earthquake-Resistant Timber Frames in the Mediterranean Area, edited by Ruggieri Nicola, Gennaro Tampone, and Raffaele Zinno, 171. Springer,Cham. doi:10.1007/978-3-319-16187-7.

CEN EC5 1.2. 2004. “Eurocode 5 - Design of Timber Structures Part 1-2: General - Structural Fire Design.” Eurocode 5 Design of Timber Structures 2004: 1-69. doi:10.1680/cien.2001.144.6.39. 
Commissione tecnica per la microzonazione sismica. 2014. Manuale per L'analisi Della Condizione Limite per l'Emergenza (CLE) Dell'insediamento Urbano. Versione 1.0. Roma.

http://www.protezionecivile.gov.it/resources/cms/documents/CLE2.pdf.

Concreto Revista de Ingeniería y Arquitectura. 1919. “Edificio de La Bolsa de Corredores.” Concreto Revista de Ingeniería Y Arquitectura.

Curls, J.S, and S. Wilson. 2015. The Oxford Dictionary of Architecture. 3th ed. Oxford University Press. doi:10.1093/acref/9780199674985.001.0001.

Duţu, A., H. Sakata, and Y. Yamazaki. 2015. "Experimental Study on Timber-Framed Masonry Structures.” In Historical Earthquake-Resistant Timber Frames in the Mediterranean Area, edited by Nicola Ruggieri, Gennaro Tampone, and Raffaele Zinno, 171. Springer, Cham.

EN 1998-1. 2004. Eurocode 8: Design of Structures for Earthquake Resistance. Part 1: General Rules, Seismic Actions and Rules for Buildings. Vol. 3.

Eujenio, N. 2015. “Sistema Constructivo de Madera En Armaduras de Techumbre.” Tesis de licenciatura, Universidad Técnica Federico Santa María.

Farzad, N. 1989. The Seismic Design Handbook. Structural Engineering Series, Van Nostrand Reinhold, New York. $2^{\circ}$. Springer Science+Business Media, LLC. doi:10.1007/978-1-4615-1693-4.

FEMA. 2015. "Rapid Visual Screening of Buildings for Potential Seismic Hazards: A Handbook (FEMA P-154).” Federal Emergency Management Agency, no. January: 388. doi:10.4231/D3M90238V.

Formisano, A., G. Florio, R. Landolfo, and F. M. Mazzolani. 2015. "Numerical Calibration of an Easy Method for Seismic Behaviour Assessment on Large Scale of Masonry Building Aggregates.” Advances in Engineering Software 80 (C). Elsevier Ltd: 116-138. doi:10.1016/j.advengsoft.2014.09.013.

Formisano, A, G Florio, R Landolfo, and M Mazzolani, F. 2011. "Un Metodo per La Valutazione Su Larga Scala Della Vulnerabilità Sismica Degli Aggregati Storici.” XV Covegno ANDIS - L’Ingegneria Sismica in Italia.

Gana P., Wall F., Gutiérrez A., SERNAGEOMIN. Mapa geológico del área de Valparaíso-Curacaví, regiones de Valparaíso y Metropolitana, Escala 1:100.000. Santiago: SERNAGEOMIN, 1996

GNDT. 2007. Manuale per Il Rilevamento Della Vulnerabilità Sisimica Degli Edifici. Istruzione per La Compilazione Della Scheda Di $2^{\circ}$ Livello.

Grünthal, G. 1998. European Macroseismic Scale 1998. Vol. 15. Luxembourg: Centre Européen de Géodynamique et de Séismologie.

Guevara-Perez, L. T. 2012. "Soft Story and Weak Story in Earthquake Resistant Design : A Multidisciplinary Approach.” In In Proceedings of the 15th World Conference on Earthquake Engineering - WCEE, 518-519. Lisboa.

Herrera, G. R., J. C. Vielma, A. H. Barbat, and L. G. Pujades. 2013. "Estado Del Conocimiento Sobre Metodologías de Evaluación de Vulnerabilidad Sismica de Edificios.” Ingenieria Y Sociedad UC 1 (8). Carabobo: 7-28. http://servicio.bc.uc.edu.ve/ingenieria/revista/index1.htm.

Hurtado, M., M Santander, and G. Muñoz. 2016. "Construction Features of the Historical Architecture in Valparaiso Harbor: The Brick Masonry Buildings of the Architect EOF Harrington.” Journal of Construction 15 (3): 67-76.

Indirli, M. 2009. "Organization of a Geographic Information System (GIS) Database on Natural Hazards and Structural Vulnerability for the Historic Center of San Giuliano Di Puglia (Italy) and the City of Valparaiso (Chile).” International Journal of Architectural Heritage 3 (4): 276-315. doi:10.1080/15583050902803780.

Instituto Nacional de Normalización. 2009. "NCh433.Of1996 Modificada En 2009 - Earthquake Resistant Design of Buildings,” 1-43. http://ecommerce.inn.cl/index.php.

Jiménez, B. 2015. "Los Entramados Tradicionales de Madera En Los Cerros Alegre Y Concepción. Caracterización Histórica Y Técnica de Las Viviendas de Finales Del Siglo XIX Y Comienzos Del XX.” Tesis de licenciatura, Universidad Técnica Federico Santa María.

Jorquera, N. 2015. “Culturas Sísmicas: Estrategias Vernaculares de Sismorresistencia Del Patrimonio Arquitectónico Chileno.” Arquitecturas Del Sur 32 (46): 18-29.

Lewis, M. 2009. “Stud and Balloon Frames.” In The Pacific Connection, edited by Miles Lewis, 48-73. Melburne.

Malczewski, J. 2006. "GIS-Based Multicriteria Decision Analysis: A Survey of the Literature.” International Journal of Geographical Information Science 20 (7): 703-726. doi:10.1080/13658810600661508.

Masi, A., L. Chiauzzi, C. Samela, L. Tosco, and M. Vona. 2014. "Survey of Dwellings Buildings for Seismic Loss Assessment at Urban Scale: The Case Study of 18 Villages in Val D ’ Agri , Italy” 13 (2): 471-486.

Monteiro, R., P. Ceresa, V. Cerchiello, J. Dabeek, A. Di Meo, and B. Borzi. 2016. “Towards Integrated Seismic Risk Assessment in Palestine. Application to the City of Nabulus." In VII European Congress on Computational Methods in Applied Sciences and Engineering. Crete. doi:10.7712/100016.2235.12031.

Mouroux, P., E. Bertrand, M. Bour, B. L. Brun, S. Depinois, and P. Masure. 2004. "The European RISK-UE Project : An Advanced Approach To Earthquake Risk Scenarios.” Proc: 13h World Conference on Earthquake Engineering, no. 
3329.

NTC. 2008. Technical Norms for Construction (in Italian). Rome, Italy. www.cslp.it.

NZSEE. 2016. The Seismic Assessment of Existing Buildings Technical Guidelines for Engineering - Section C9 - Timber Buildings.

Oliveira, V. 2016. Urban Morphology. An Introduction to the Study of the Physical Form of Cities. 1sted. Springer International Publishing. doi:10.1007/978-3-319-32083-0.

Oliver, P. 1997. The Encyclopaedia of Vernacular Architecture of the World. New York: Cambridge University Press.

ONEMI. 2016. "Plan de Protección Civil Municipal - Valparaíso.” Chile Preparado. http://www.onemi.cl/wpcontent/uploads/2017/09/Valparaíso-Laguna-Verde.pdf.

Panagiotis, A., and P. Vagelis. 2015. Handbook of Research on Seismic Assessment and Rehabilitation of Historic Structures. Hershey PA.

Pitilakis, K., P. Franchin, B. Khazai, and H. Wenzel. 2014. "SYNER-G: Systemic Seismic Vulnerability and Risk Assessment of Complex Urban, Utility, Lifeline Systems and Critical Facilities: Methodology and Applications.” Geotechnical, Geological and Earthquake Engineering 31. doi:10.1007/978-94-017-8835-9.

Poletti, E., and G. Vasconcelos. 2015. "Seismic Performance of Traditional Half-Timbered Walls: Experimental Results.” In Historical Earthquake-Resistant Timber Frames in the Mediterranean Area, edited by Nicola Ruggieri, Gennaro Tampone, and Raffaele Zinno, 171. Springer, Cham.

Porteous, J., and A. Kermani. 2004. Structural Timber Design to Eurocode 5. Vol. 2004. Blackwell Science Ltd. doi:10.1680/cien.2001.144.6.39.

Presidenza del Consiglio dei Ministri - Dipartimento della Protezione Civile. 2011a. Emergenza Post-sisma. Scheda per il Rilievo del Danno ai Beni Culturali - Chiese. Modello A-DC. (In Italian) http://www.beniculturali.it/mibac/multimedia/MiBAC/documents/1338454237471_allegato4.pdf

Presidenza del Consiglio dei Ministri - Dipartimento della Protezione Civile. 2011b. Manuale per la compilazione della scheda per il rilievo del danno ai beni culturali, Chiese. Modello A-DC. (In Italian). http://www.protezionecivile.gov.it/resources/cms/documents/manuale_chiese.pdf

Salazar, M. 2014. “El Carácter Técnico/Constructivo En La Obra de E.O.F. Harrington.” Tesis de Licenciatura, Universidad Técnica Federico Santa María.

Sánchez, A., and C. Jiménez. 2011. "Valparaíso: La Ciudad-Puerto Más Importante de Chile Y La Vulnerabilidad de Su Patrimonio Arquitectónico a Los Riesgos Sísmicos.” Estudios Geográficos 72 (271): 559-589. doi:10.3989/estgeogr.201122.

Siano, R., V. Sepe, G. Camata, E. Spacone, P. Roca, and L. Pelà. 2017. “Analysis of the Performance in the Linear Field of Equivalent-Frame Models for Regular and Irregular Masonry Walls.” Engineering Structures 145 (May): 190-210. doi:10.1016/j.engstruct.2017.05.017.

Staniscia, S., E. Spacone, and V. Fabietti. 2017. "Performance-Based Urban Planning: Framework and L’Aquila Historic City Center Case Study.” International Journal of Architectural Heritage 11 (5): 1-28. doi:10.1080/15583058.2017.1287977.

Taffarel, S., C. Marson, G. Bettiol, F. Da Porto, and C. Modena. 2014. "Seismic Vulnerability Assessment of Israeli Historical Cetres.” In 9th International Conference on Structural Analysis of Historical Constructions, 14-17. Mexico City.

Taffarel, S, C Marson, C Valotto, M Roverato, M Munari, F Porto, and C Modena. 2016. “Seismic Vulnerability Maps of Timisoara Historical Center Based on Fragility Curves.” In 10th International Conference on Structural Analysis of Historical Constructions, 1605-1612. Leuven.

UNISDR. 1999. "Risk Assessment Tools for Diagnosis of Urban Areas Against Seismic Disasters (RADIUS).” http://www.geohaz.org/risk-assessment-tools-for-diagnosis-of-u.

UNISDR. 2009. “Terminology on Disaster Risk Reduction.” International Stratergy for Disaster Reduction (ISDR), 35. doi:978-600-6937-11-3.

Valluzzi, M. R., E. Garbin, and M. D. Benetta. 2010. “In-Plane Strengthening of Timber Floors for the Seismic Improvement of Masonry Buildings.” WCTE 2010. 11th World Conference on Timber Engineering, no. June 2016: 2-8.

Vicente, R. 2008. "Estratégias E Metodologias Para Intervenções de Reabilitação Urbana. Avaliação Da Vulnerabilidade E Do Risco Sísmico Do Edificado Da Baixa de Coimbra.” PhD diss, Aveiro University.

Vicente, R., S. Parodi, S. Lagomarsino, H. Varum, and J. A. R. Mendes da Silva. 2008. "Seismic Vulnerability Assessment Damage Scenarios and Loss Estimation. Case Study of the Old City Centre of Coimbra, Portugal.” In The 14th World Conference on Earthquake Engineering. Beijing. 


\section{Figures Captions}

Figure 1. Available survey forms typologies: (a) Gruppo Nazionale per la Difesa dai Terremoti (GNDT 2007), (b) FEMA154 Rapid visual Screening of Buildings for Potential Seismic Hazards (ATC, 2002), (c) AeDES (Baggio et al. 2007) and (d) SASPARM 2.0 project (Monteiro et al. 2016).

Figure 2. Example of pre-field desk survey: original technical documentation of the Baburizza building settled in Cerro Alegre in Valparaíso (Chile) constructed in 1917: (a) elevation drawing, (b) first-floor plan and (c) technical specification (source: Historical archive of Municipal Construction Management of Valparaíso, DOM).

Figure 3. Proposed survey form: (a) Section 1 “General Information” and (b) Section 2 "Building Typology” with information on the number of stories, structural system homogeneity, and building age.

Figure 4. Proposed survey forms for (a) masonry and (b) reinforced concrete buildings: identification of the main lateral load resistant system.

Figure 5. Proposed survey forms for (a) steel/iron mixed and (b) timber frame buildings: identification of the main lateral load resistant system.

Figure 6. Timber main load-resistant systems: (a) Let-in brace, (b) Diagonal brace and (c) Dog leg brace.

Figure 7. Proposed survey form: (a) Section 3 "Structural Regularity" and (b) Section 4 "Soil and foundations conditions".

Figure 8. Proposed survey form: (a) Section 5 "Non-structural elements”, (b) Section 6 "Damage conditions” and (c) Section 7 "Current condition of conservation".

Figure 9. Flow chart of the building survey process.

Figure 10. Pilot study-area of Valparaíso: (a) Sotomayor square, (b) Cerro Alegre and Cerro Concepción, c) World Heritage Site zones with safety functions, possible interfering buildings and evacuation routes at the Emergency Limit Condition and d) survey path.

Figure 11. Typical features of masonry buildings in Valparaíso: (a-b) façades in Almirante Montt street, (c) façade in Arturo Prat street, (d) staggered masonry walls (images by Salazar (2014), and e) main section of the Hotel Reina Victoria in Sotomayor square (by Salazar (2014).

Figure 12. Typical features of masonry buildings in Valparaíso: (a) timber frame internal partition in Urriola street, (b) steel reinforcing structure, (c) timber story with reinforcing steel truss in Almirante Montt street, (d) gravity wall, (e) rock hillside visible from the interior of a building, and (f) side wall.

Figure 13. Typical reinforced concrete buildings in Valparaíso: (a) main façade of the Consejo de la Cultura y las Artes building (1918), (b) main façade of the Compañia Chilena de Navegación Intraoceánica building (1955), (c) the Cooperativa Vitalicia building (1947), (d) the Bavestrello compound in Alvaro Besa street (1927), (e) corner building in Anibal Pinto square (1929) and (d) historical façade in Arturo Pratt Street.

Figure 14. Typical mixed iron-reinforced concrete building (Bolsa de Valores de Valparaíso): (a) façade, (b-c) technical report and plan of the ground level, (d-e) roof and dome damages and (f) interior columns. 
Figure 15. Typical mixed iron-RC buildings in Valparaíso: (a) Ex Banco de Chile dating back to 1919, (b) Ex Banco de Londres y Río de la Plata dating back to 1914, (c) Banco de Chile dating back to 1893.

Figure 16. Typical timber frame buildings in Valparaíso: (a-b-c) located in Urriola and (d) Almirante Mont streets.

Figure 17. Typical timber structure configurations in Valparaíso: (a) view of a representative load bearing system, (b) mortise and tenon joints, (c) mortise and tenon with notching joints, (d) half-dovetail joint, (e) external wall filled with adobe, (f) internal wall of lath and plaster, (g) connection of timber story to the walls and (h) connection of timber story to the brick strip footing foundation.

Figure 18. Typical slope adaptation strategies of historical buildings: (a) recurrent solution in Valparaíso dating back to 1932 and (b) house in Urriola street (1900s).

Figure 19. GIS mapping of the structural typologies (a) and their statistical distribution (b). Representative timber frame dwelling (c), masonry building (d), mixed iron-RC building (e) and RC building (f).

Figure 20. GIS mapping of lateral-load resisting systems of the buildings (a-b) and statistical distributions for each typology (c).

Figure 21. Buildings' irregularity (a), position in aggregate (b) and (c) façades of buildings along Urriola street.

Figure 22. Slope and retaining walls configuration: a) GIS mapping of mean slope and (b) retaining wall typologies, (c) representative case in Almirante Montt street, (d-e) typical retaining walls and foundations.

Figure 23. Representative non-structural elements and damage conditions: (a) large dimension bow-window, (b) poorly connected balcony, (c) severe damage of RC cornice, (d) sheathing detachment, (e) empty timber frame wall and (f) timber joists attacked by termites.

Figure 24. GIS mapping of current condition of conservation (a) and statistical results (b). 


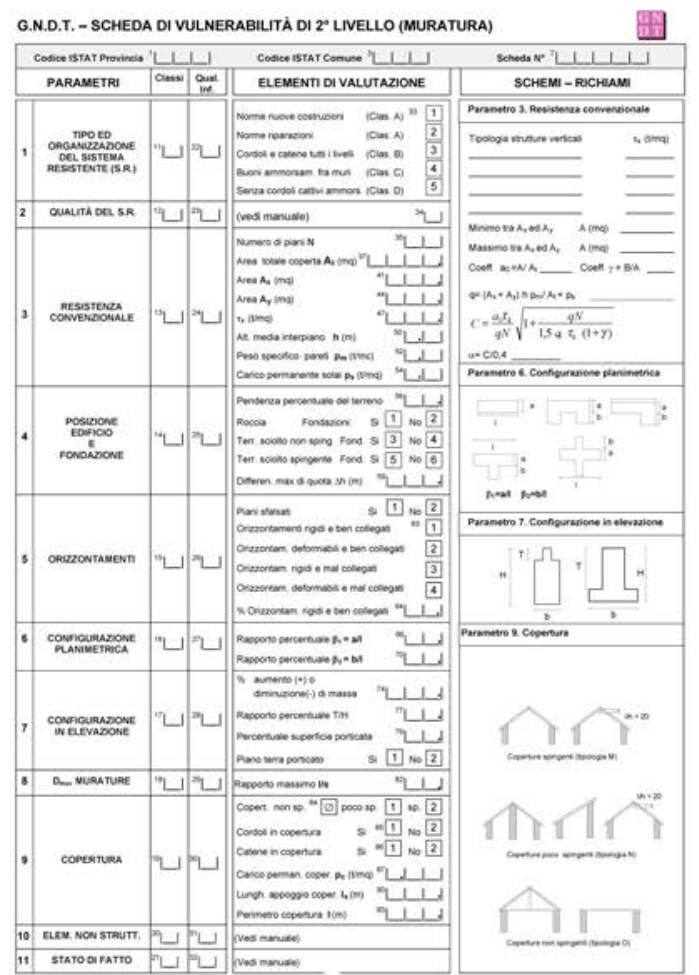

a)

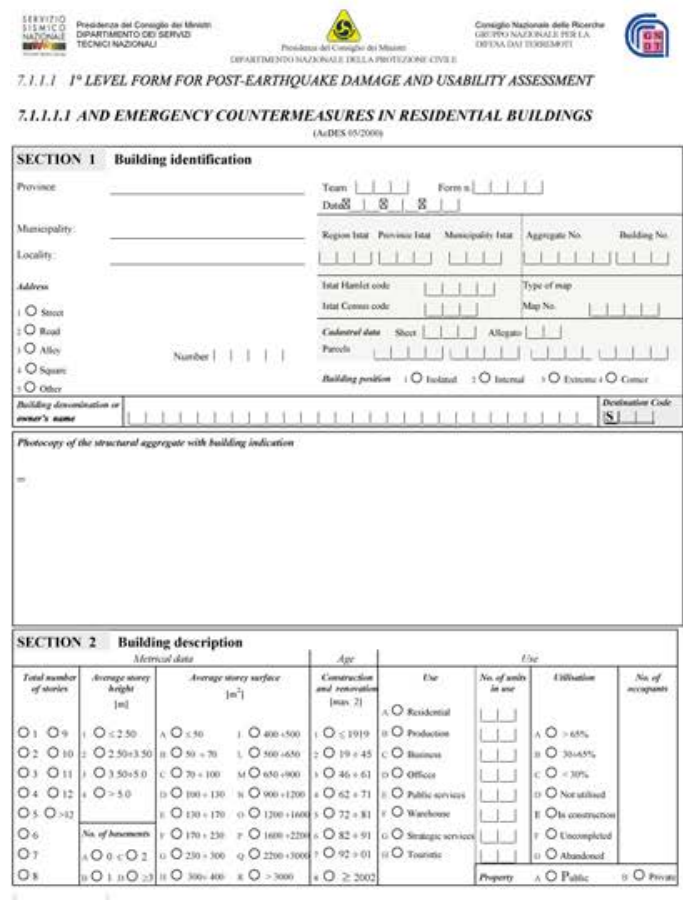

85

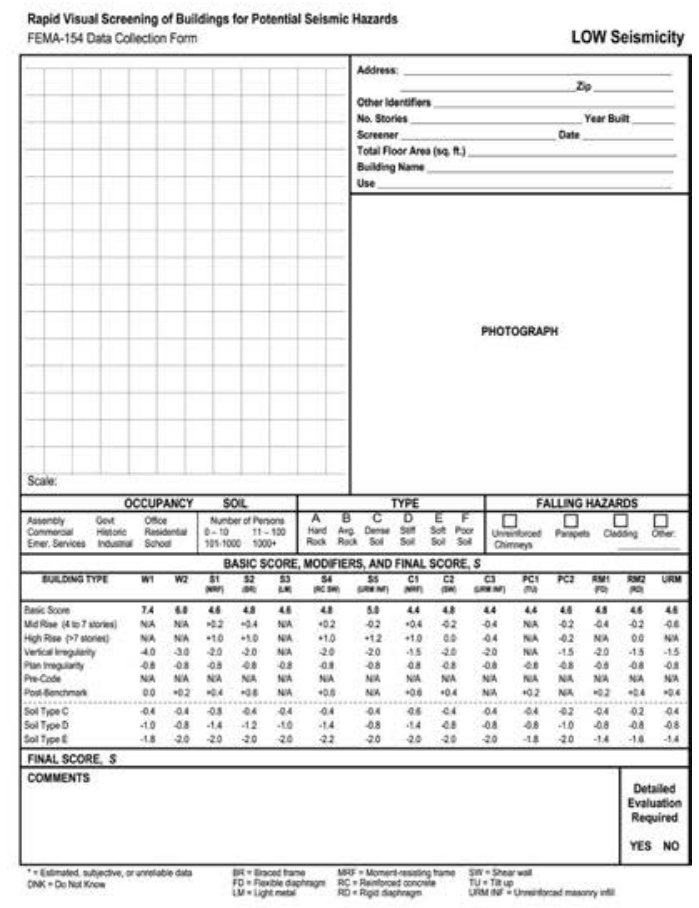

b)

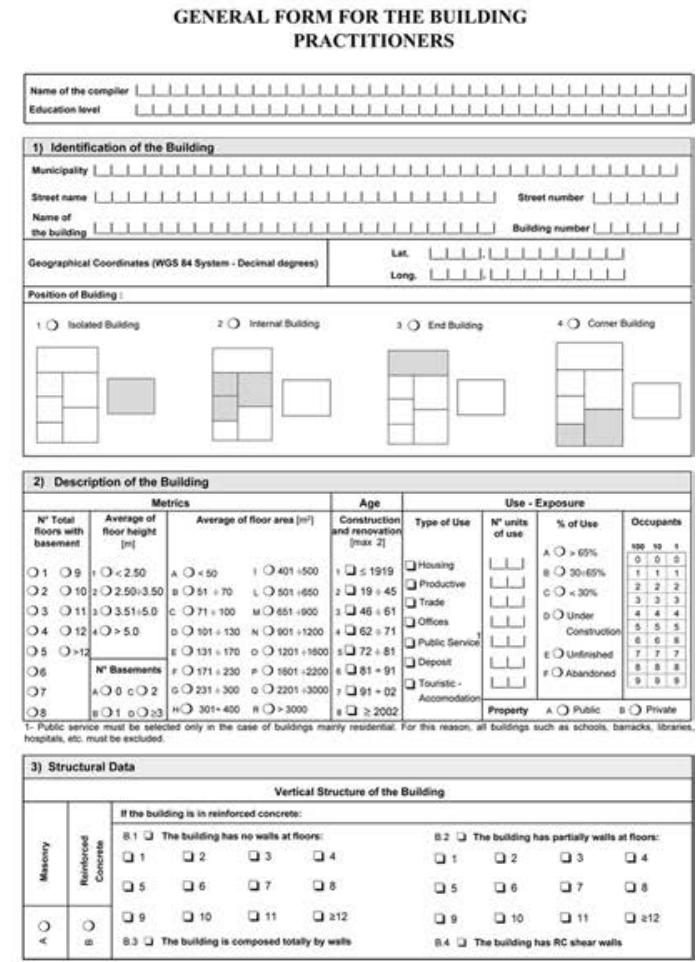

d)

Figure 1. Available survey forms typologies: (a) Gruppo Nazionale per la Difesa dai Terremoti (GNDT 2007), (b) FEMA154 Rapid visual Screening of Buildings for Potential Seismic Hazards (ATC, 2002), (c) AeDES (Baggio et al. 2007) and (d) SASPARM 2.0 project (Monteiro et al. 2016). 


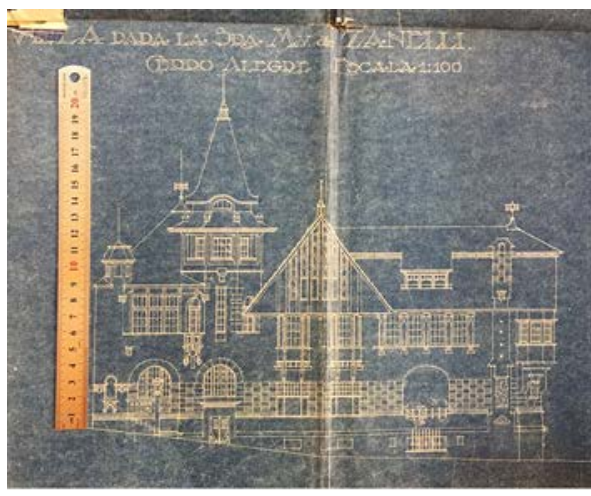

a)

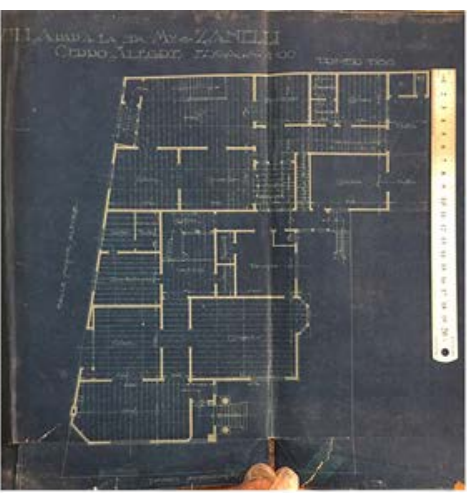

b)

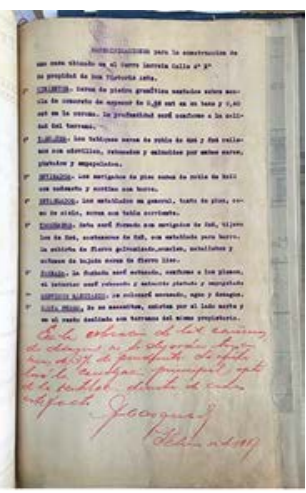

c)

Figure 2. Example of pre-field desk survey: original technical documentation of the Baburizza building settled in Cerro Alegre in Valparaíso (Chile) constructed in 1917: (a) elevation drawing, (b) first-floor plan and (c) technical specification (source: Historical archive of Municipal Construction Management of Valparaíso, DOM). 


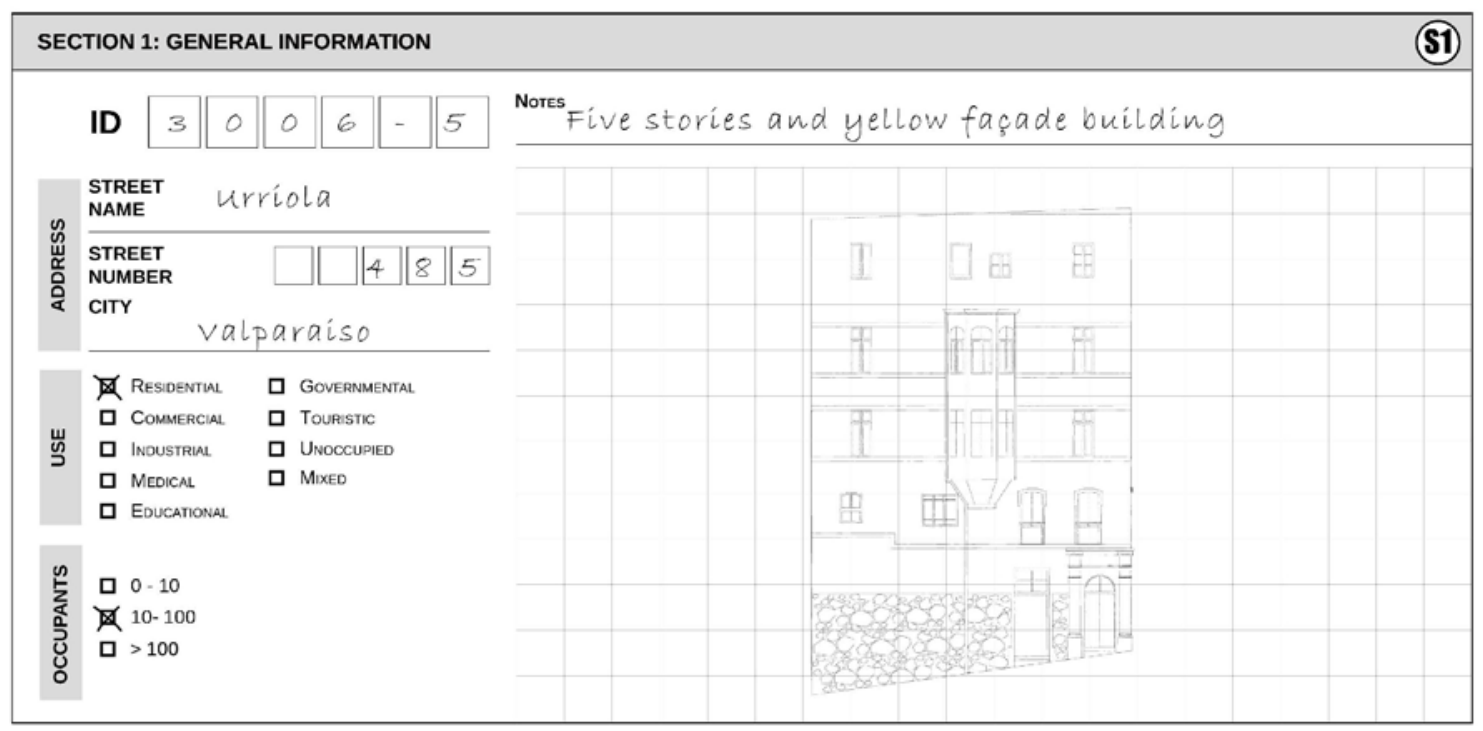

a)

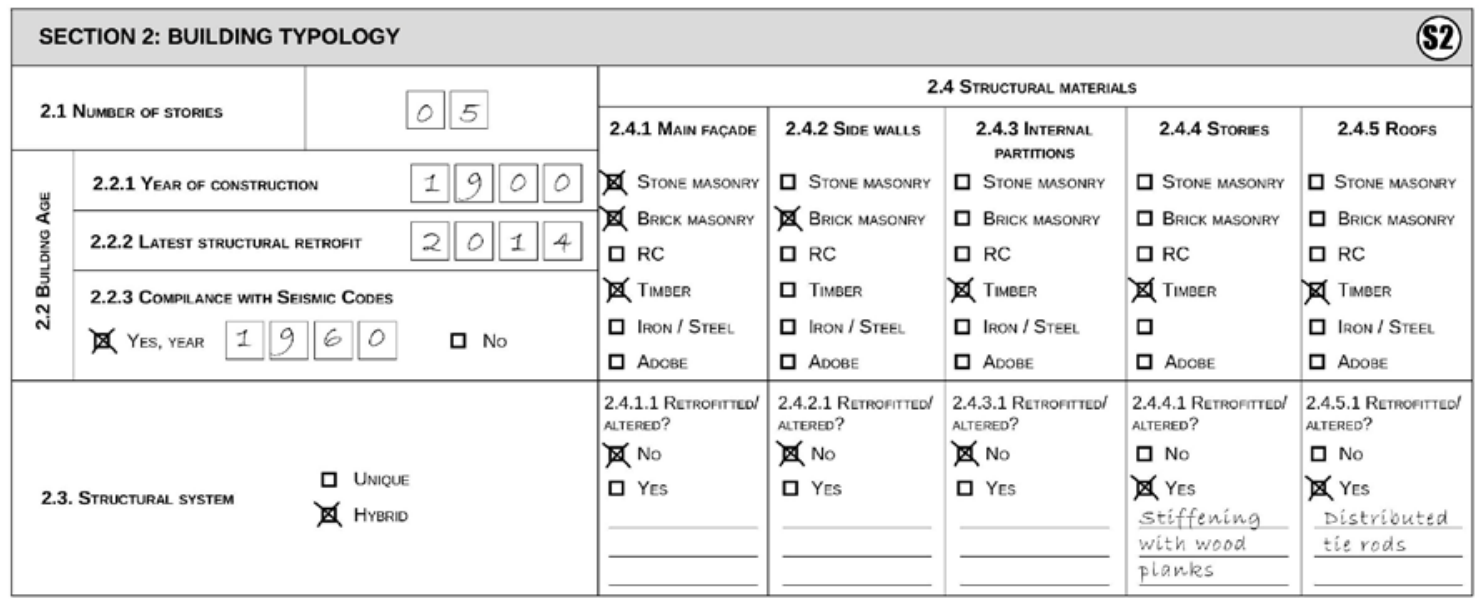

b)

Figure 3. Proposed survey form: (a) Section 1 "General Information" and (b) Section 2 "Building Typology" with information on the number of stories, structural system homogeneity, and building age. 


\begin{tabular}{|c|c|c|c|c|c|c|c|c|c|c|c|c|}
\hline & & \multirow{3}{*}{ 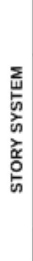 } & \multicolumn{3}{|c|}{ RIGID AND WELL CONNECTED } & \multicolumn{3}{|c|}{ SEMI-RIGID AND CONNECTED } & \multicolumn{2}{|c|}{$\begin{array}{l}\text { FLEXIBLE ANOJOR } \\
\text { BADLY CONNECTED }\end{array}$} & \multirow{2}{*}{ 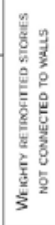 } & \multirow[b]{2}{*}{$\begin{array}{l}3 \\
\frac{3}{3} \\
\frac{2}{2} \\
3\end{array}$} \\
\hline \multirow{2}{*}{\multicolumn{2}{|c|}{ 2.5. MASONRY LATERAL LOAD RESISTANT SYSTEM }} & & $\begin{array}{l}\text { CAST IN } \\
\text { PUACE OR } \\
\text { PRECAST } \\
\text { RC SLAR } \\
\text { WITH } \\
\text { CONCRETE } \\
\text { TOPPING }\end{array}$ & 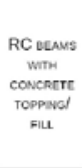 & $\begin{array}{l}\text { MetML } \\
\text { OECK } \\
\text { WITH } \\
\text { CONCRETE } \\
\text { FILL }\end{array}$ & $\begin{array}{l}\text { CAST IN } \\
\text { PUACE OR } \\
\text { PACENST } \\
\text { RC SLAB } \\
\text { WLo } \\
\text { CONCRETE } \\
\text { TOPPING }\end{array}$ & $\begin{array}{l}\text { TMEER } \\
\text { STOFY WITM } \\
\text { OOURLE } \\
\text { SHEATHING } \\
\text { OF WOODEN } \\
\text { BOARDS }\end{array}$ & 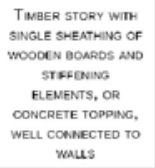 & $\begin{array}{l}\text { TMBBER } \\
\text { STORY WITH } \\
\text { SHNGL } \\
\text { SHEATHNG } \\
\text { OF WOCOEN } \\
\text { BOARDS }\end{array}$ & $\begin{array}{l}\text { STEEL/ } \\
\text { IRON } \\
\text { OEANS } \\
\text { WTH } \\
\text { BRICKTLE } \\
\text { CELLNGS } \\
\text { (YAUTED } \\
\text { OR NOT) }\end{array}$ & & \\
\hline & & & 1 & 2 & 3 & 4 & 5 & 6 & 7 & 8 & 9 & 10 \\
\hline \multirow{3}{*}{$\begin{array}{l}\text { REINFORCED OR } \\
\text { CONFINED } \\
\text { BRICK/CONCRETE } \\
\text { MASONRY }\end{array}$} & 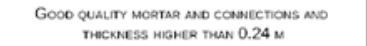 & A & 口 & $\square$ & 口 & $\square$ & 口 & $\square$ & 口 & 口 & $\square$ & $\square$ \\
\hline & 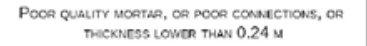 & B & 口 & $\square$ & $\square$ & 口 & 口 & $\square$ & 口 & 口 & $\square$ & $\square$ \\
\hline & $\begin{array}{l}\text { POOR QURUTY MORTAR NO COAAECTONS, AND } \\
\text { TMECKNESS LOWER THAN } 0.24 \mathrm{M}\end{array}$ & c & $\square$ & ㅁ & 口 & ㅁ & 口 & ㅁ & 口 & ㅁ & 口 & $\square$ \\
\hline \multirow{6}{*}{$\begin{array}{l}\text { UNREINFORCED } \\
\text { MASONRY }\end{array}$} & 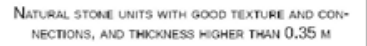 & D & 口 & ㅁ & ㅁ & 口 & 口 & ㅁ & ㅁ & 口 & 口 & $\square$ \\
\hline & $\begin{array}{l}\text { NATURAL GOOVE UNTS WUTH IRACQULAR TEXTURE, OR } \\
\text { RAD CONNECTIONS, OR THCKNESS LOWER THAN } 0.35 \mathrm{M}\end{array}$ & E & $\square$ & $\square$ & 口 & 口 & 口 & 口 & 口 & 口 & $\square$ & $\square$ \\
\hline & $\begin{array}{l}\text { NATLRAL STOME UNTS WITH IASECULAR TEXTURE, BAO } \\
\text { CONNECTONS, AND THICKNESS LOWER ThAN } 0.35 \mathrm{M}\end{array}$ & $\mathrm{F}$ & 口 & 口 & 口 & ㅁ & 口 & 口 & ㅁ & 口 & 口 & $\square$ \\
\hline & 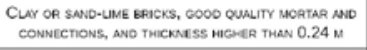 & G & ㅁ & ㅁ & 口 & ㅁ & 口 & $\mathbb{X}$ & 口 & 口 & 口 & $\square$ \\
\hline & $\begin{array}{l}\text { CLAY OR SAND-LLME BQICKS, BAD QUALTYY MORTAR OR } \\
\text { COMNECTIONS, OR THICKNESS LOMER THAN } 0.24 \mathrm{M}\end{array}$ & H & 口 & ㅁ & 口 & 口 & 口 & ㅁ & ㅁ & 口 & 口 & 口 \\
\hline & 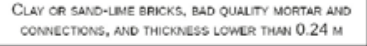 & 1 & 口 & 口 & 口 & $\square$ & 口 & 口 & 口 & ㅁ & 口 & $\square$ \\
\hline \multicolumn{2}{|r|}{ 2.6 Roof System } & \multicolumn{4}{|c|}{ A $\square$ NON- THRUSTING } & \multicolumn{3}{|c|}{ B D SughtLY THRUSTING } & \multicolumn{4}{|c|}{ C口ThRusting } \\
\hline
\end{tabular}

a)

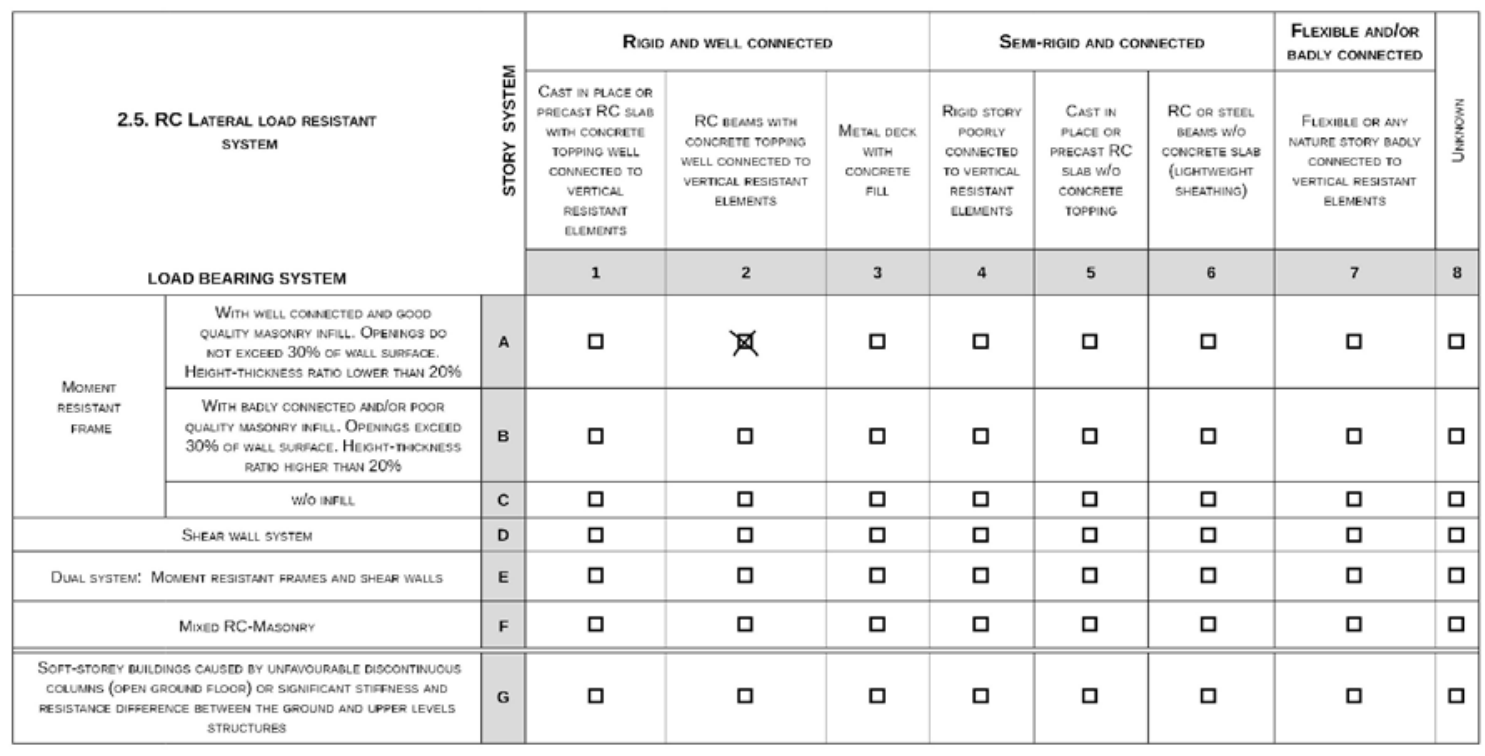

b)

Figure 4. Proposed survey forms for (a) masonry and (b) reinforced concrete buildings: identification of the main lateral load resistant system. 


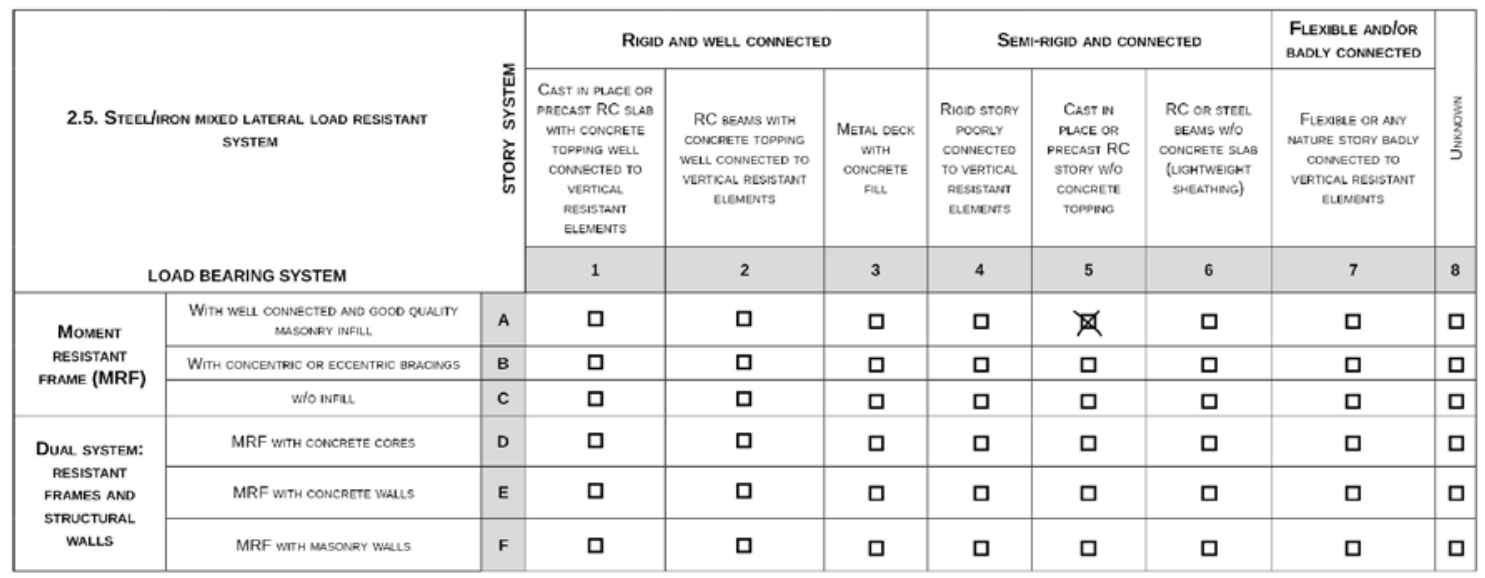

a)

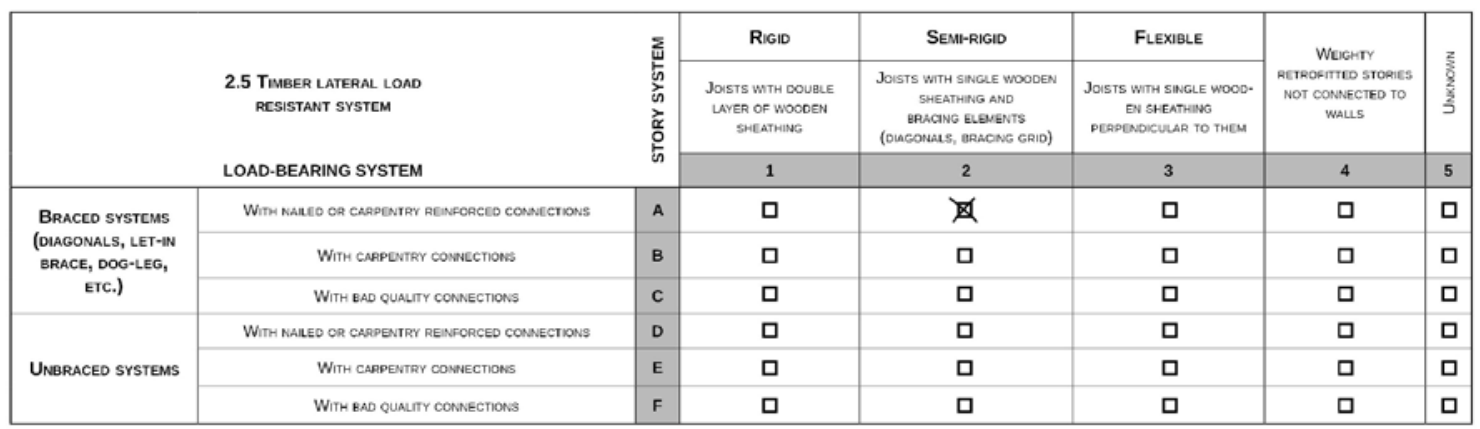

\begin{tabular}{|c|c|c|c|}
\hline $\begin{array}{l}2.6 \text { SECONDARY } \\
\text { SIIFFENING ELEMENTS }\end{array}$ & \multicolumn{2}{|c|}{ 2.6.1 INFLLL } & 2.6.2 EXTERNAL SHEATHING \\
\hline
\end{tabular}

2.7 Roof SYSTEM

A. Non- thrusting

B $\mathrm{S}$ SLIGHTLY THRUSTING

CD Thrusting

b)

Figure 5. Proposed survey forms for (a) steel/iron mixed and (b) timber frame buildings: identification of the main lateral load resistant system. 


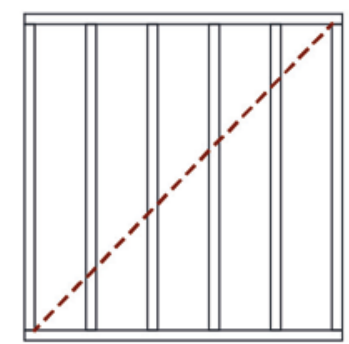

a)

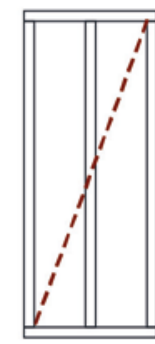

b)

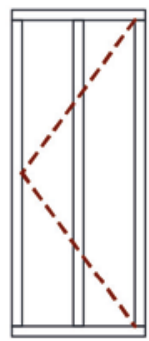

c)

Figure 6. Timber main load-resistant systems: (a) Let-in brace, (b) Diagonal brace and (c) Dog leg brace. 


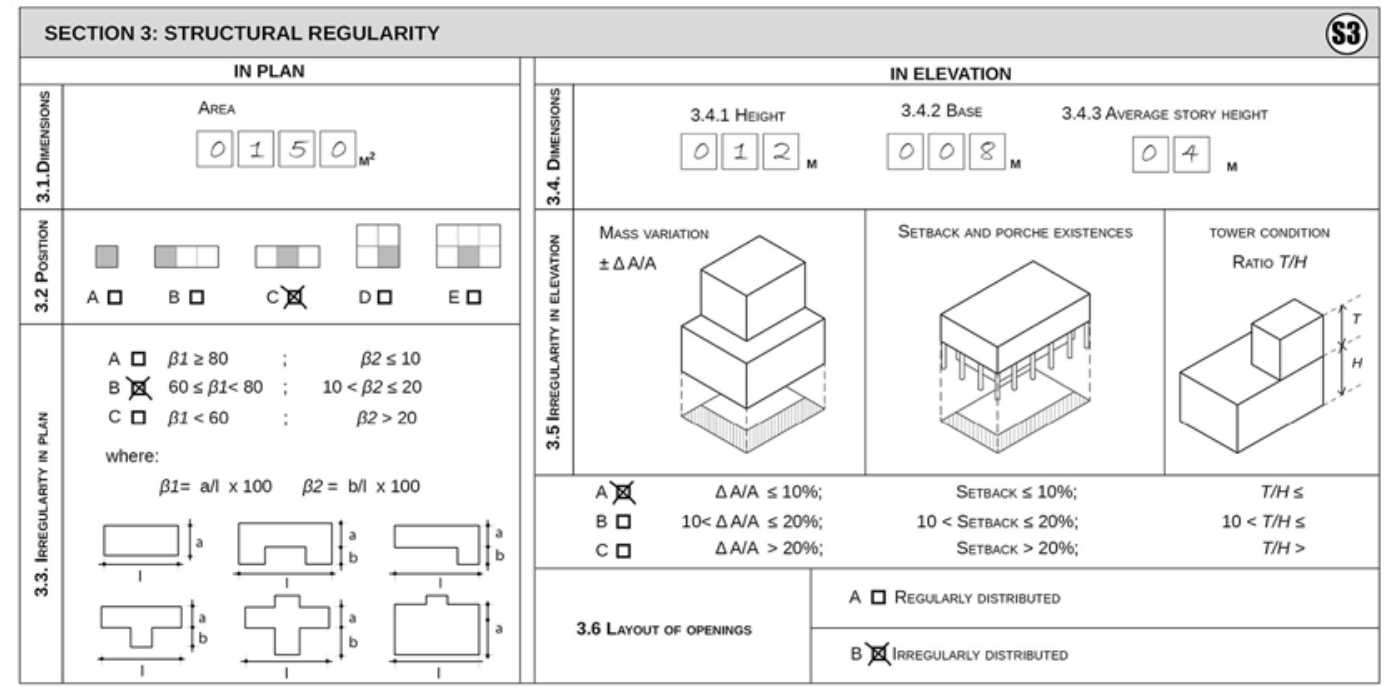

a)

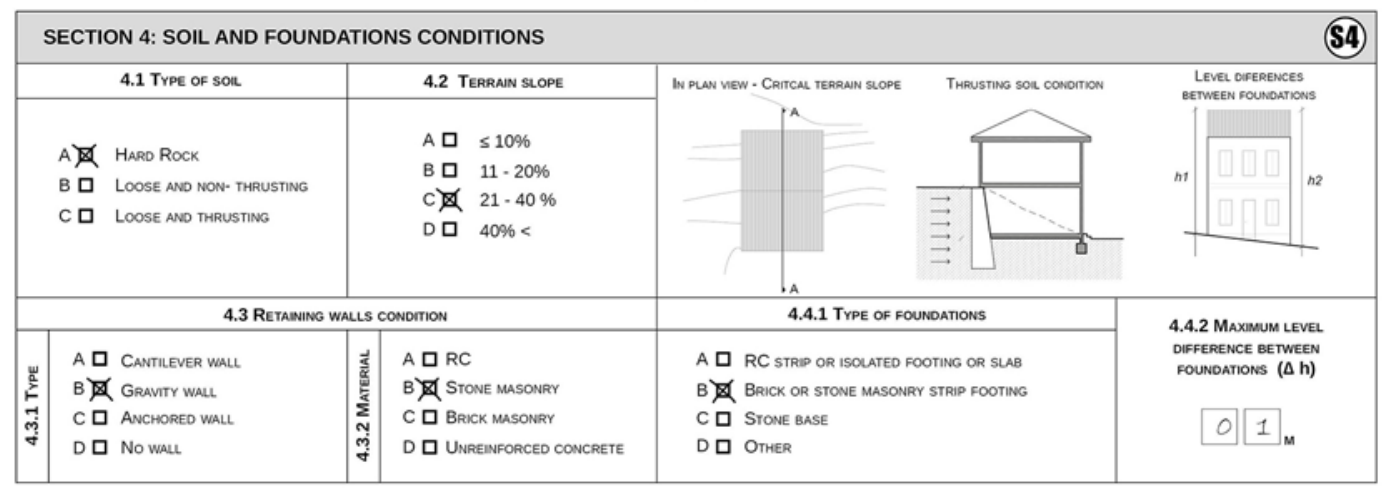

b)

Figure 7. Proposed survey form: (a) Section 3 "Structural Regularity" and (b) Section 4 "Soil and foundations conditions". 


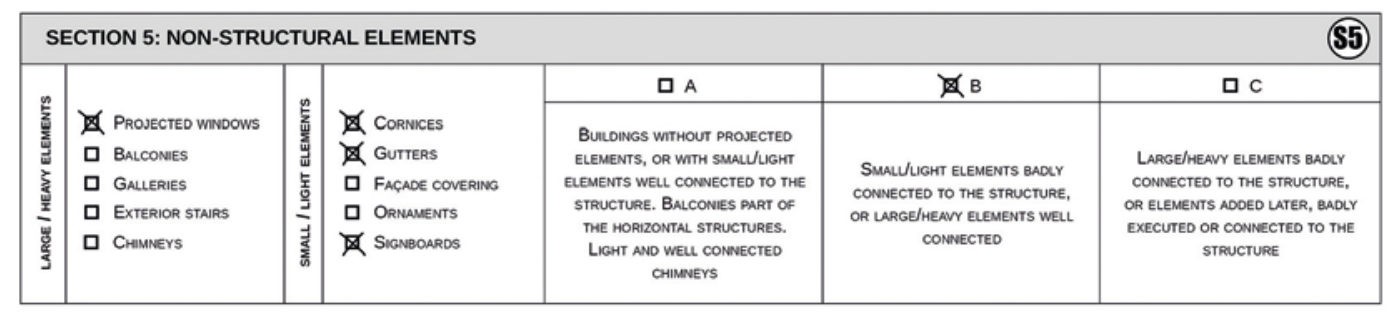

a)

\begin{tabular}{|c|c|c|c|c|c|}
\hline \multicolumn{6}{|c|}{ SECTION 6: DAMAGE CONDITION } \\
\hline \multicolumn{2}{|c|}{ Damage Grade } & \multirow{2}{*}{$\begin{array}{c}\text { NuLL } \\
1\end{array}$} & \multirow{2}{*}{$\frac{\text { D1 - SLIGHT }}{2}$} & \multirow{2}{*}{$\begin{array}{c}\text { D2 - MEDUUM-SEVERE } \\
3\end{array}$} & \multirow{2}{*}{$\begin{array}{c}\text { D3 - Vear HeAVY } \\
4 \\
\end{array}$} \\
\hline & & & & & \\
\hline 6.1 LOAD-BEARING SYSTEM & A & 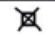 & 口 & ㅁ & 口 \\
\hline 6.2 Stories & $\mathbf{B}$ & 口 & 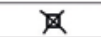 & 口 & $\square$ \\
\hline 6.3 Roofs & c & $\square$ & 口 & 口 & $\not$ \\
\hline 6. 4 NON-STRUCTURAL ELEMENTS & D & 口 & 口 & X & $\square$ \\
\hline
\end{tabular}

b)

\begin{tabular}{|c|c|c|c|c|c|}
\hline \multicolumn{6}{|c|}{ SECTION 7: CURRENT CONDITION OF CONSERVATION } \\
\hline $\begin{array}{l}A \\
\square\end{array}$ & $\begin{array}{l}\text { GOOO CONOITION OF RESISTANT ELEMENTS AND/OR } \\
\text { MATERLLLS. NO LATER STRUCTURAL ADDITIONS, OR SMALL } \\
\text { ANO WELL EXECUTED ONES }\end{array}$ & $\stackrel{B}{\alpha}$ & $\begin{array}{l}\text { SUGHT TO MEOIUM OAMAGE GRADE OF RESISTANT ELEMENT } \\
\text { AND/OR MATERLALS. SOME LATER STRUCTURAL ADOIIONS } \\
\text { POORLY EXECUTED, OR LARGE ADOMONS WELL EXECUTED }\end{array}$ & $\begin{array}{l}\text { C } \\
\text { 口 }\end{array}$ & $\begin{array}{l}\text { HEAVY DAMAGE GRADE OF RESISTANT ELEMENTS ANO/OR } \\
\text { MATERMLL. LARGE LATER STRUCTURAL ADOITONS POORLY } \\
\text { CONNECTED OR EXECUTED }\end{array}$ \\
\hline
\end{tabular}

c)

Figure 8. Proposed survey form: (a) Section 5 “Non-structural elements”, (b) Section 6 "Damage conditions” and (c) Section 7 "Current condition of conservation". 


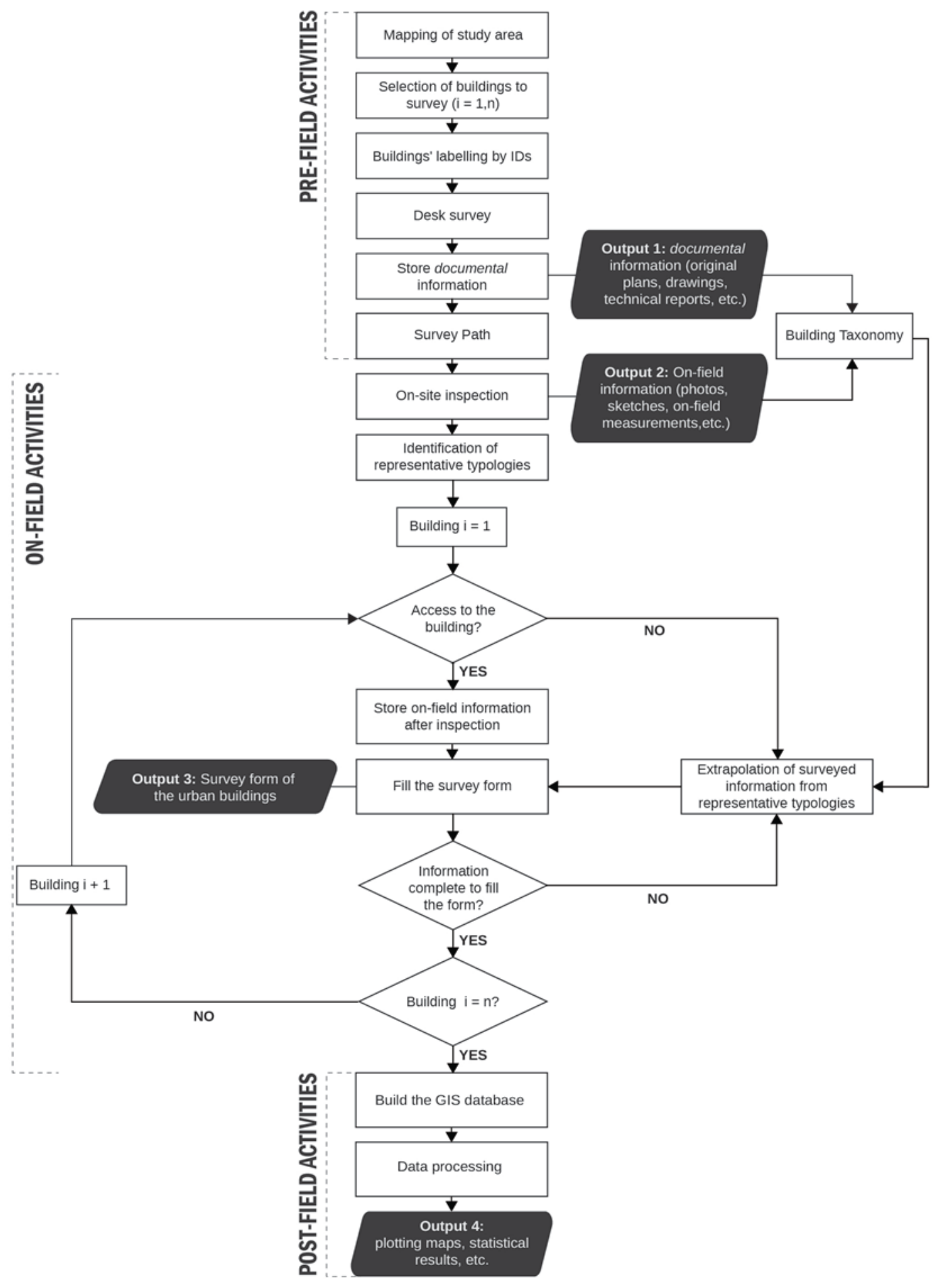

Figure 9. Flow chart of the building survey process. 


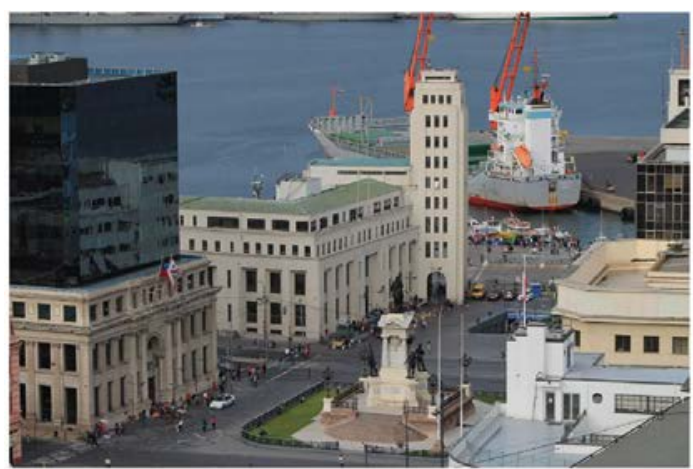

a)

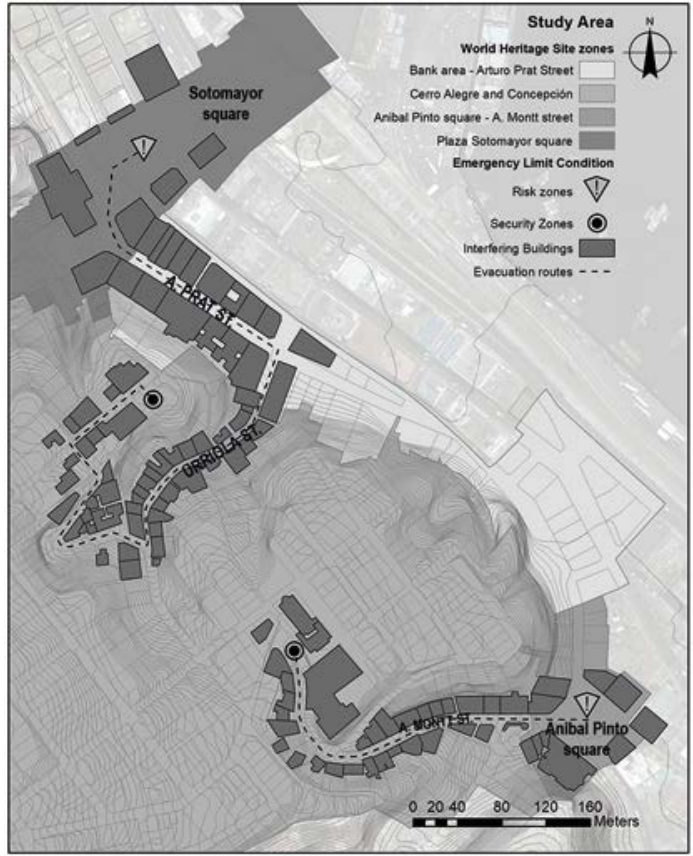

c)

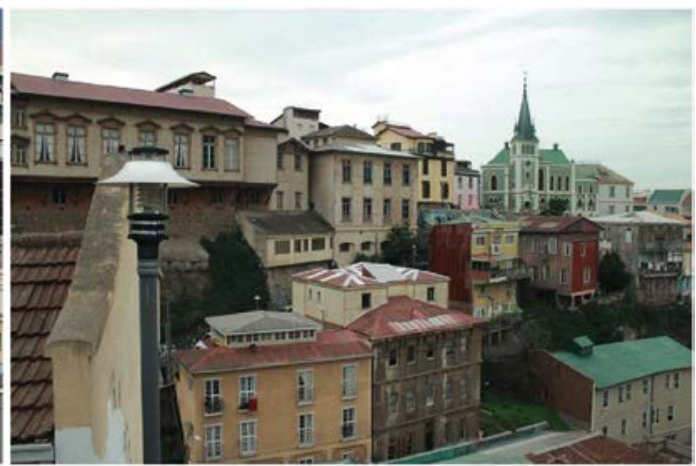

b)

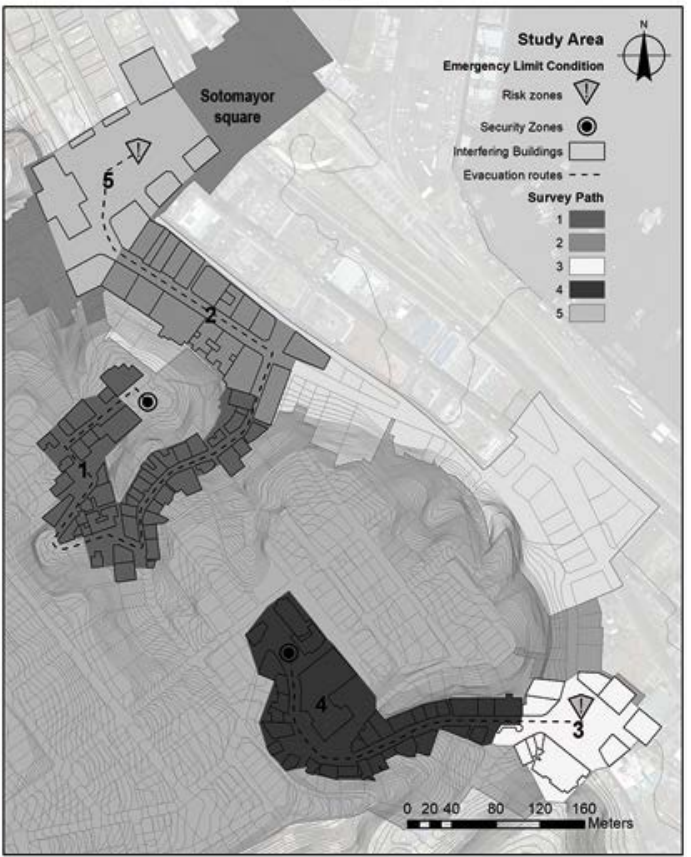

c)

Figure 10. Pilot study-area of Valparaíso: (a) Sotomayor square, (b) Cerro Alegre and Cerro Concepción, c) World Heritage Site zones with safety functions, possible interfering buildings and evacuation routes at the Emergency Limit Condition and d) survey path. 


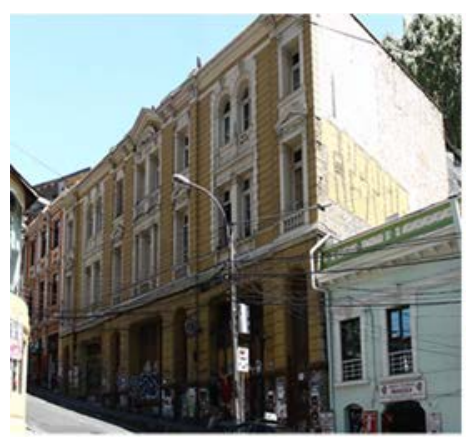

a)

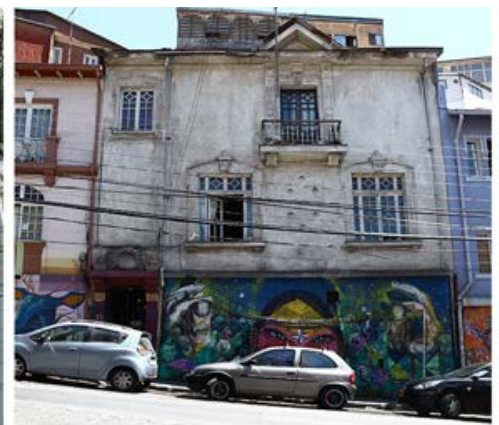

b)

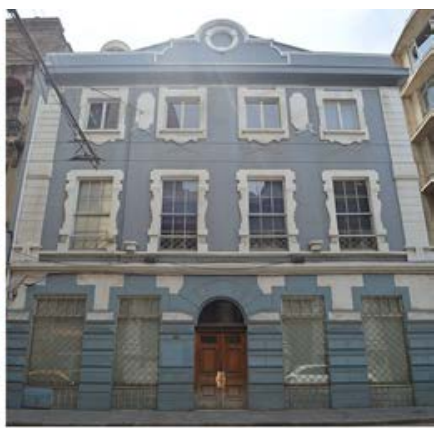

c)

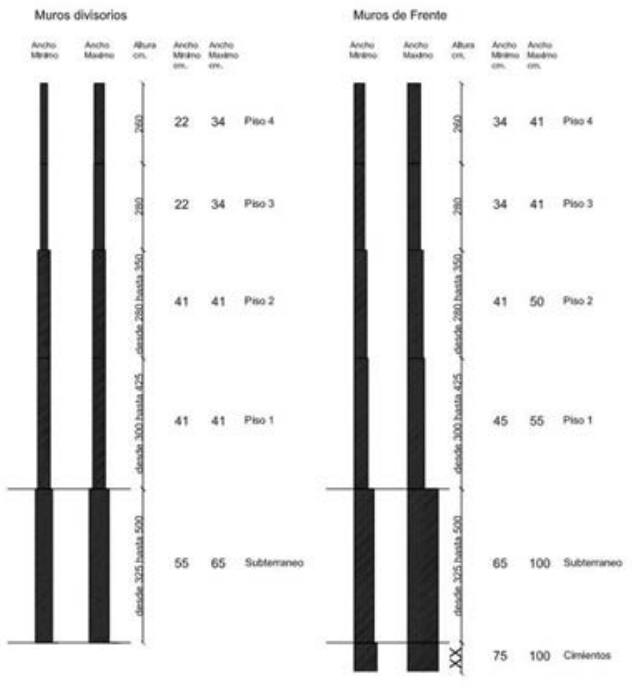

d)

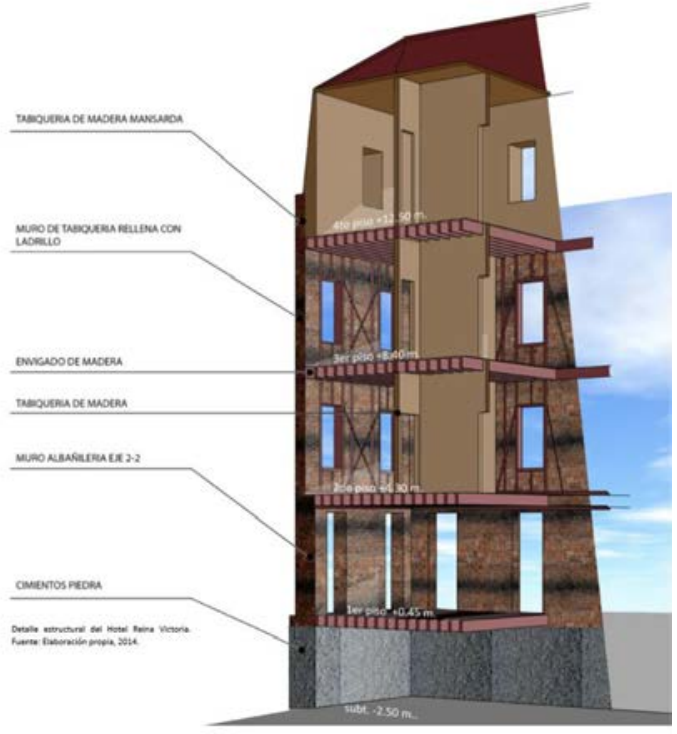

e)

Figure 11. Typical features of masonry buildings in Valparaíso: (a-b) façades in Almirante Montt street, (c) façade in Arturo Prat street, (d) staggered masonry walls (images by Salazar (2014), and e) main section of the Hotel Reina Victoria in Sotomayor square (by Salazar (2014). 


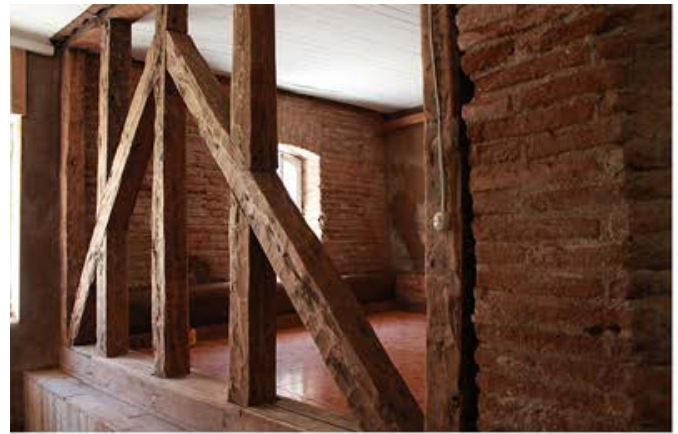

a)
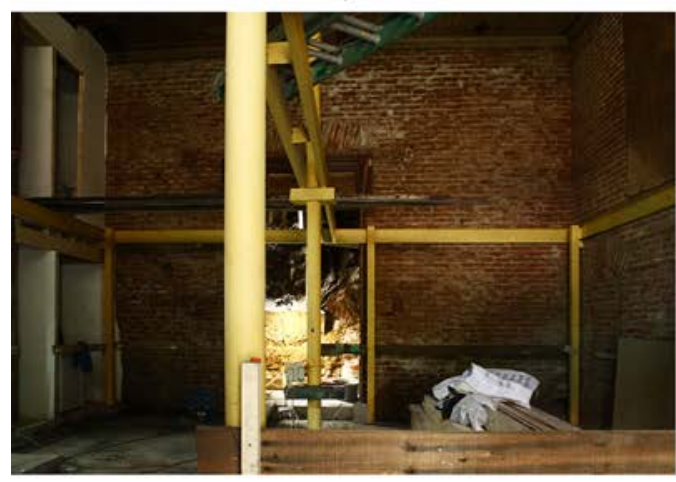

b)

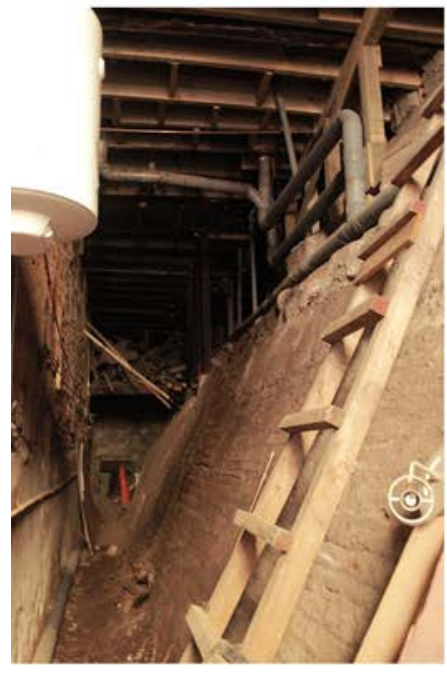

d)

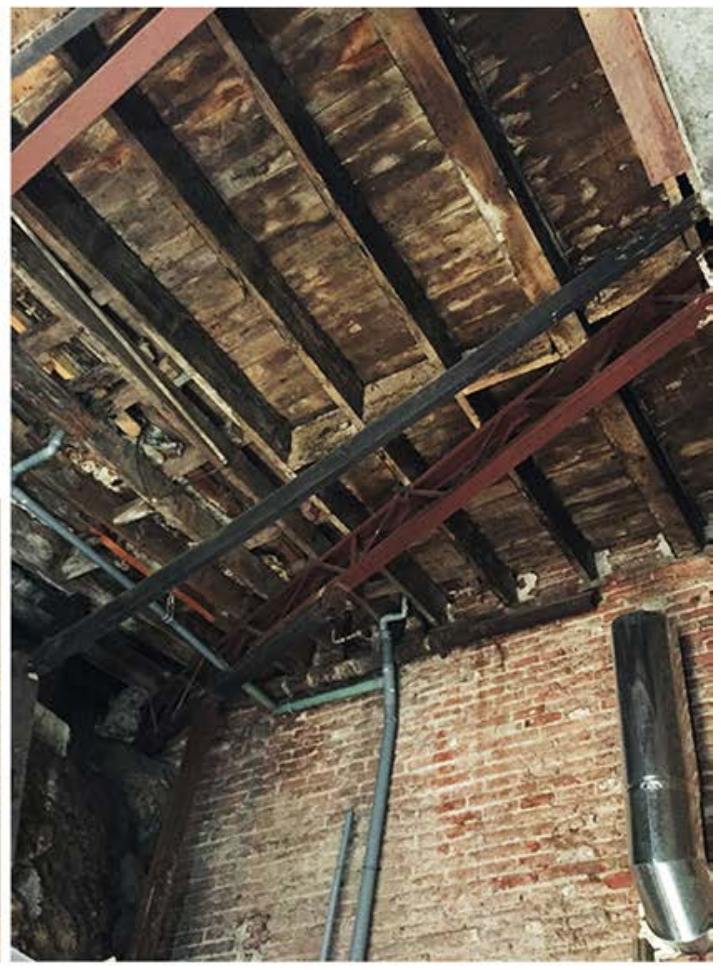

c)

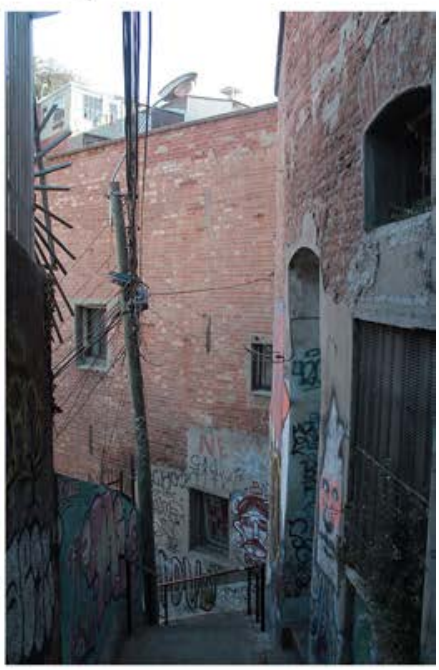

f)

Figure 12. Typical features of masonry buildings in Valparaíso: (a) timber frame internal partition in Urriola street, (b) steel reinforcing structure, (c) timber story with reinforcing steel truss in Almirante Montt street, (d) gravity wall, (e) rock hillside visible from the interior of a building, and (f) side wall. 


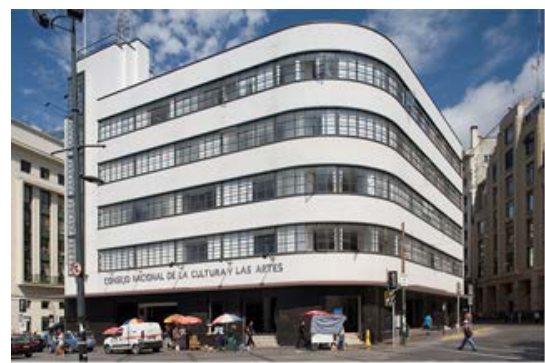

a)

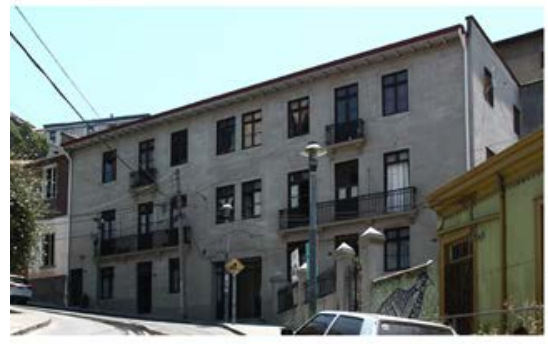

d)

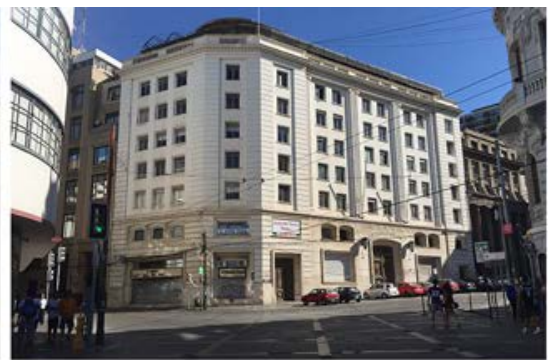

b)

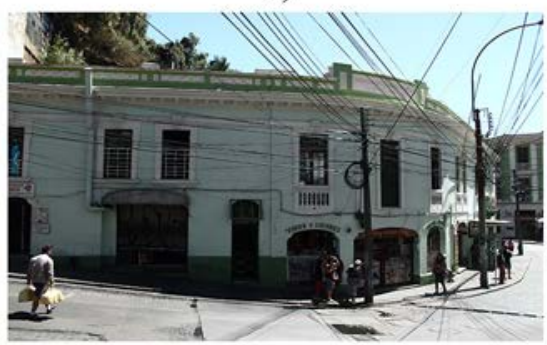

e)

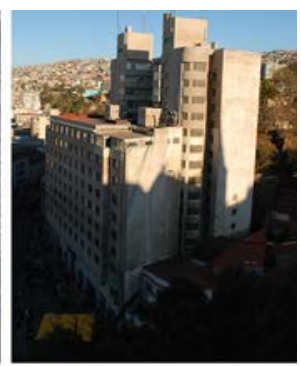

c)

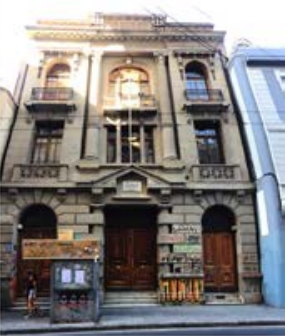

f)

Figure 13. Typical reinforced concrete buildings in Valparaíso: (a) main façade of the Consejo de la Cultura y las Artes building (1918), (b) main façade of the Compañia Chilena de Navegación Intraoceánica building (1955), (c) the Cooperativa Vitalicia building (1947), (d) the Bavestrello compound in Alvaro Besa street (1927), (e) corner building in Anibal Pinto square (1929) and (d) historical façade in Arturo Pratt Street. 


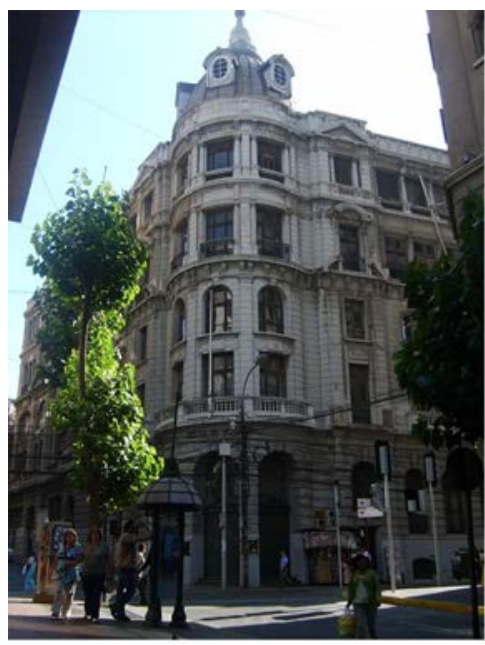

a)

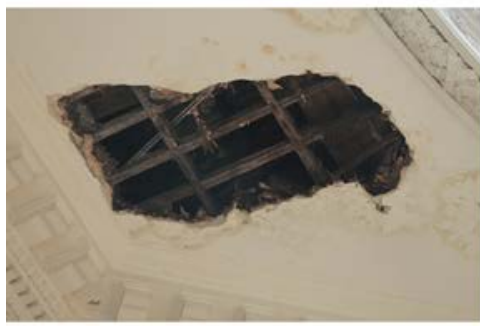

d)

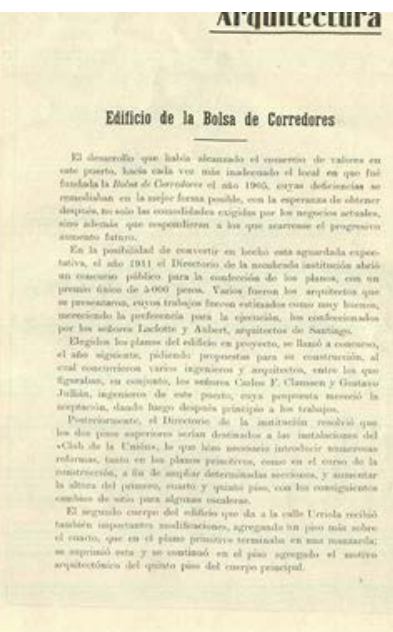

b)

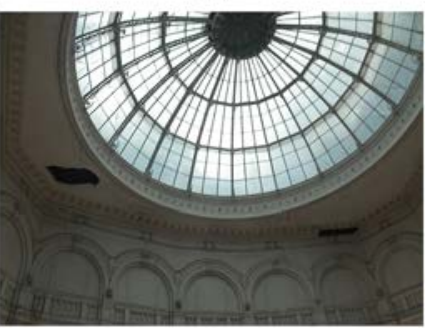

e)

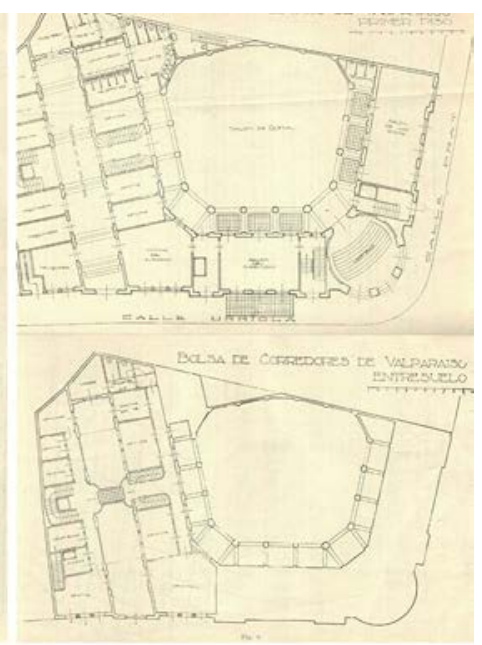

c)

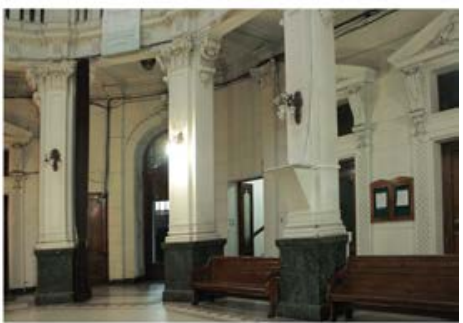

f)

Figure 14. Typical mixed iron-reinforced concrete building (Bolsa de Valores de Valparaíso): (a) façade, (b-c) technical report and plan of the ground level, (d-e) roof and dome damages and (f) interior columns 


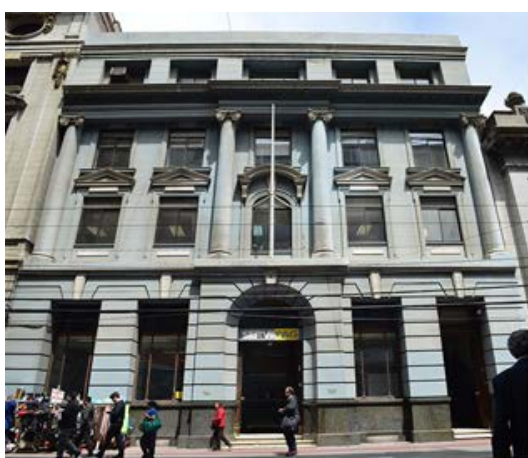

a)

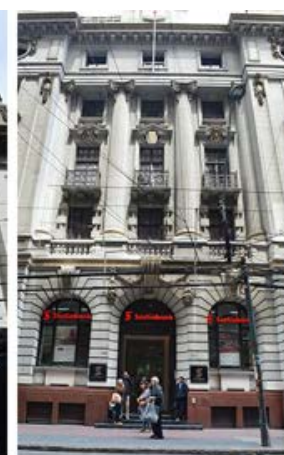

b)

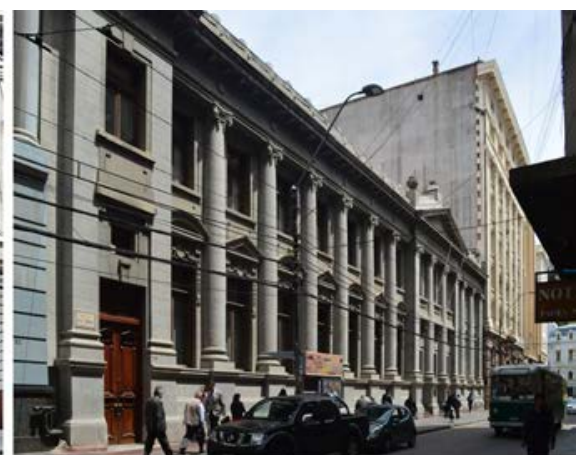

c)

Figure 15. Typical mixed iron-RC buildings in Valparaíso: (a) Ex Banco de Chile dating back to 1919, (b) Ex Banco de Londres y Río de la Plata dating back to 1914, (c) Banco de Chile dating back to 1893. 


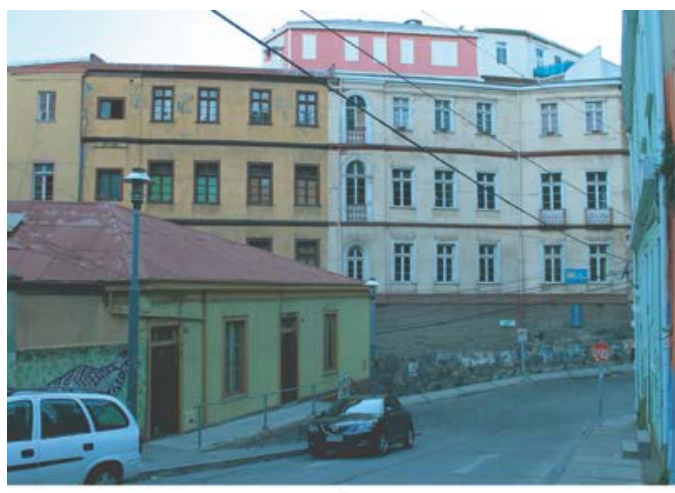

a)

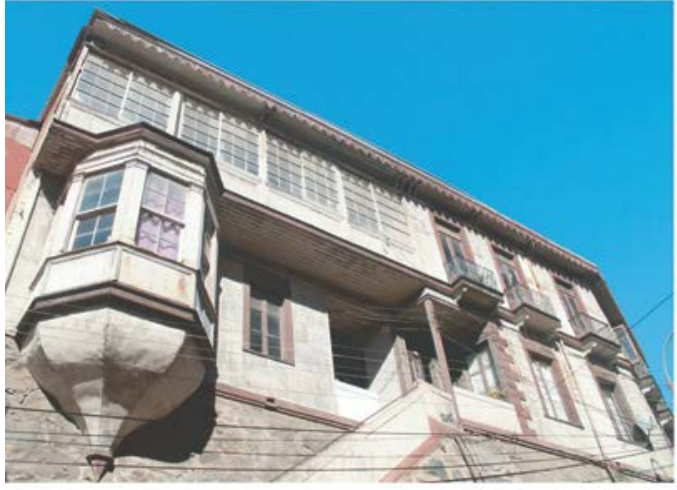

c)

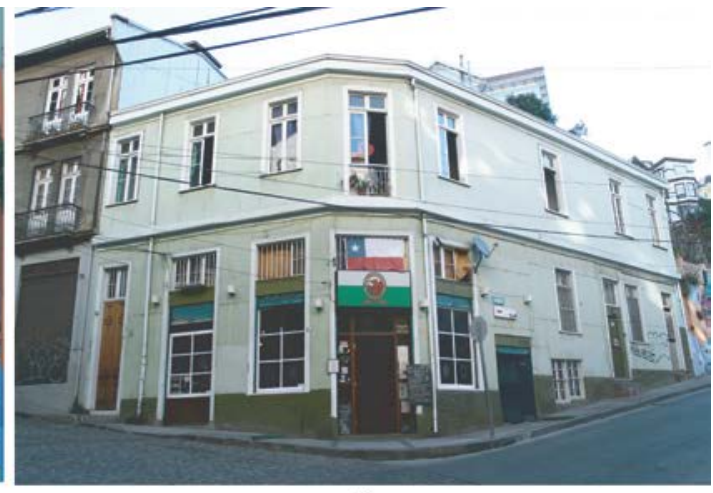

b)

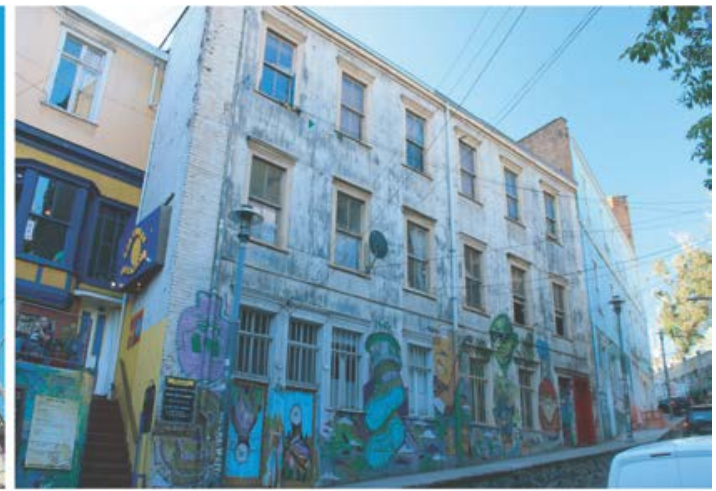

d)

Figure 16. Typical timber frame buildings in Valparaíso: (a-b-c) located in Urriola and (d) Almirante Mont streets. 


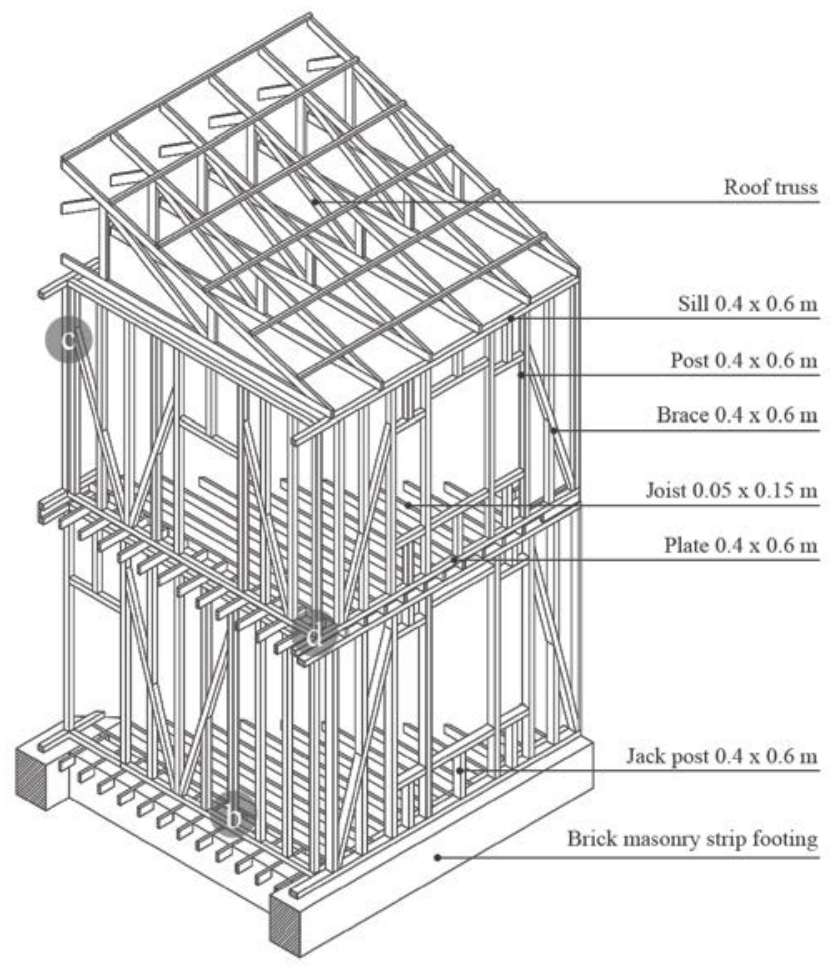

a)

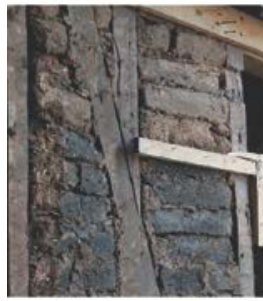

e)

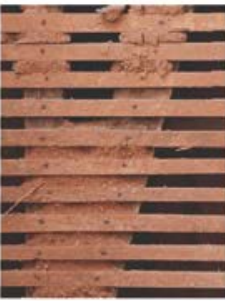

f)

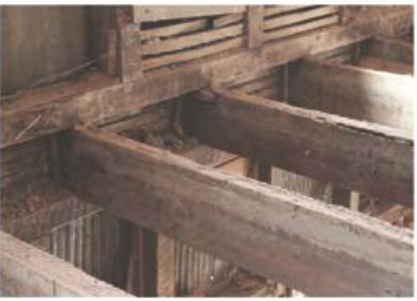

g)

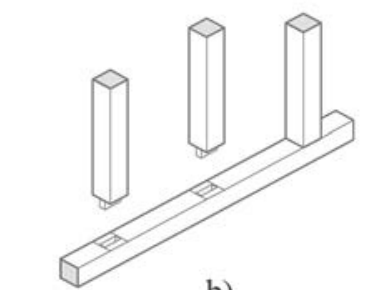

b)
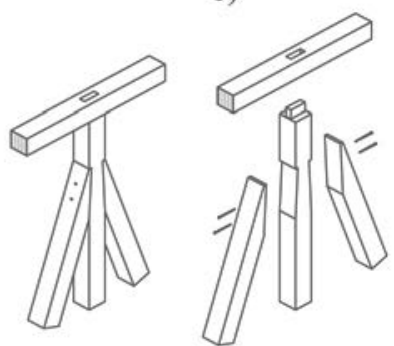

c)

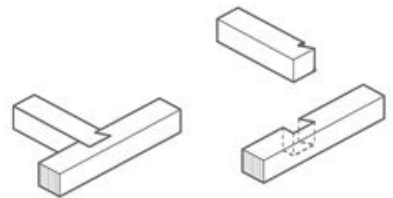

d)

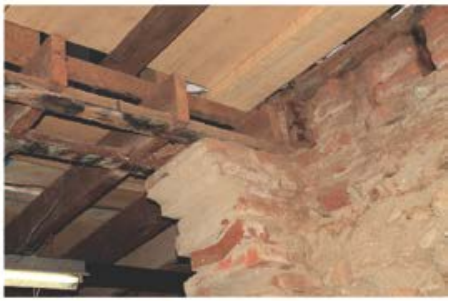

h)

Figure 17. Typical timber structure configurations in Valparaíso: (a) view of a representative load bearing system, (b) mortise and tenon joints, (c) mortise and tenon with notching joints, (d) half-dovetail joint, (e) external wall filled with adobe, (f) internal wall of lath and plaster, (g) connection of timber story to the walls and (h) connection of timber story to the brick strip footing foundation. 


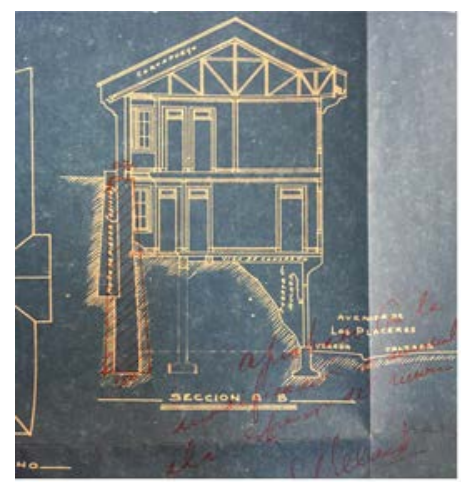

a)

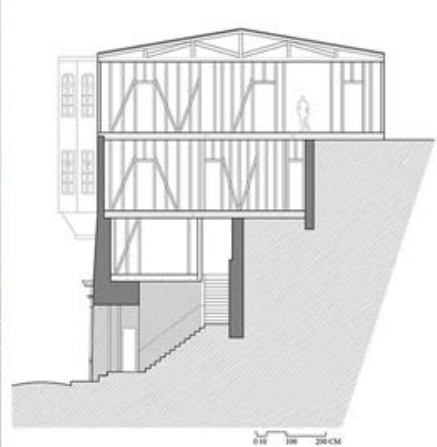

b)

Figure 18. Typical slope adaptation strategies of historical buildings: (a) recurrent solution in Valparaíso dating back to 1932 and (b) house in Urriola street (1900s). 


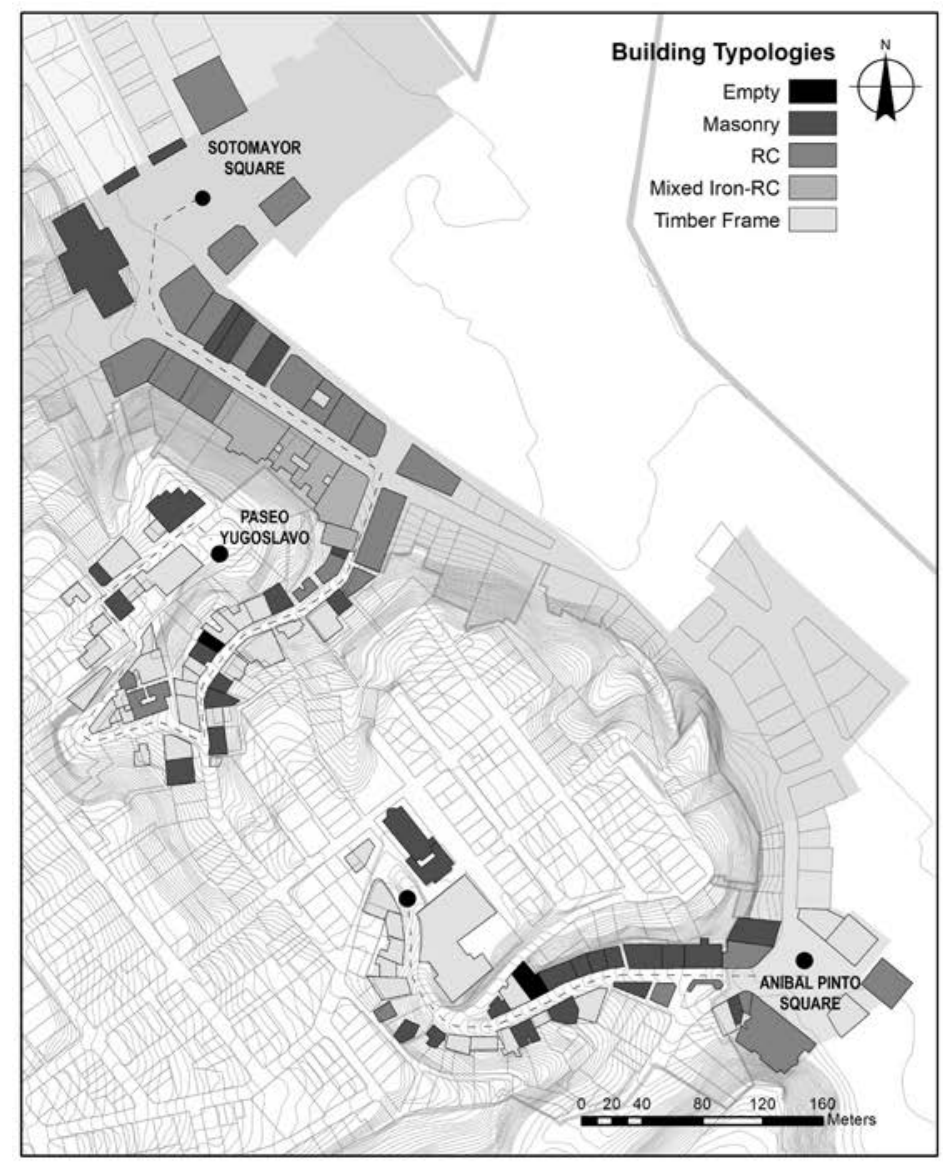

a)

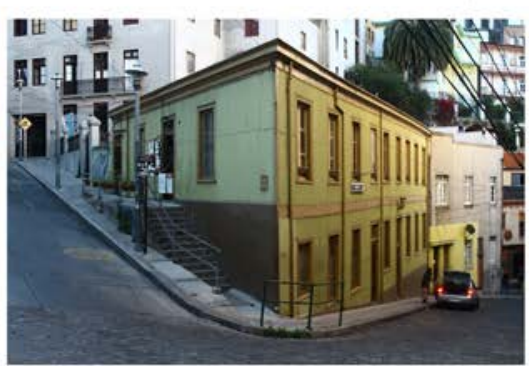

c)

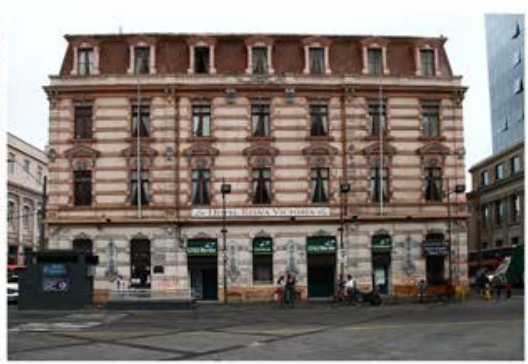

d)

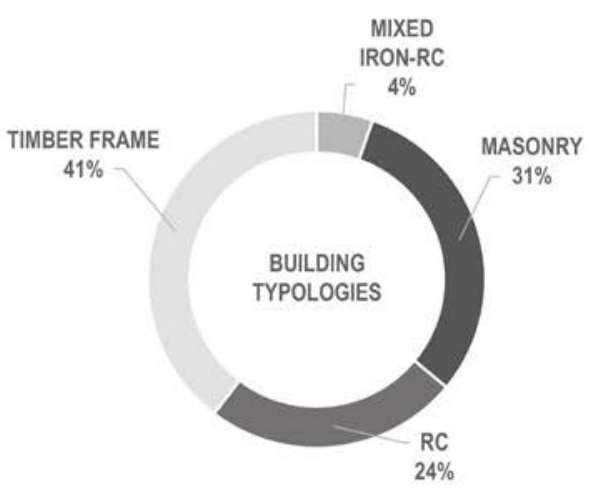

b)

Figure 19. GIS mapping of the structural typologies (a) and their statistical distribution (b). Representative timber frame dwelling (c), masonry building (d), mixed iron-RC building (e) and RC building (f). 


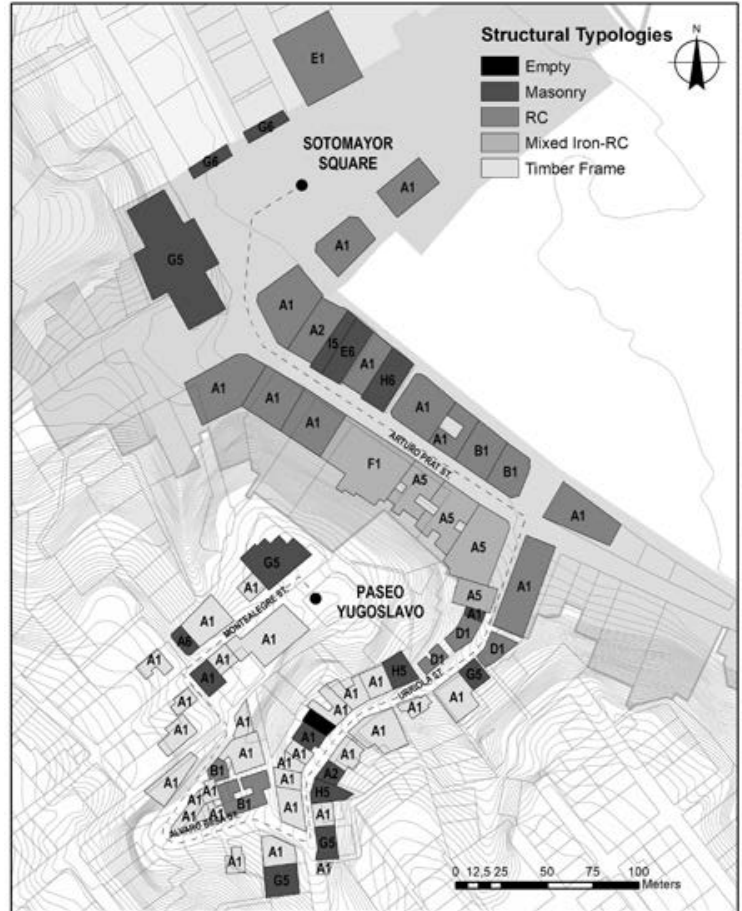

a)

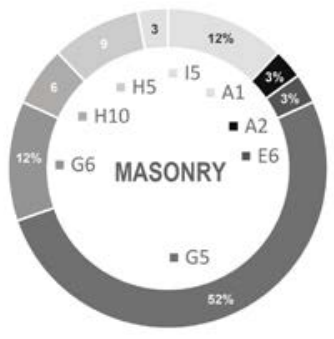

34 BUILDINGS

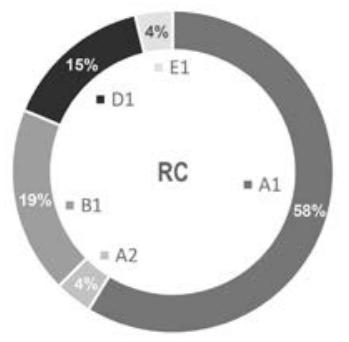

27 BUILDINGS

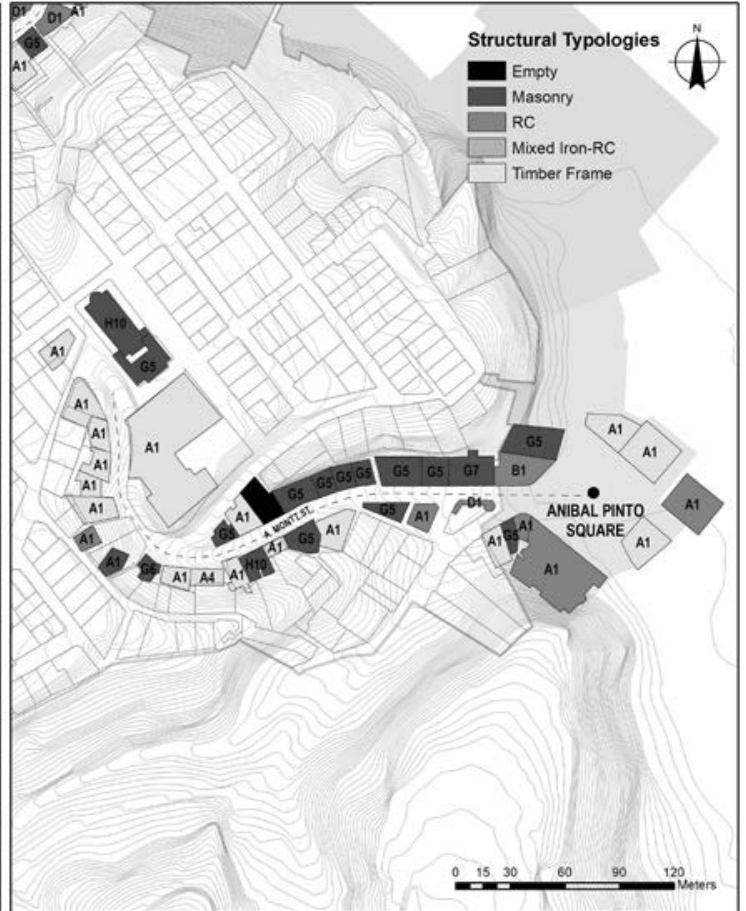

b)

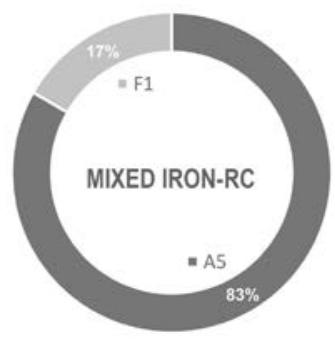

5 BUILDINGS

c)

Figure 20. GIS mapping of lateral-load resisting systems of the buildings (a-b) and statistical distributions for each typology (c). 


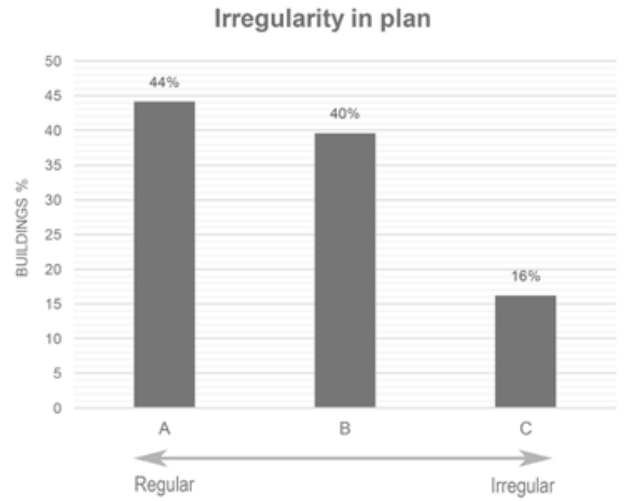

a)

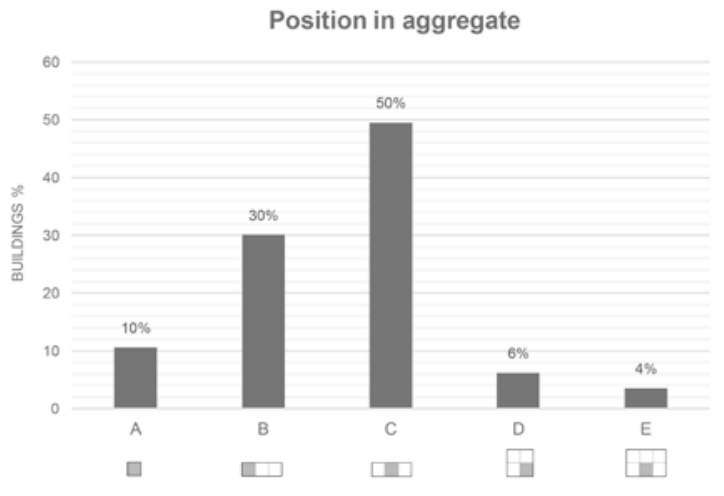

b)

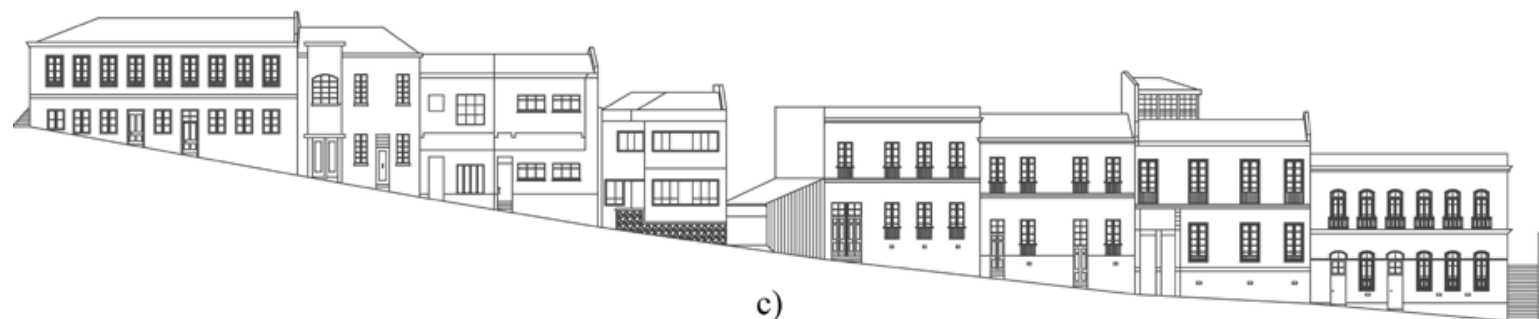

Figure 21. Buildings' irregularity (a), position in aggregate (b) and (c) façades of buildings along Urriola street. 


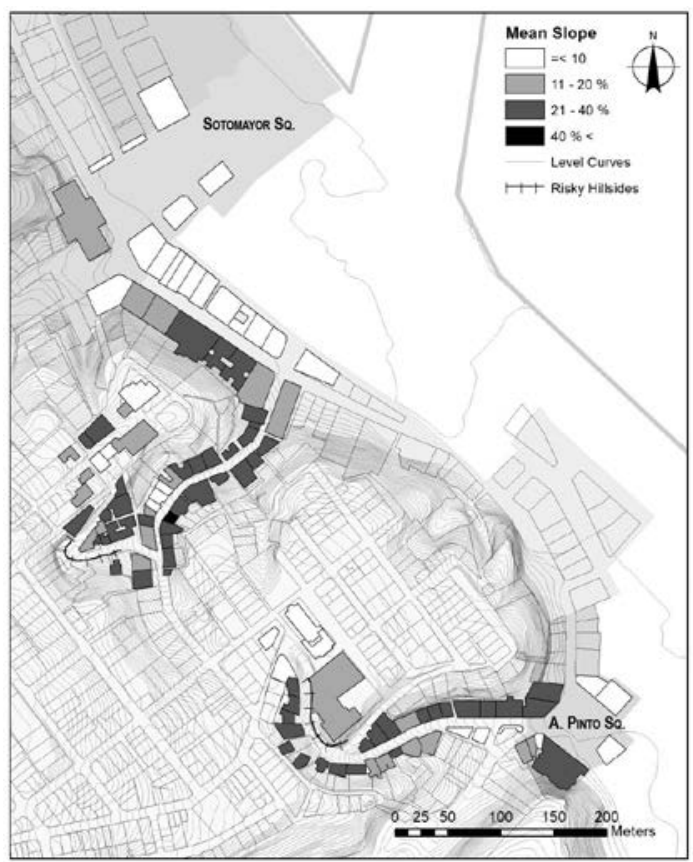

a)

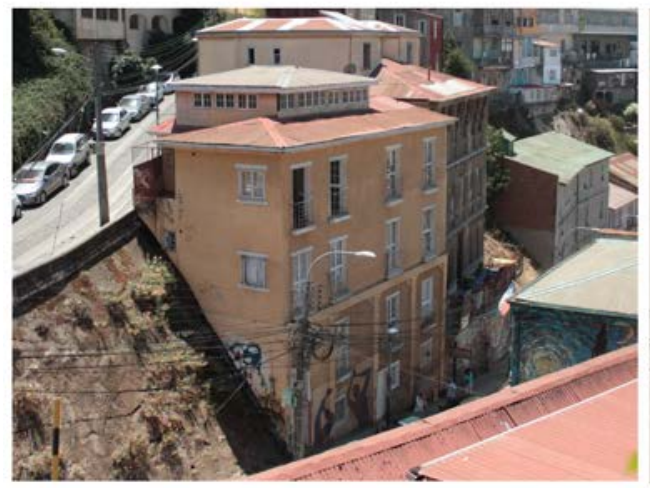

c)

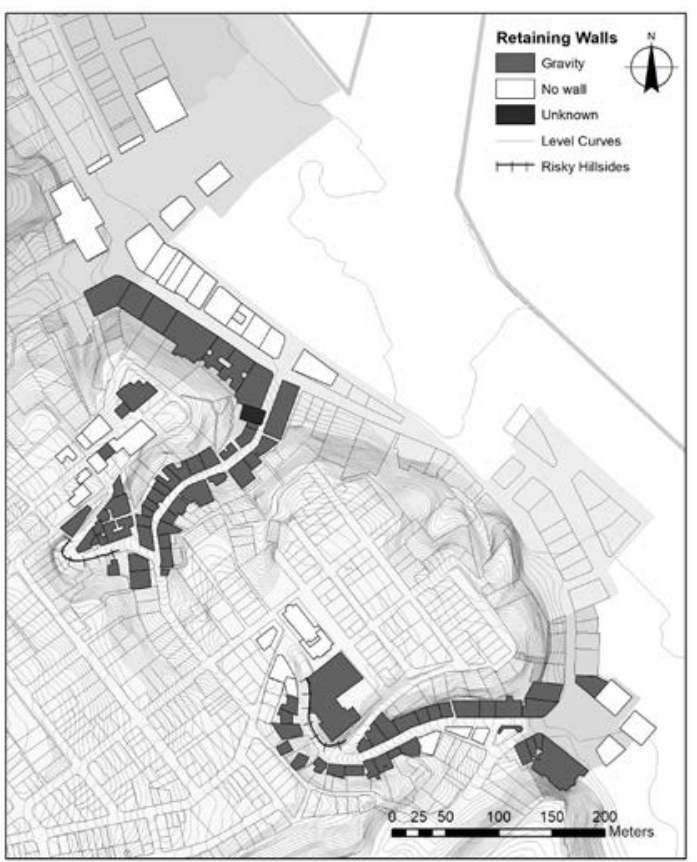

b)

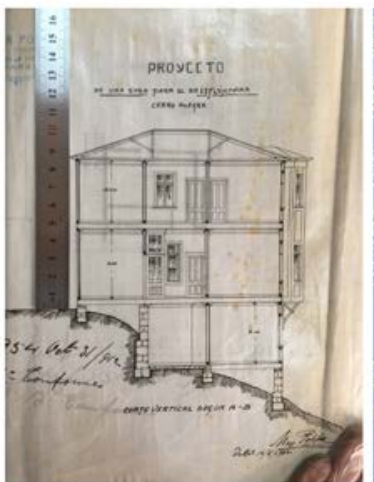

d)

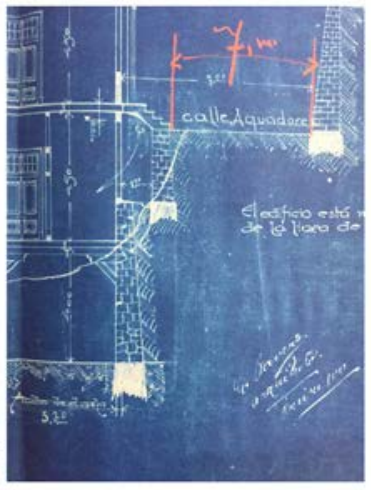

e)

Figure 22. Slope and retaining walls configuration: a) GIS mapping of mean slope and (b) retaining wall typologies, (c) representative case in Almirante Montt street, (d-e) typical retaining walls and foundations. 


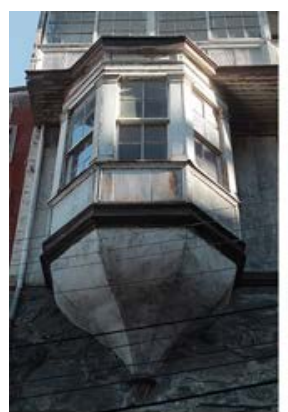

a)

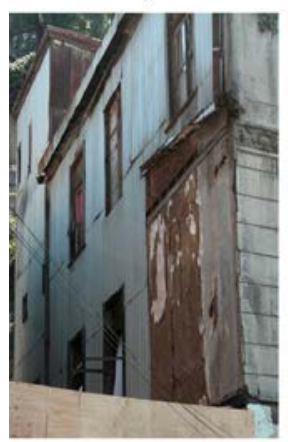

d)

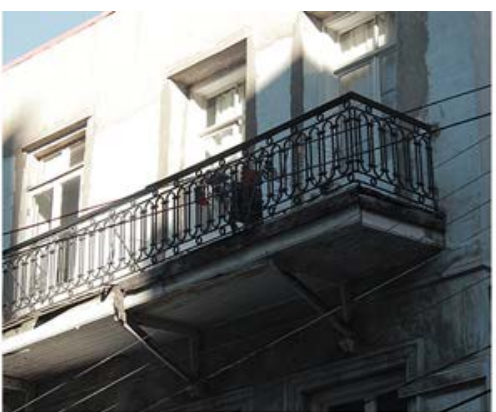

b)

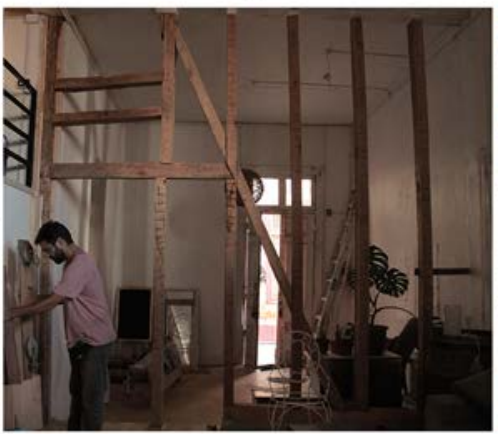

e)

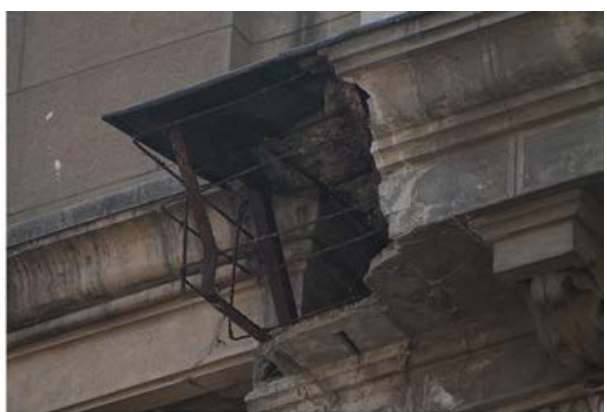

c)

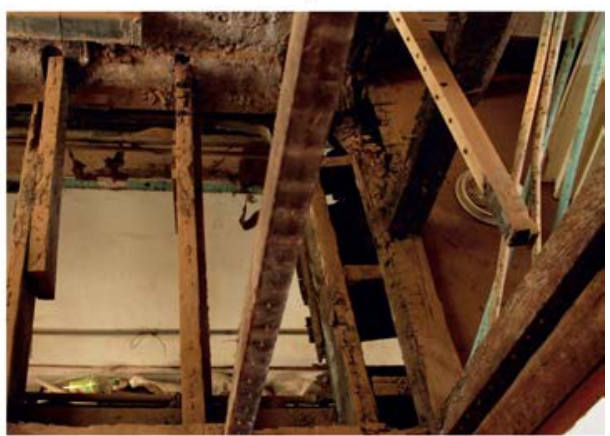

f)

Figure 23. Representative non-structural elements and damage conditions: (a) large dimension bow-window, (b) poorly connected balcony, (c) severe damage of RC cornice, (d) sheathing detachment, (e) empty timber frame wall and (f) timber joists attacked by termites. 


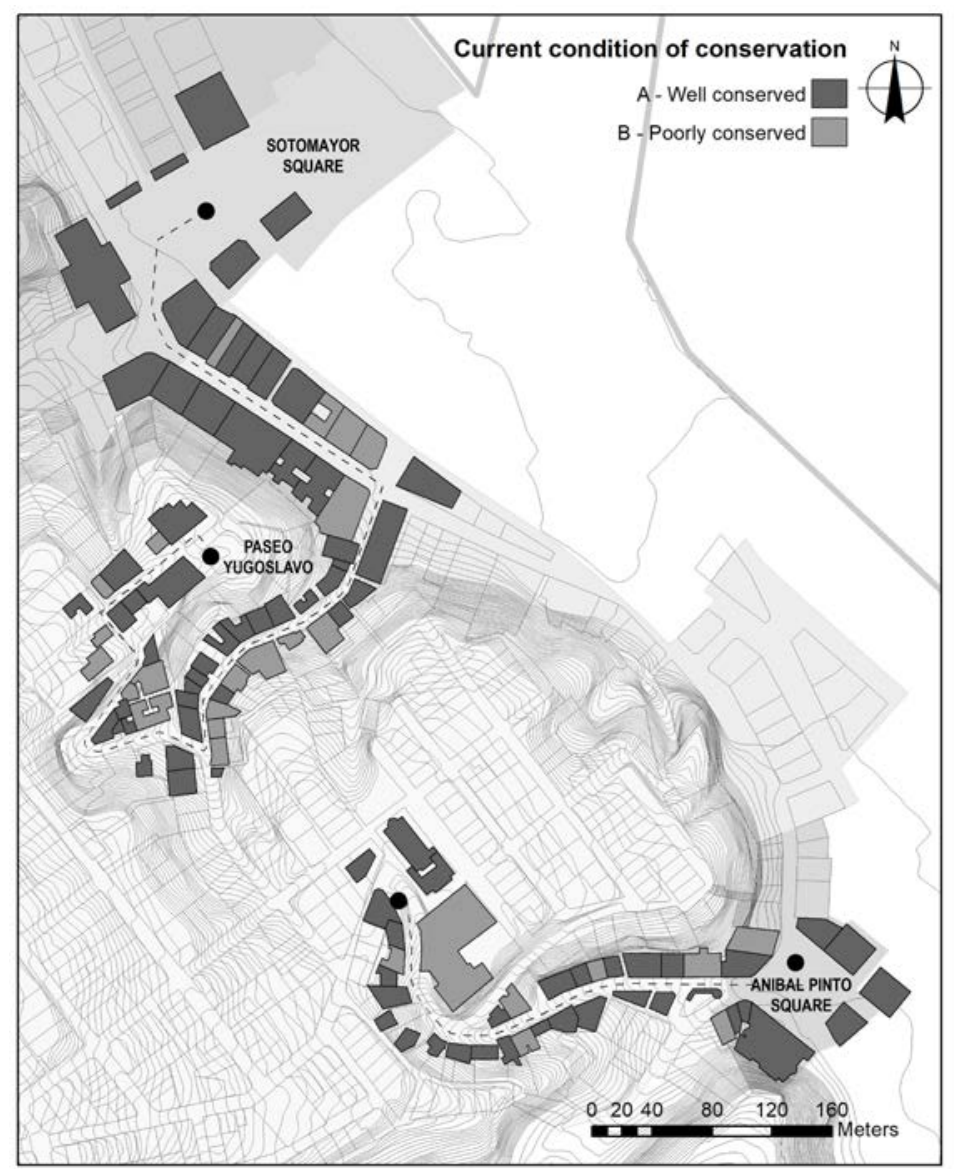

a)

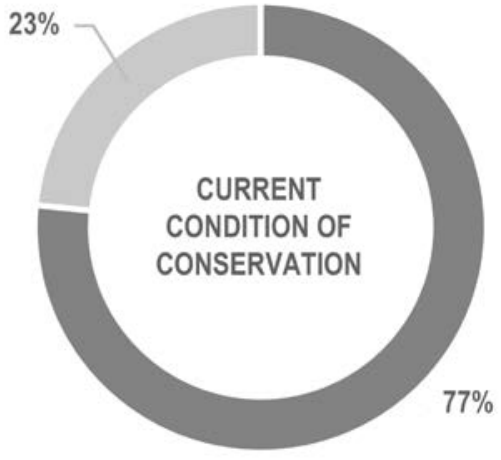

- WELL CONSERVED

a POORLY CONSERVED

b)

Figure 24. GIS mapping of current condition of conservation (a) and statistical results (b). 